JOÃO ROSTAIZER BAEZA

\title{
CONTROLE NÃO LINEAR APLICADO A MALHAS DE CONTROLE COM VÁLVULAS DE ALTO ATRITO
}

Dissertação apresentada à Escola Politécnica da Universidade de São Paulo para obtenção do título de Mestre em Engenharia

SÃO PAULO

2013 
JOÃO ROSTAIZER BAEZA

\section{CONTROLE NÃO LINEAR APLICADO A MALHAS DE CONTROLE COM VÁLVULAS DE ALTO ATRITO}

Dissertação apresentada à Escola Politécnica da Universidade de São Paulo para obtenção do título de Mestre em Engenharia Área de Concentração:

Engenharia de Sistemas Orientador:

Prof. Dr. Claudio Garcia

SÃO PAULO 
Este exemplar foi revisado e corrigido em relação à versão original, sob responsabilidade única do autor e com a anuência de seu orientador.

São Paulo, 18 de abril de 2013.

Assinatura do autor

Assinatura do orientador

FICHA CATALOGRÁFICA

Baeza, João Rostaizer

Controle não linear aplicado a malhas de controle com válvulas de alto atrito / J.R. Baeza. - versão corr. -- São Paulo, 2013.

$91 \mathrm{p}$.

Dissertação (Mestrado) - Escola Politécnica da Universidade de São Paulo. Departamento de Engenharia de Telecomunicações e Controle.

1.Atrito 2.Válvulas de controle 3.Controle não linear 4.Línearização por realimentação I.Universidade de São Paulo. Escola Politécnica. Departamento de Engenharia de Telecomunicações e Controle II.t. 
Dedico este trabalho aos meus pais João Pedro e Edna, minha irmã Paola e à minha querida noiva Adriana. 


\section{AGRADECIMENTOS}

Agradeço ao professor Dr. Claudio Garcia pela orientação e apoio para a realização do trabalho.

À Escola Politécnica da Universidade de São Paulo pela formação acadêmica, infraestrutura e oportunidades proporcionadas. Em especial aos professores que participaram da minha formação.

Aos meus pais, familiares e à minha noiva Adriana por todo o apoio e compreensão. Sem estas pessoas este trabalho não seria possível. 


\section{RESUMO}

As válvulas de controle são elementos finais muito importantes na indústria de processos, pois são as responsáveis por controlar a pressão em dutos ou vazão dos fluidos de processo, impactando diretamente na qualidade do produto final. Por serem elementos mecânicos móveis estão sujeitas ao atrito, uma não linearidade que quando excessiva, pode causar oscilações e erros na abertura da válvula. A presença de oscilações nas malhas de controle aumenta a variabilidade das variáveis de processo, o desgaste dos componentes e o consumo de energia, além de provocar o desperdício de materiais. $O$ desenvolvimento de novas técnicas de compensação de atrito é fundamental para melhorar o desempenho das malhas de controle, sendo, portanto, de grande interesse para a indústria de processos industriais. Este trabalho apresenta o estudo de cinco compensadores não lineares: controlador rastreador de trajetória, controlador por modos deslizantes, controlador por modos deslizantes integrador, controlador por modelo interno não linear e controlador PI não linear, os quais são desenvolvidos desde a teoria à implementação prática em uma válvula de controle real. Os resultados obtidos, mostram que os controladores projetados apresentaram desempenho bastante satisfatórios, sendo que o controlador por modos deslizantes e por modos deslizante integrador apresentaram os melhores desempenho.

Palavras-chave: Compensação de atrito; válvulas de controle; controle não linear; linearização por realimentação. 


\section{ABSTRACT}

Control valves are very important final elements in process industry, due they are the responsible to control the pressure in pipelines and the flow of the process fluids, directly impacting in the quality of the final product. Due to the mechanical mobile elements, they are subjected to friction, a nonlinearity that can generate oscillations and errors in the valve aperture. Oscillations in the control loops increase the process variability, wear in the actuators and the power consumption, besides generating raw material waste. The development of new friction compensation techniques is very important to increase the control loops performance, therefore, it is of great interest for the process industry. This work presents the study of five nonlinear compensators: Trajectory tracking controller, sliding mode controller, sliding mode controller integrator, nonlinear internal model controller and nonlinear PI controller, which ones are developed from theory to practical implementation in a real control valve. The results show that the controllers presented satisfactory performance, where the sliding mode controller and sliding mode control integrator presented the best performance.

Keywords: Friction compensation; control valves; nonlinear control; feedback linearization. 


\section{Lista de Figuras}

Figura 2.1 Válvula de controle tipo globo com atuador pneumático (Adaptado Emerson, 2005)

Figura 2.2 Válvula de controle tipo borboleta com atuador pneumático (Adaptado

Emerson, 2005)

Figura 2.3 Principais elementos de uma válvula tipo globo (Adaptado Emerson, 2005)

Figura 2.4 Comparação entre função tangente hiperbólica e função sign 10

Figura 2.5 Comparação entre os modelos de atrito e válvula real 11

Figura 3.1 Sistema de controle com linearização exata 15

Figura 3.2 Diagrama de blocos do sistema linearizado 18

Figura 3.3 Superfície de escorregamento para um sistema de segunda ordem 22

Figura 3.4 Chattering para um sistema de segunda ordem 25

Figura 3.5 Diagrama de blocos do controlador IMC 27

Figura 3.6 Diagrama de blocos do controlador IMC genérico 28

Figura 3.7 Diagrama de blocos do controlador IMC não linear 30

Figura 5.1 Diagrama de blocos da simulação 40

Figura 5.2 Resposta ao degrau simulada da válvula linearizada e do modelo linear desejado. 43

Figura 5.3 Resultado da simulação do controlador rastreador de trajetória . 44

Figura 5.4 Resultado da simulação do rastreador de trajetória com ruído e parâmetros $10 \%$ menores. 45

Figura 5.5 Sinal de saída do controlador rastreador de trajetória simulado com ruído e parâmetros $10 \%$ menores 46

Figura 5.6 Resultado da simulação do controlador rastreador de trajetória com ruído e parâmetros $10 \%$ maiores 
Figura 5.7 Sinal de saída do controlador de trajetória simulado com ruído e parâmetros $10 \%$ maiores

Figura 5.8 Resultado da simulação do controlador por modos deslizantes sem a camada limite

Figura 5.9 Sinal da saída do controlador por modos deslizantes sem a camada limite

Figura 5.10 Superfície de escorregamento sem a camada limite. 49

Figura 5.11 Resultado da simulação do controlador por modos deslizantes com a camada limite 50

Figura 5.12 Sinal de saída do controlador por modos deslizantes simulado com a camada limite

Figura 5.13 Superfície de escorregamento com a camada limite.

Figura 5.14 Resultado da simulação do controlador por modos deslizantes com os parâmetros $10 \%$ menores

Figura 5.15 Sinal de saída do controlador por modos deslizantes simulado com os parâmetros $10 \%$ menores

Figura 5.16 Superfície de escorregamento do controlador por modos deslizantes simulado com os parâmetros $10 \%$ menores 53

Figura 5.17 Resultado da simulação do controlador por modos deslizantes com os parâmetros $10 \%$ maiores 53

Figura 5.18 Sinal de saída do controlador por modos deslizantes simulado com os parâmetros $10 \%$ maiores

Figura 5.19 Superfície de escorregamento do controlador por modos deslizantes simulado com os parâmetros $10 \%$ maiores. 54

Figura 5.20 Resultado da simulação do controlador por modos deslizantes integrador com os parâmetros $10 \%$ menores. 56

Figura 5.21 Sinal de saída do controlador por modos deslizantes integrador simulado com os parâmetros $10 \%$ menores. 56 
Figura 5.22 Superfície de escorregamento do controlador por modos deslizantes integrador simulado com os parâmetros $10 \%$ menores

Figura 5.23 Resultado da simulação do controlador por modos deslizantes integrador com os $10 \%$ maiores

Figura 5.24 Sinal de saída do controlador por modos deslizantes integrador com os parâmetros $10 \%$ menores

Figura 5.25 Superfície de escorregamento do controlador por modos deslizantes integrador com os parâmetros $10 \%$ maiores.

Figura 5.26 Resultado da simulação do controlador por modelo interno não linear com os parâmetros $10 \%$ menores 60

Figura 5.27 Sinal de saída do controlador por modelo interno não linear com os parâmetros $10 \%$ menores

Figura 5.28 Resultado da simulação do controlador por modelo interno não linear com os parâmetros $10 \%$ maiores.

Figura 5.29 Sinal de saída do controlador por modelo interno simulado não linear com os parâmetros $10 \%$ maiores.

Figura 5.30 Resultado da simulação do controlador PI não linear com os parâmetros $10 \%$ menores 63

Figura 5.31 Sinal de saída do controlador PI não linear simulado com os parâmetros $10 \%$ menores 63

Figura 5.32 Resultado da simulação do controlador PI não linear com os parâmetros $10 \%$ maiores

Figura 5.33 Sinal de saída do controlador PI não linear com os parâmetros $10 \%$ maiores

Figura 5.34 Resultado da simulação do controlador PI tradicional. 65

Figura 5.35 Sinal de saída do controlador PI tradicional simulado...... 66

Figura 6.1 Diagrama de blocos do procedimento experimental 69

Figura 6.2 Resposta do controlador rastreador de trajetória na válvula de controle real 
Figura 6.3 Sinal de saída do controlador rastreador de trajetória na válvula de controle real

Figura 6.4 Resposta do controlador por modos deslizantes na válvula de controle real

Figura 6.5 Sinal de saída do controlador por modos deslizantes na válvula de controle real 73

Figura 6.6 Superfície de escorregamento do controlador por modos deslizantes na válvula de controle real 74

Figura 6.7 Tempo de alcance na superfície de escorregamento do controlador por modos deslizantes na válvula real.

Figura 6.8 Resposta do controlador por modos deslizantes integrador na válvula de controle real. 76

Figura 6.9 Sinal de saída do controlador por modos deslizantes integrador na válvula de controle real.

Figura 6.10 Superfície de escorregamento do controlador por modos deslizantes integrador na válvula de controle real 77

Figura 6.11 Tempo de alcance na superfície de escorregamento do controlador por modos deslizantes integrador na válvula de controle real

Figura 6.12 Resposta do controlador por modelo interno não linear na válvula de controle real.

Figura 6.13 Sinal de saída do controlador por modelo interno não linear na válvula de controle real.

Figura 6.14 Resposta do controlador PI não linear na válvula de controle real 81

Figura 6.15 Sinal de saída do controlador PI não linear na válvula de controle real ...81

Figura 6.16 Resposta do controlador PI tradicional na válvula de controle real 83

Figura 6.17 Sinal de saída do controlador PI tradicional na válvula de controle real .. 83 Figura 6.18 Resposta do controlador PI tradicional filtrado na válvula de controle real 


\section{Lista de tabelas}

Tabela 2.1 - Parâmetros estimados da válvula de controle.......................................11

Tabela 5.1 - Parâmetros da válvula para simulação ............................................... 42

Tabela 5.2 - Parâmetros de simulação do controlador rastreador de trajetória............44

Tabela 5.3 - Parâmetros de simulação do controlador rastreador resintonizados........45

Tabela 5.4 - Parâmetros de simulação do controlador por modos deslizantes ............48

Tabela 5.5 - Parâmetros de simulação do controlador por modos deslizantes

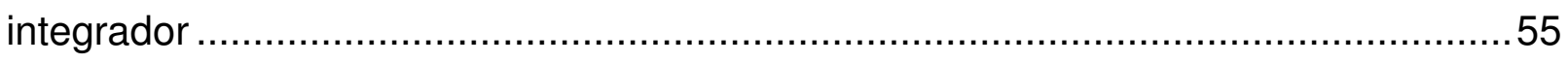

Tabela 5.6 - Parâmetros de simulação do controlador por modelo interno não linear 60

Tabela 5.7 - Parâmetros de simulação do controlador PI não linear ............................62

Tabela 5.8 - Parâmetros de simulação do controlador PI tradicional ...........................65

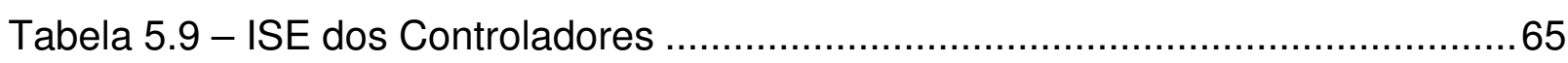

Tabela 6.1 - Parâmetros da válvula para os experimentos ………………………....69

Tabela 6.2 - Parâmetros do controlador rastreador de trajetória.................................71

Tabela 6.3 - Análise do controlador rastreador de trajetória ..................................... 72

Tabela 6.4 - Parâmetros do controlador por modos deslizantes .................................72

Tabela 6.5 - Análise do controlador por modos deslizantes.....................................75

Tabela 6.6 - Parâmetros do controlador por modos deslizantes integrador ..................75

Tabela 6.7 - Análise do controlador por modos deslizantes integrador .......................78

Tabela 6.8 - Parâmetros do controlador por modelo interno não linear .......................78

Tabela 6.9 - Análise do controlador por modelo interno não linear ..............................8 80

Tabela 6.10 - Parâmetros do controlador PI não linear ...........................................80

Tabela 6.11 - Análise do controlador PI não linear..................................................82

Tabela 6.12 - Parâmetros do controlador PI tradicional .............................................82 


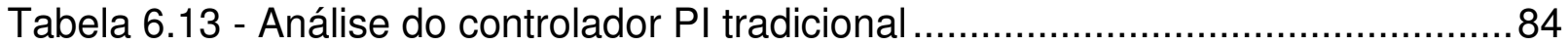

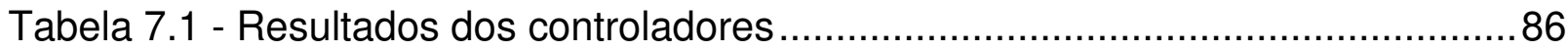




\section{Sumário}

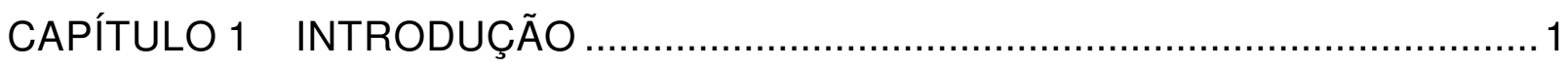

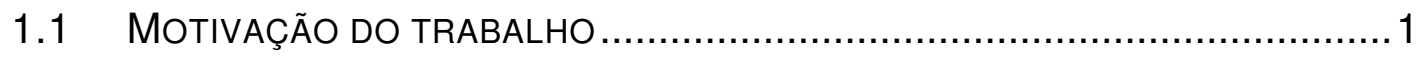

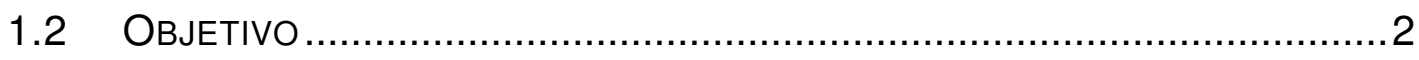

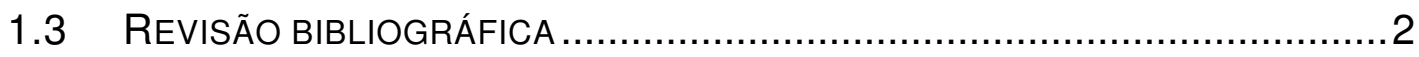

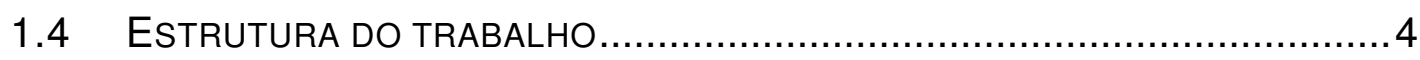

CAPÍTULO 2 MODELAGEM DA VÁLVULA DE CONTROLE ............................. 5

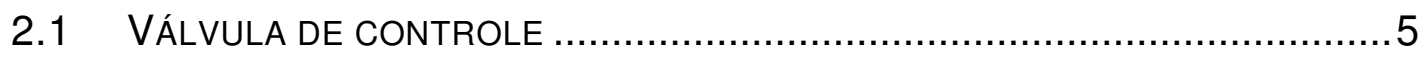

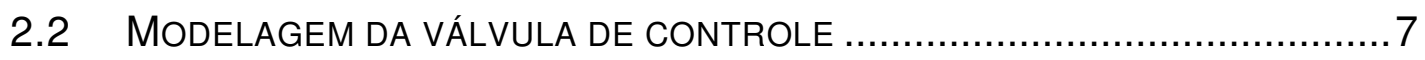

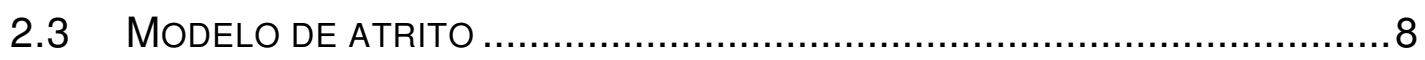

2.4 DINÂMICA DE PRESSURIZAÇÃO DO ATUADOR .................................. 12

CAPÍTULO 3 FORMULAÇÃO TEÓRICA DOS CONTROLADORES ....................13

3.1 LINEARIZAÇÃO POR REALIMENTAÇÃO ........................................ 13

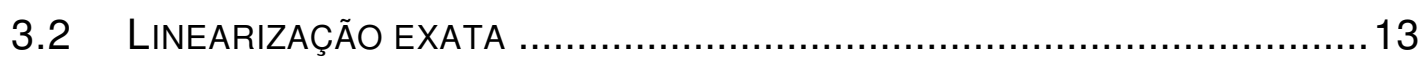

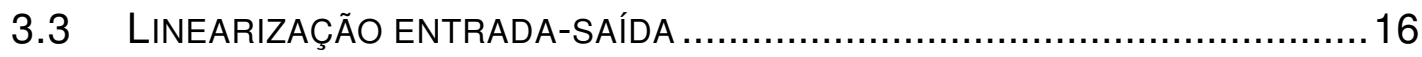

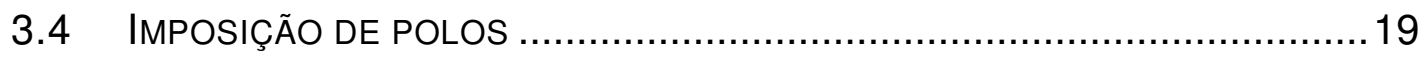

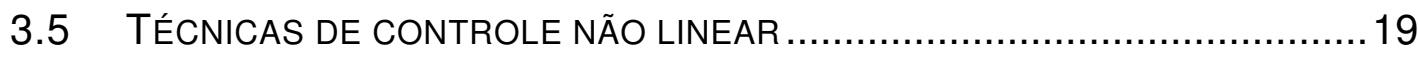

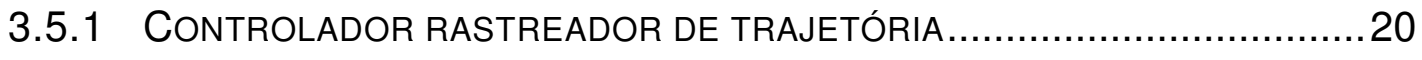

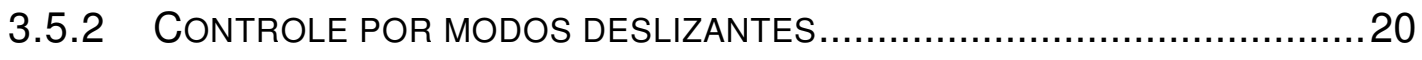

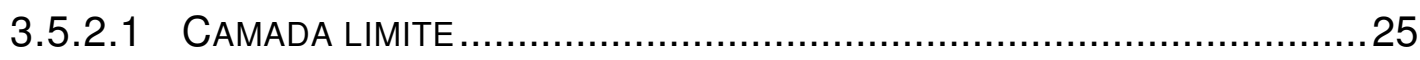

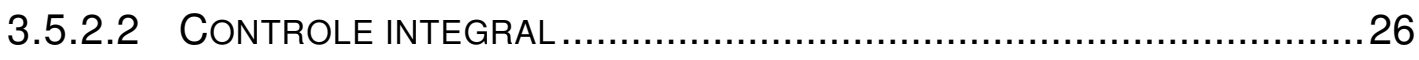

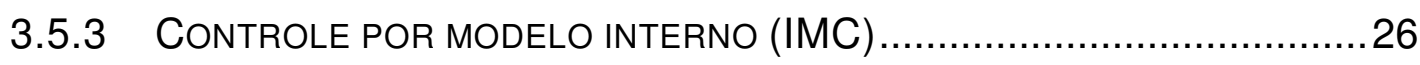

CAPÍTULO 4 TÉCNICAS DE CONTROLE APLICADAS A VÁLVULAS DE CONTROLE

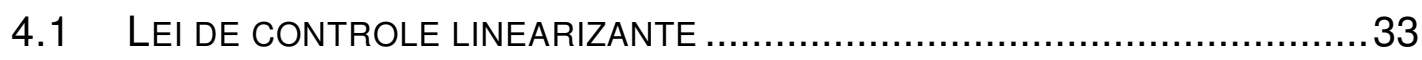


4.2 LEI DE CONTROLE LINEARIZANTE COM IMPOSIÇÃO DE POLOS .................35

4.3 CONTROLADOR RASTREADOR DE TRAJETÓRIA ................................ 36

4.4 CONTROLADOR POR MODOS DESLIZANTES.................................... 36

4.5 CONTROLADOR POR MODOS DESLIZANTES INTEGRADOR ......................37

4.6 CONTROLADOR POR MODELO INTERNO NÃO LINEAR $\ldots \ldots \ldots \ldots \ldots \ldots \ldots \ldots . \ldots . \ldots \ldots$

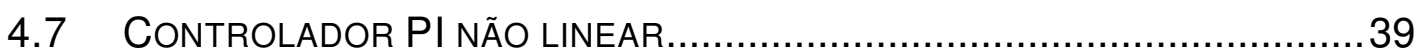

CAPÍTULO 5 RESULTADOS SIMULADOS .............................................. 40

5.1 LINEARIZAÇÃO E IMPOSIÇÃO DE POLOS .................................... 42

5.2 CONTROLADOR RASTREADOR DE TRAJETÓRIA ...............................4 43

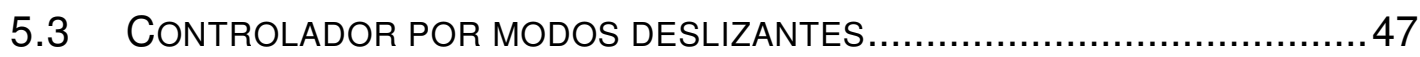

5.4 CONTROLADOR POR MODOS DESLIZANTES INTEGRADOR ....................55

5.5 CONTROLADOR POR MODELO INTERNO NÃO LINEAR ...........................59

5.6 CONTROLADOR PI NÃO LINEAR.............................................. 62

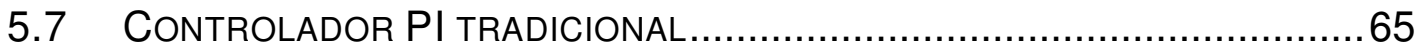

5.8 COMPARAÇÃO dOS RESULTADOS ........................................... 66

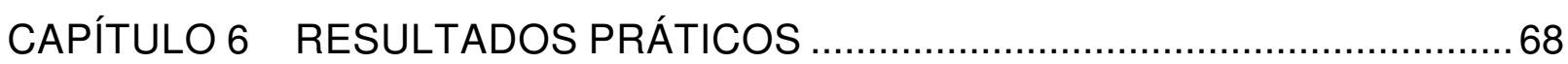

6.1 PROCEDIMENTO EXPERIMENTAL ................................................6 68

6.2 CONTROLADOR RASTREADOR DE TRAJETÓRIA ..................................70

6.3 CONTROLADOR POR MODOS DESLIZANTES ...................................... 72

6.4 CONTROLADOR POR MODOS DESLIZANTES INTEGRADOR ..................... 75

6.5 CONTROLADOR POR MODELO INTERNO NÃO LINEAR .......................... 78

6.6 CONTROLADOR PI NÃO LINEAR.............................................. 80

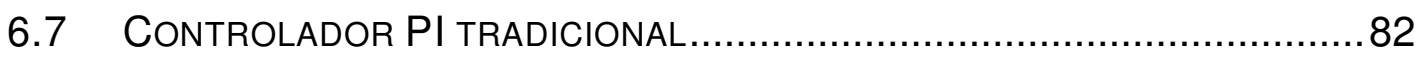

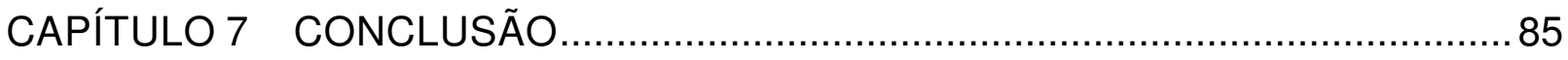

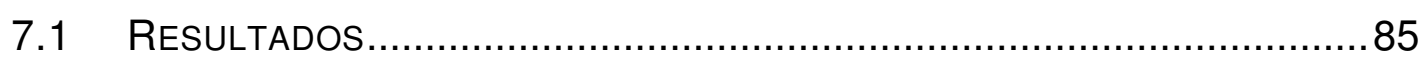

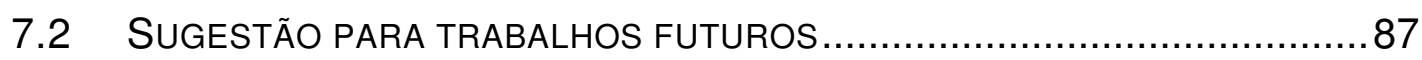


REFERÊNCIAS BIBLIOGRÁFICAS

89 


\section{CAPÍTULO 1 INTRODUÇÃO}

Um dos principais objetivos do controle de processos industriais é que as variáveis de processo estejam o mais próximo possível dos valores de referência. Porém, mesmo quando estas variáveis atingem o valor de referência é comum ocorrer oscilações em torno deste valor. Esta variação é denominada variabilidade da malha de controle, um efeito indesejado que provoca perdas de material do processo, gastos de energia e desgaste dos elementos da malha.

Há várias causas para a variabilidade, entre elas a sintonia inadequada dos controladores do processo, válvulas de controle mal dimensionadas, perturbações do processo, atrito elevado em válvulas de controle, não linearidades do processo, etc (Bialkowski, 1998).

Válvulas de controle são um dos atuadores mais utilizados na indústria de processo. Por serem as únicas partes móveis da malha estão sujeitas ao atrito, o qual, quando é elevado, pode provocar oscilações nas malhas. Estima-se que $20 \%$ a $30 \%$ das malhas de controle oscilem devido ao atrito em válvulas de controle (Desborough e Miller, 2001).

\subsection{MotivaÇão do trabalho}

Para eliminar as oscilações provocadas por válvulas de controle com elevado atrito é preciso fazer a manutenção destes elementos. Porém, em muitas situações é impossível retirá-las, pois isto implicaria em parar o processo produtivo, gerando grandes perdas para a indústria. Assim, a válvula apenas poderá ser removida nas paradas programadas, as quais em alguns casos ocorrem entre longos períodos de tempo. Logo, a malha de controle opera com oscilações por longos períodos, reduzindo de forma significativa a eficiência do processo. 
Portanto, é de grande interesse prático o desenvolvimento de novas técnicas de controle que melhorem o desempenho de válvulas de controle com alto atrito, já que, isto resultaria em tornar o processo produtivo mais eficiente e sustentável.

\subsection{ObJetivo}

O objetivo deste trabalho é projetar compensadores não lineares utilizando a técnica de linearização por realimentação, visando melhorar o desempenho de válvulas de controle com alto atrito.

O trabalho apresenta a modelagem da válvula de controle, essencial para projeto dos controladores, a formulação teórica dos controladores e discussões sobre o projeto dos algoritmos de controle. Além disso, são apresentados resultados simulados e práticos com uma válvula de controle real.

Os resultados de cada controlador são analisados e discutidos, sendo que são analisados o erro em regime estacionário, a distância percorrida pela haste, a variabilidade e a robustez aos erros nos parâmetros de atrito.

\subsection{REVISÃo BIBLIOGRÁFICA}

$\mathrm{Na}$ literatura há diversos modelos de atrito para válvulas de controle. Em (Garcia, 2008) realizou-se uma análise dos principais modelos de atrito, os quais foram submetidos a testes conforme normas ISA para válvulas de controle reais.

Romano e Garcia (2008) apresentaram em um artigo a estimação de parâmetros de atrito de Karnopp para uma válvula de controle real, através do método proposto por Ravanbod-Shirazi and Besançon-Voda (2003).

Uehara (2009) apresenta em sua dissertação de mestrado a quantificação de atrito de válvulas de controle para o modelo de atrito de Kano. 
Romano (2010) apresenta na sua tese de doutorado a estimação e identificação de atrito em válvulas de controle.

Para compensação de atrito, há na literatura métodos baseados ou não em modelos. Em 1987, Costas Kravaris e Chang-Bock Chung apresentaram um compensador baseado em modelo que combina o controlador PI (proporcional e integral) com a técnica de linearização por realimentação.

Isidori (1989) apresenta em seu livro a teoria de controle geométrico com ampla discussão teórica sobre a técnica de linearização por realimentação.

Michael Henson e Dale Seborg (1991) propuseram em um artigo a técnica denominada NLIMC (Nonlinear Internal Model Control ), a qual utiliza a técnica de linearização em conjunto com a técnica de controle por modelo interno.

Os mesmos autores (1997) apresentam em seu livro técnicas de identificação de sistemas e controle não linear, aplicados para processos industriais. No livro é possível encontrar exemplos e aplicações da técnica de linearização por realimentação em conjunto com outras como o controle por modelo internos e o controlador PI.

Slotine e Li (1991) apresentam em seu livro técnicas de controle não linear com enfoque aplicado. No livro são discutidas, entre outros temas da área teoria de controle, as técnicas de controle geométrico e por modos deslizantes. Um aspecto bastante importante no livro é a discussão e a solução proposta para eliminar o efeito do chattering gerado no controle por modos deslizantes.

Edwards e Spurgeon (1998) apresentam em seu livro a técnica de controle por modos deslizantes aplicada para sistemas lineares, com ampla discussão teórica e exemplos de aplicação. De acordo com os autores a técnica de controle por modos deslizantes foi criada com base na teoria de controle de estrutura variável (VSCS - Variable Structure Control Systems) desenvolvida na Russia nos anos 60. Porém, as ideias foram apenas conhecidas através dos trabalhos de Itkis (1976) e Utikin (1977).

Kayihan e Doyle (2000) apresentaram o método de compensação de atrito para válvulas de controle baseado em uma estrutura NLIMC em conjunto com um 
observador não linear de Luenberger para estimar a posição e velocidade da haste. Porém, o modelo interno utilizado pelo controlador é linear.

Hägglund em 2002 publicou o método de compensação de atrito não baseado em modelo denominado knocker, o qual propõe que seja aplicada uma série de pulsos contínuos no atuador da válvula.

O mesmo autor em 2007 propõe um método de estimação e compensação de banda morta para válvulas de controle. No qual, a própria banda morta estimada é somada ao sinal de controle para a sua compensação.

Srinivasan e Rengaswamy (2007) apresentaram outro método de compensação de atrito não baseado em modelo denominado two-move, o qual se baseia em dois estados de operação, um para retirar a válvula da posição travada e outro para manter a válvula na posição desejada.

\subsection{EStRutura do tRabalHo}

No capítulo 2 é apresentado o modelo dinâmico de uma válvula de controle pneumática e uma discussão a respeito dos modelos de atrito.

O capítulo 3 apresenta a formulação teórica necessária para o desenvolvimento e discussão dos controladores propostos. Já o capítulo 4 apresenta o projeto dos algoritmos do capítulo 3 para a válvula de controle.

O capítulo 5 é responsável por apresentar o projeto dos controladores em ambiente simulado.

No capítulo 6 são apresentados os resultados práticos da implementação do algoritmo de controle em uma válvula de controle real.

Finalmente, no capítulo 7 são apresentadas as conclusões e sugestões para trabalhos futuros. 


\section{CAPÍTULO 2 MODELAGEM DA VÁLVULA DE CONTROLE}

Neste capítulo apresenta-se a modelagem da válvula de controle, discutindo aspectos da sua estrutura física e modelos de atrito.

\subsection{VÁLVULA DE CONTROLE}

As válvulas de controle podem ser divididas estruturalmente em duas partes principais: o corpo e o atuador. O sinal de controle que chega ao atuador é o responsável por gerar a força para a atuação da válvula, este sinal pode ser pneumático ou elétrico, sendo que o pneumático é o mais utilizado na indústria de processos. O corpo da válvula contém os elementos mecânicos responsáveis pelo controle da vazão ou pressão. O corpo pode ser de ação rotativa ou linear. A figura 2.1 apresenta uma válvula de controle com acionamento linear do tipo globo e a figura 2.2 a válvula tipo borboleta com acionamento rotativo (Emerson, 2005).

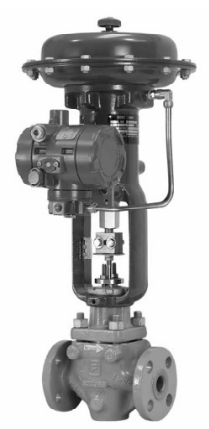

Figura 2.1 Válvula de controle tipo globo com atuador pneumático (Adaptado Emerson, 2005). 


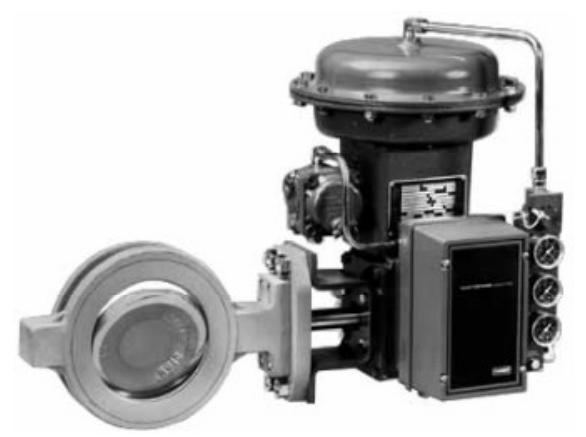

Figura 2.2 Válvula de controle tipo borboleta com atuador pneumático (Adaptado Emerson, 2005).

Este trabalho aborda a modelagem e o controle de válvulas com acionamento linear do tipo globo, pois este é o modelo mais utilizado na indústria de processos. A figura 2.3 apresenta os principais elementos deste tipo de válvula.

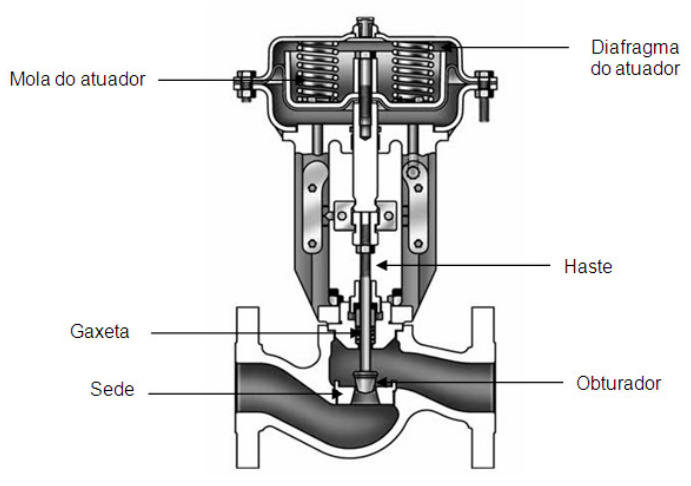

Figura 2.3 Principais elementos de uma válvula tipo globo (Adaptado Emerson, 2005).

Através da figura 2.3 pode-se observar que o atuador é composto por dois elementos principais: a mola e o diafragma, sendo que o atuador recebe o sinal de pressão vindo muitas vezes de um conversor, o qual recebe um sinal elétrico (tensão ou corrente) e o converte para pressão, fazendo com que o diafragma movimente a haste e o obturador, elemento que controla a vazão para que o fluido escoe na sede do corpo. A mola, naturalmente, age como força restauradora do movimento. No corpo da válvula há ainda um elemento vedante, denominado gaxeta, o qual tem a função de vedar a haste para que não haja vazamento de fluido. A gaxeta pode ser de grafite, carbono ou teflon, sendo que este é o elemento responsável pelo atrito nas válvulas de controle. 
Na indústria há válvulas que operam em malha aberta, ou seja, não há um controlador dedicado para corrigir a posição da haste. Porém, há também válvulas que possuem um controlador dedicado, denominado posicionador, que recebe uma referência desejada de abertura da válvula e o controlador corrige a posição para atingir a referência desejada.

\subsection{MOdELAGEM dA VÁLVULA DE CONTROLE}

Para o estudo e desenvolvimento de algoritmos de controle para compensação de atrito é fundamental um modelo que represente adequadamente o comportamento dinâmico de uma válvula de controle.

Segundo (Garcia, 2008), uma válvula de controle pode ser modelada pela seguinte equação de balanço de forças:

$$
m \cdot \ddot{x}=\sum \text { Forças }=F_{\text {Pressão }}-F_{\text {Mola }}-F_{\text {Atrito }}-F_{\text {Fluido }}-F_{\text {Assentamento }}
$$

onde:

$m$ : massa das partes móveis

$x$ : posição da haste

$F_{\text {Pressão }}=P \cdot S_{a}$ : força aplicada pelo atuador, sendo $S_{a}$ a área do atuador e $P$ a pressão aplicada

$F_{\text {Mola }}=K \cdot x$ : força elástica da mola, sendo $K$ a constante elástica da mola

$F_{\text {Atrito }}$ : força de atrito

$F_{\text {Fluido }}$ : força devida à queda de pressão do fluido através da válvula

$F_{\text {Assentamento }}$ : força necessária para travar a válvula na sede 
Nota-se que na equação 2.1 não se considerou a força gravitacional, pois a massa das partes móveis é bastante baixa, assim esta força é desprezível comparada com as outras.

De acordo com (Kayihan \& Doyle, 2000) a força do fluido, $F_{\text {Fluido }}$, pode ser desprezada na equação (2.1), pois esta é duas ordens de grandeza menor do que a força de atrito e da mola. A força de assentamento, $F_{\text {Assentamento }}$, apesar de não ser desprezível, também não será considerada neste trabalho, pois ela opera apenas na faixa final de atuação da válvula, na qual não há mais movimento da haste, apenas o obturador está sendo forçado contra a sede. Dessa forma, os algoritmos de controle desenvolvidos neste trabalho irão considerar a válvula operando em regime de $0 \mathrm{a}$ $100 \%$, sem levar em conta as forças que não afetam o comportamento da malha de controle. Portanto, a equação (2.1) pode ser reescrita conforme a equação (2.2), a qual será o modelo dinâmico utilizado durante todo o trabalho.

$$
m \cdot \ddot{x}=\sum \text { Forç̧as }=F_{\text {Pressão }}-F_{\text {Mola }}-F_{\text {Atrito }}
$$

\subsection{Modelo de ATRito}

Conforme (Garcia, 2008), há modelos de atrito desde os mais simples com um ou dois parâmetros, até os mais complexos com sete parâmetros. Assim, é importante selecionar o modelo mais simples, que descreva de forma adequada o atrito. A força de atrito pode ser descrita pela equação (2.3) que é denominado modelo de atrito clássico.

$$
F_{\text {Atrito }}=\left[F_{C}+\left(F_{S}-F_{C}\right) \cdot e^{-\left(\frac{\dot{x}}{V_{s}}\right)^{2}}\right] \cdot \operatorname{sign}(\dot{x})+F_{V} \cdot \dot{x}
$$

onde:

$$
\operatorname{sign}(x)=\left\{\begin{array}{cc}
1, & x>0 \\
0, & x=0 \\
-1, & x<0
\end{array}\right.
$$


$F_{C}$ : coeficiente de atrito de Coulomb

$F_{S}:$ coeficiente de atrito estático

$F_{V}$ : coeficiente de atrito viscoso

$V_{S}:$ velocidade de Stribeck

$x$ : posição da haste

$\dot{x}$ : velocidade da haste

A função sign() presente no modelo possui uma descontinuidade e os algoritmos de controle propostos neste trabalho necessitam de um sistema contínuo e suave. Dessa forma, para contornar este problema, conforme foi proposto por (Kayihan e Doyle, 2000) utiliza-se a função tangente hiperbólica, a qual possui um comportamento semelhante à função sign(), porém é contínua e suave. Assim o modelo pode ser reescrito como a equação (2.4).

$$
F_{\text {Atrito }}=\left[F_{C}+\left(F_{S}-F_{C}\right) \cdot e^{-\left(\frac{\dot{x}}{V_{S}}\right)^{2}}\right] \cdot \tanh (\sigma \cdot \dot{x})+F_{V} \cdot \dot{x}
$$

A figura 2.4 mostra a função $\tanh (\sigma \cdot \dot{\mathrm{x}})$ para dois valores de $\sigma$.

onde:

$\sigma:$ constante positiva 


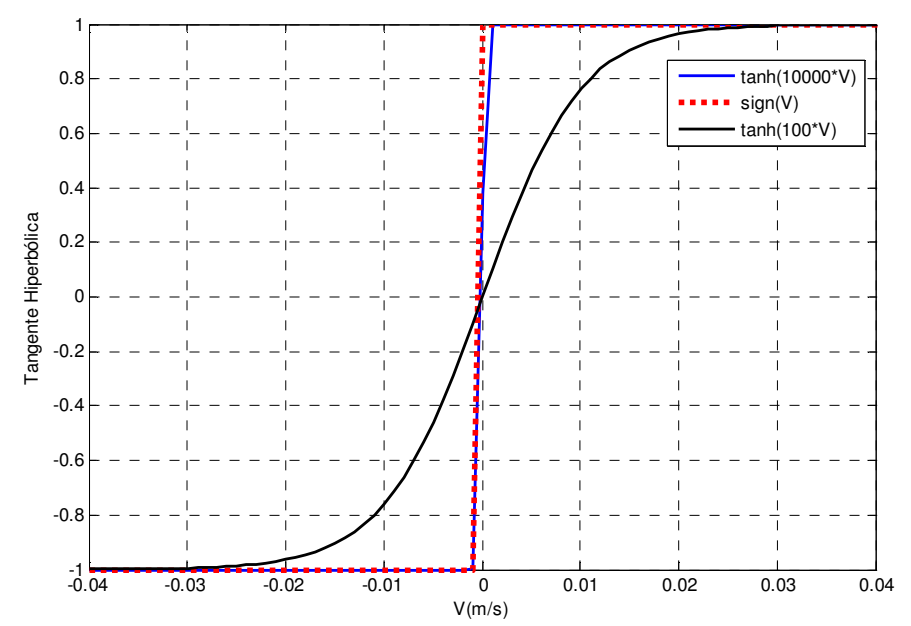

Figura 2.4 Comparação entre função tangente hiperbólica e função sign.

Através da figura (2.4) nota-se claramente que quanto maior o valor de $\sigma$ mais próxima a função tangente hiperbólica fica da função sign().

O modelo de atrito clássico possui um inconveniente para ser simulado devido à função sign(), já que nas simulações a válvula nunca atinge a velocidade nula e o sistema passa a oscilar em torno deste valor. Dessa forma, o modelo de atrito de Karnopp é comumente adotado, já que possui uma abordagem em que o problema da velocidade nula é tratado através de uma velocidade limite DV, tornando a sua simulação mais eficiente e efetiva.

Segundo (Garcia, 2008), o modelo de Karnopp apresenta uma boa relação entre uma relativa simplicidade de ser implementado em ambiente simulado e a representação adequada no efeito do atrito em válvulas de controle. A equação (2.5) apresenta o modelo de Karnopp.

$$
F_{\text {Atrito }}=\left\{\begin{array}{lr}
F_{C} \cdot \operatorname{sign}(\dot{x})+F_{V} \cdot \dot{x} & s e|\dot{x}| \geq D V \\
F_{\text {Pressão }}-k \cdot x & \text { se }|\dot{x}|<D V \text { e }\left|F_{\text {Pressão }}-k \cdot x\right| \leq F_{S} \\
F_{S} \cdot \operatorname{sign}\left(F_{\text {Pressão }}-k \cdot x\right) & \text { se }|\dot{x}|<D V \text { e }\left|F_{\text {Pressão }}-k \cdot x\right|>F_{S}
\end{array}\right.
$$

onde:

$D V$ : velocidade limite 
Entretanto, para o projeto dos controladores, será utilizado o modelo descrito pela equação (2.4), pois os algoritmos de controle propostos necessitam de um modelo com estrutura contínua.

A tabela 2.1 apresenta os parâmetros estimados da válvula de controle com gaxetas de grafite presente no laboratório.

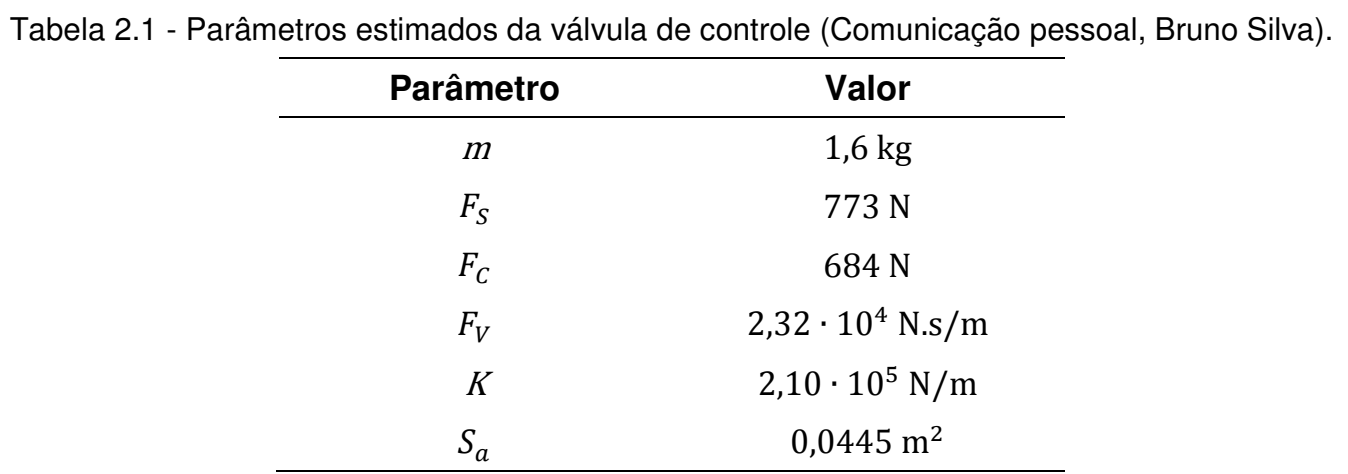

A figura 2.5 apresenta a comparação da válvula de controle real, com o modelo de Karnopp e o modelo $2.4 \operatorname{com} \sigma=10000$.

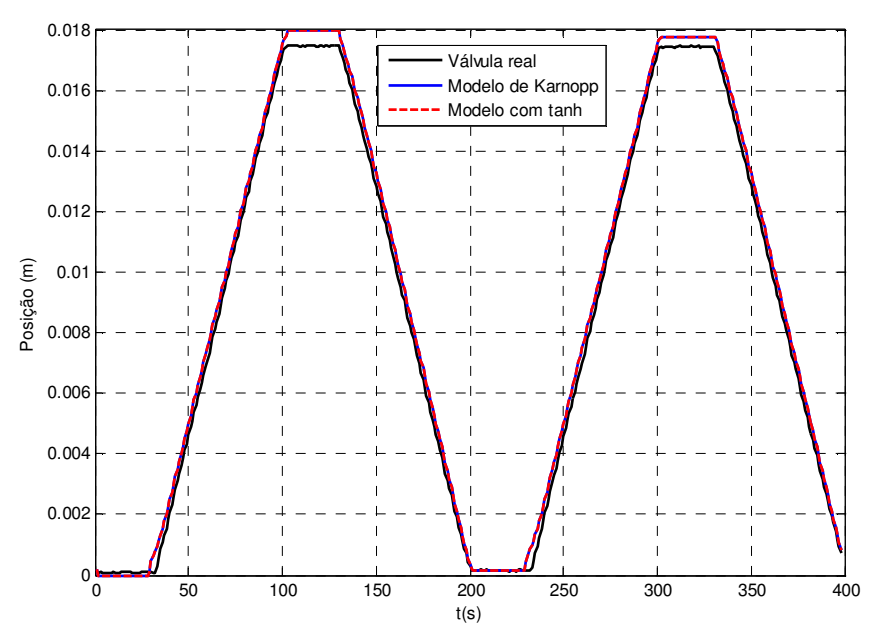

Figura 2.5 Comparação entre os modelos de atrito e válvula real.

A figura 2.5 mostra que o modelo 2.4 representa a válvula de controle de forma adequada. 


\subsection{DINÂMICA DE PRESSURIZAÇÃO DO ATUADOR}

Normalmente em válvulas de controle pneumáticas industriais, o sinal de controle elétrico é convertido para pressão através de um conversor (V/P ou I/P), o qual envia o sinal de pressão, preenchendo com ar comprimido o atuador para movimentar o diafragma e deslocar a haste da válvula. Claramente, esta dinâmica não é desprezível, dessa forma para se obter um modelo mais adequado da válvula de controle é preciso considerá-la. Neste trabalho, a dinâmica de pressurização do atuador é modelada como de primeira ordem, conforme a equação (2.6).

$$
\frac{P(s)}{U(s)}=\frac{K_{p}}{\tau \cdot s+1}
$$

onde:

$K_{p}$ : ganho estático do atuador

$\tau$ : constante de tempo

$U$ : sinal de controle em Volts

$P$ : sinal de pressão 


\section{CAPÍTULO 3 FORMULAÇÃO TEÓRICA DOS CONTROLADORES}

Este capítulo apresenta a formulação teórica das técnicas de controle que serão estudadas neste trabalho. O capítulo aborda a técnica de linearização por realimentação, controlador rastreador de trajetória, controlador por modos deslizantes, controlador por modelo interno e o controlador PI não linear.

\subsection{LINEARIZAÇÃO POR REALIMENTAÇÃO}

A técnica de linearização por realimentação tem sido utilizada em diversas aplicações práticas, como no controle de aviões, helicópteros e robôs (Slotine, 1991). A ideia principal desta técnica é transformar um sistema não linear em um total ou parcialmente linear e a partir disto utilizar as técnicas de controle para rastrear a referência desejada.

\subsection{LINEARIZAÇÃO EXATA}

Seja um sistema com uma entrada e uma saída da forma afim, ou linear no controle, dado pelo sistema (3.1).

$$
\left\{\begin{array}{l}
\dot{x}=f(x)+g(x) \cdot u \\
y=h(x)
\end{array}\right.
$$

onde $f(x)$ e $g(x)$ são campos vetoriais suaves pertencentes ao $\mathbb{R}^{n}$ e $h(x)$ uma função escalar suave, ou seja, todas as derivadas parciais, de qualquer ordem, existem e são contínuas. 
O problema da linearização exata consiste em encontrar em uma região $\Omega$ no $\mathbb{R}^{n}$, uma transformação de coordenadas $z=T(x)$ (um difeomorfismo) e uma realimentação não linear do tipo:

$$
u=\alpha(x)+\beta(x) \cdot v
$$

de forma que o sistema (3.1) seja representado nas novas coordenadas $z$ da seguinte forma:

$$
\dot{z}=A \cdot z+b \cdot v
$$

onde:

$v$ : nova entrada do sistema

$$
A=\left[\begin{array}{ccccc}
0 & 1 & 0 & \ldots & 0 \\
0 & 0 & 1 & \ldots & \ldots \\
\ldots & \ldots & \ldots & \ldots & \ldots \\
\ldots & \ldots & \ldots & \ldots & \ldots \\
0 & 0 & 0 & \ldots & 1 \\
0 & 0 & 0 & \ldots & 0
\end{array}\right] \quad b=\left[\begin{array}{c}
0 \\
0 \\
. \\
. \\
0 \\
1
\end{array}\right] \text {, sendo que } A: n x n \text { e } b: n x 1
$$

Ou seja, o sistema (3.1) passa a ter uma relação entrada-estado linear.

Para apresentar a condição necessária e suficiente para a linearização exata é preciso definir o conceito de grau relativo: o sistema possui grau relativo $\mathrm{p}$ se as seguintes condições forem satisfeitas (Isidori, 1989):

1- $L_{g} L_{f}^{k} h(x)=0$, para todo $k=0 \ldots p-2$

2- $L_{g} L_{f}^{p-1} h(x) \neq 0$

onde $L_{f} h(x)$ é a derivada de Lie da função escalar $h(x)$ na direção do campo $f(x)$, dada por:

$$
\begin{gathered}
L_{f}^{0} h=h \\
L_{f} h(x)=\sum_{i=1}^{n} \frac{\partial h}{\partial x_{i}} \cdot f_{i}(x)
\end{gathered}
$$




$$
L_{f}^{i} h=L_{f}\left(L_{f}^{i-1} h\right)
$$

Em outras palavras, o grau relativo de um sistema é a quantidade de vezes que a saída do sistema deve ser derivada para que o sinal de entrada $u$ apareça explicitamente na equação.

Se e somente se o sistema (3.1) possuir grau relativo $p=n$, o problema da linearização exata possui solução, ou seja, se o grau relativo do sistema for igual à dimensão do sistema, este poderá ser totalmente linearizado através da lei de controle (3.2), onde (Isidori, 1989)::

$$
\alpha(x)=\frac{-L_{f}^{p} h(x)}{L_{g} L_{f}^{p-1} h(x)} \quad \text { e } \quad \beta(x)=\frac{1}{L_{g} L_{f}^{p-1} h(x)}
$$

Nestas condições, a mudança de coordenadas $z=T(x)$ é dada por:

$$
\begin{gathered}
z_{1}=h(x) \\
z_{2}=L_{f} h(x) \\
\cdots \\
z_{n}=L_{f}^{n-1} h(x)
\end{gathered}
$$

A figura 3.1 apresenta o digrama de blocos do sistema com a implementação do algoritmo de linearização exata.

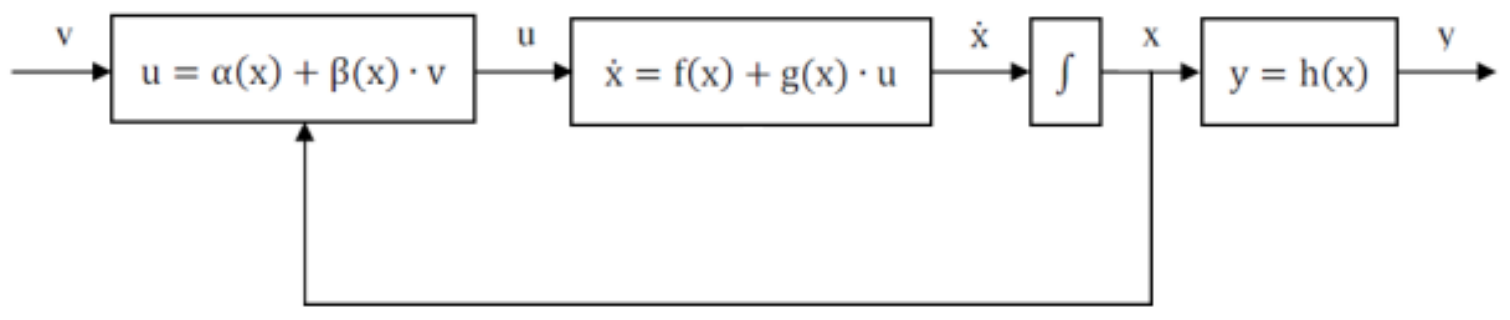

Figura 3.1 Sistema de controle com linearização exata. 


\subsection{LINEARIZAÇÃO ENTRADA-SAÍDA}

Em muitos casos práticos não é necessário que o sistema seja totalmente linearizado, mas sim que se tenha uma relação entrada-saída linear, já que dessa forma podem ser aplicadas as técnicas de controle linear para controlar a saída.

Dado o sistema (3.1), derivando a saída tem-se:

$$
\dot{y}=\frac{\partial h(x)}{\partial x} \cdot(f(x)+g(x) \cdot u)=L_{f} h(x)+L_{g} h(x) \cdot u
$$

Supondo que o sistema tenha grau relativo $p$, então a entrada $u$ apenas aparece explicitamente na $p$-ésima derivada de $y$, assim:

$$
\dot{y}=L_{f} h(x)
$$

Derivando novamente tem-se que:

$$
\ddot{y}=\frac{\partial\left(L_{f} h(x)\right)}{\partial x} \cdot(f(x)+g(x) \cdot u)=L_{f}^{2} h(x)+L_{g}\left(L_{f} h(x)\right) \cdot u
$$

Na $p$-ésima derivada tem-se:

$$
y^{p}=L_{f}^{p} h(x)+\left(L_{g} L_{f}^{p-1} h(x)\right) \cdot u
$$

Nesta derivada tem-se uma relação entrada-saída e aplicando-se a lei de controle (3.2) na entrada u, tem-se:

$$
y^{p}=v
$$

Ou seja, com a lei de controle (3.2) tem-se uma relação linear entre a nova entrada $v$ e a saída $y$.

Para que o sistema (3.1) seja linearizado entre entrada e saída é necessário que o grau relativo $p$ seja menor ou igual à dimensão do sistema. Dessa forma, a lei de controle (3.2) promove a linearização entre entrada e saída. 
Quando o grau relativo $(p)$ do sistema for menor do que a sua dimensão $(n)$, utilizando a realimentação de estados (3.2), o sistema (3.1) descrito no novo sistema de coordenadas é dado por:

$$
\begin{gathered}
\dot{\mathrm{z}}_{1}=\mathrm{z}_{2} \\
\dot{z}_{2}=z_{3} \\
\ldots \\
\dot{z}_{p-1}=z_{p} \\
\dot{z}_{p}=v \\
\dot{z}_{p+1}=q_{r+1}(z) \\
\ldots \\
\dot{z}_{n}=q_{n}(z) \\
y=z_{1}
\end{gathered}
$$

Dessa forma, o sistema (3.1), com a mudança de coordenadas $z=T(x)$ e a realimentação (3.2), é agora descrito por $p$ equações diferenciais lineares e $n-p$ equações diferenciais não lineares em $z$ representadas por $q(\xi, \eta)$, porém a relação entrada-saída é linear. Dessa forma, pode-se escrever a função de transferência no domínio de Laplace:

$$
H(s)=\frac{Y(s)}{V(s)}=\frac{1}{s^{p}}
$$

O sistema nas novas coordenadas também pode ser escrito sem a realimentação $u$, da seguinte forma:

$$
\begin{gathered}
\dot{z}_{1}=z_{2} \\
\dot{z}_{2}=z_{3} \\
\ldots \\
\dot{z}_{p-1}=z_{p} \\
\dot{z}_{p}=L_{f}^{p} h(x)+L_{g} L_{f}^{p-1} h(x) \cdot u
\end{gathered}
$$




$$
\begin{gathered}
\dot{\eta}=q(\xi, \eta) \\
y=z_{1}
\end{gathered}
$$

onde:

$\eta=\left[\begin{array}{c}z_{p+1} \\ \vdots \\ \vdots \\ z_{n}\end{array}\right] \quad$ e $\quad \xi=\left[\begin{array}{c}z_{1} \\ \vdots \\ \vdots \\ z_{p}\end{array}\right]$

A partir desta notação pode-se definir a dinâmica zero de um sistema, a qual está presente no caso em que a linearização é feita e o grau relativo é menor do que a dimensão do sistema.

A dinâmica zero de um sistema é a dinâmica na qual a entrada e a condição inicial foram escolhidas para que a saída, $y$, seja identicamente nula. Se a saída $y$ for nula, implicará que o vetor $\xi$ também será nulo. A dinâmica zero pode ser descrita pela seguinte equação (Isidori, 1989):

$$
\dot{\eta}=q(0, \eta)
$$

Se a dinâmica zero for assintoticamente estável, o sistema (3.1) é assintoticamente de fase mínima (Slotine,1991).

A figura 3.2 apresenta o diagrama de blocos do sistema nas novas coordenadas, quando o grau relativo $p<n$.

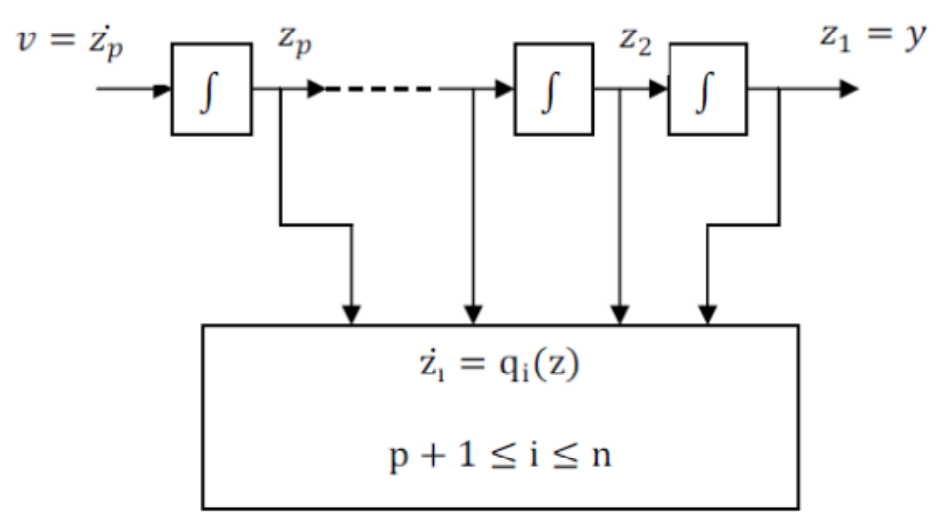

Figura 3.2 Diagrama de blocos do sistema linearizado. 


\subsection{IMPOSIÇÃO DE POLOS}

Após a linearização entrada-saída, obtém-se uma relação entre entrada e saída linear dada pela equação (3.8), porém esta relação não é estável. Se o grau relativo do sistema for igual à dimensão do sistema, através da realimentação de estados (3.2) e a mudança de coordenadas $z=T(x)$, tem-se um sistema linear controlável. Portanto, é possível impor, através de uma realimentação de estados, os polos desejados para estabilizar o sistema.

A lei de controle (3.11) lineariza o sistema e impõe os polos desejados para o sistema 3.1 (Isidori,1989):

$u=\frac{1}{L_{g} L_{f}^{p-1} h(x)} \cdot\left(-L_{f}^{p} h(x)-C_{0} \cdot h(x)-C_{1} \cdot L_{f} h(x)-\cdots-C_{p-1} \cdot L_{f}^{p-1} h(x)+w\right)$

onde:

$w$ : nova entrada do sistema

Para a realimentação (3.11) estabilizar o sistema, as raízes do polinômio $p(s)=C_{0}+C_{1} \cdot s+\cdots+C_{p-1} \cdot s^{p-1}+s^{p}$ devem ter parte real negativa. Caso o sistema tenha grau relativo $p<n$, será possível estabilizar o sistema se a dinâmica zero for assintoticamente estável. Nestas condições, a relação entradasaída pode ser escrita como:

$$
\frac{Y(s)}{W(s)}=\frac{1}{s^{p}+C_{p-1} \cdot s^{p-1}+\cdots+C_{1} \cdot s+C_{0}}
$$

\subsection{TÉCNICAS DE CONTROLE NÃO LINEAR}

Esta seção apresenta as técnicas de controle não linear para que o sistema siga a referência desejada, já que a lei de controle para a linearização proposta no item anterior apenas realiza a linearização do sistema, não possuindo uma 
abordagem para rastrear a referência. Todas as leis de controle propostas são aplicadas em conjunto com a técnica de linearização por realimentação.

\subsubsection{CONTROLADOR RASTREADOR DE TRAJETÓRIA}

Dado um sistema afim, deseja-se que, através de uma lei controle, a sua saída $y$ percorra uma trajetória suave desejada $y_{d}(t)$, de forma que:

$$
\lim _{t \rightarrow \infty}\left(\mathrm{y}(\mathrm{t})-\mathrm{y}_{\mathrm{d}}(\mathrm{t})\right)=\lim _{t \rightarrow \infty} e(t)=0
$$

Se a trajetória desejada $y_{d}(t)$ possuir as derivadas de ordem 0 a $p-1$ definidas e limitadas, e a dinâmica zero for assintoticamente estável e limitada, a lei de controle (3.13) leva o erro $e(t)$ para zero (Isidori,1989).

$$
u=\frac{1}{L_{g} L_{f}^{p-1} h(x)} \cdot\left(-L_{f}^{p} h(x)+y_{d}{ }^{(p)}-\sum_{1}^{p} C_{i-1}\left(L_{f}^{i-1} h(x)-y_{d}{ }^{(i-1)}\right)\right)
$$

Aplicando-se a lei de controle (3.13) obtém-se a relação (3.14):

$$
\tilde{y}^{p}+C_{i-1} \cdot \tilde{y}^{p-1}+\cdots+C_{0} \cdot \tilde{y}=0
$$

.onde:

$\tilde{y}=y-y_{d}$

\subsubsection{CONTROLE POR MODOS DESLIZANTES}

A técnica de controle por modos deslizantes baseia-se na teoria de sistema com estrutura variável (Edwards e Spurgeon, 1998). Estes sistemas, como o nome sugere, são um conjunto de subsistemas contínuos governados por uma lei de 
controle descontínua, a qual atua de acordo com o estado do sistema, perturbações e referência do sistema (Utkin, 1993).

Dessa forma, dado o sistema SISO (3.1) contínuo, a lei de controle (3.15) é uma lei de controle com estrutura variável, cujas regras de chaveamento estão definidas pela função contínua $S(x)$ (Utkin, 1993).

$$
\mathrm{u}=\left\{\begin{array}{lll}
u^{+}(x) & \text { se } & S(x)>0 \\
u^{-}(x) & \text { se } & S(x)<0
\end{array}\right.
$$

O problema de controle é projetar $S(x)$ (superfície de escorregamento), $u^{+}(x)$ e $u^{-}(x)$, de forma que o sistema atinja e permaneça em $M=\left\{x \in \mathbb{R}^{n}: S(x)=0\right\}$.

Para isso, a superfície de escorregamento deve ser ao menos localmente atrativa em um domínio $\Omega$ de forma que (Edwards e Spurgeon, 1998):

$$
\lim _{S \rightarrow 0^{+}} \dot{S}<0 \quad \text { e } \quad \lim _{S \rightarrow 0^{-}} \dot{S}>0
$$

Assim, neste caso a superfície de escorregamento em $D$ é tal que:

$$
D=M \cap \Omega=\{x \in \Omega: S(x)=0\}
$$

De acordo com (Edwards e Spurgeon, 1998) esta condição pode ser substituída por:

$$
S \cdot \dot{S}<0
$$

Uma condição mais forte para (3.16) é dada por (3.17).

$$
S \cdot \dot{S} \leq-\eta|s|
$$

onde:

$\eta$ : Constante positiva

Através da condição (3.17) é fácil verificar que o sistema $\dot{S}(x)=0$ é estável, escolhendo $S^{2}(x)$ como função de Lyapunov. 
Slotine (1991) define a superfície de escorregamento conforme a equação (3.18)

$$
S(x, t)=\sum_{i=1}^{n-1}\left(\frac{d^{i} \tilde{y}}{d^{i} t}+\lambda^{i} \cdot \tilde{y}\right)
$$

onde:

$\tilde{y}=y-y_{d}$

$\lambda$ : constante positiva

Nota-se que a superfície (3.18) é uma equação dinâmica do erro de rastreamento.

Assim para um sistema de segunda ordem:

$$
S=\dot{\tilde{y}}+\lambda \cdot \tilde{y}
$$

onde:

$\lambda$ : é uma constante do projeto positiva, que está relacionada com a taxa em que o erro de rastreamento tende a zero quando o sistema já atingiu a superfície.

A figura 3.3 apresenta a superfície de escorregamento para um sistema de segunda ordem $(n=2)$.

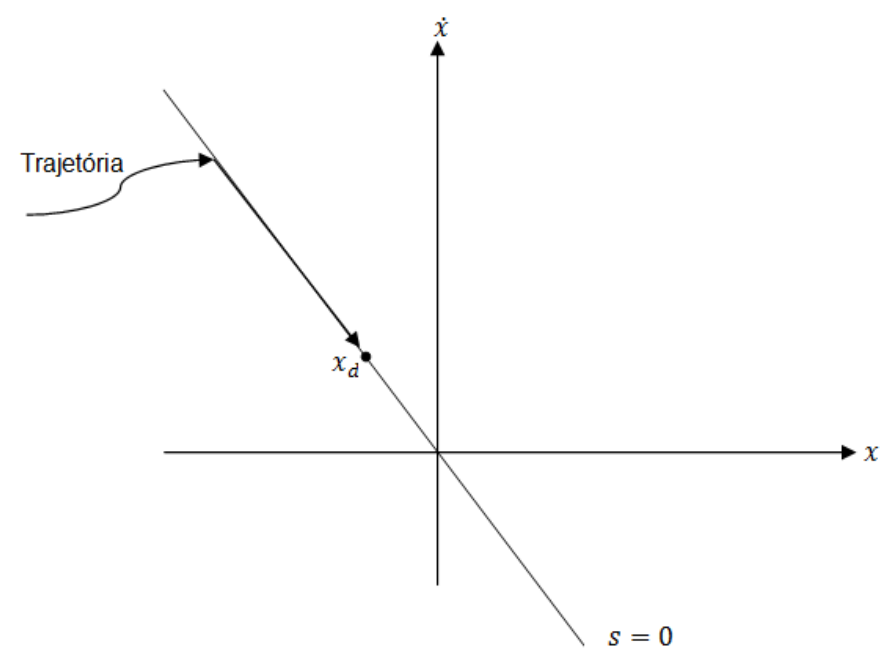

Figura 3.3 Superfície de escorregamento para um sistema de segunda ordem. 
Se o sistema (3.1) possui grau relativo $n$, este pode ser reescrito como a equação (3.20).

$$
y^{(n)}=a(x)+b(x) \cdot u
$$

onde:

$b(x)=L_{g} L_{f}^{n-1} h(x)$

$a(x)=L_{f}^{n} h(x)$

Seja o sistema (3.20) estimado, tal que:

$$
y^{(n)}=\hat{a}(x)+\hat{b}(x) \cdot u
$$

onde:

$\hat{a}(x)=L_{\hat{f}}^{p} \hat{h}(x)$

$\hat{b}(x)=L_{\hat{g}} L_{\hat{f}}^{n-1} \hat{h}(x)$

$\hat{f}$ : Estimativa da função $f$ do sistema (3.1)

$\hat{g}$ : Estimativa da função $g$ do sistema (3.1)

$\hat{h}$ : Estimativa da função $h$ do sistema (3.1)

Para obter a lei de controle, considerando um sistema de segunda ordem na superfície $S=0$, tem-se que (Slotine,1991):

$$
\dot{S}=\ddot{y}-\ddot{y}_{d}+\lambda \cdot \dot{\tilde{y}}=a+b \cdot u-\ddot{y}_{d}+\lambda \cdot \dot{\tilde{y}}=0
$$

Através de (3.22), a melhor aproximação da lei de controle contínua $\hat{u}$ baseada no modelo (3.21) de ordem 2 que permite $\dot{S}=0$, é tal que:

$$
\hat{u}=\frac{\left.\left(\ddot{y}_{d}-\hat{a}(x)-\lambda \cdot \dot{\tilde{y}}\right)\right)}{\hat{b}(x)}
$$


Como há incertezas no modelo, para compensar os erros adiciona-se a parcela descontínua. Assim, de forma genérica, a lei de controle por modos deslizantes é dada por (3.24):

$$
u=\frac{\left(\hat{u}-K_{c} \cdot \operatorname{sign}(S)\right)}{\hat{b}(x)}
$$

Portanto, conforme a condição de escorregamento (3.17), deve-se projetar o ganho para garantir que a condição de escorregamento seja satisfeita e compensar os erros entre o modelo e o sistema real. Nota-se que as funções $u^{+}(x)$ e $u^{-}(x)$ são definidas através do sinal da função sign().

Neste caso, de acordo com (Slotine, 1991), a condição de escorregamento é satisfeita se:

$$
K_{c} \geq \gamma \cdot(A+\eta)+(\gamma-1) \cdot|\hat{u}|
$$

onde:

$|a(x)-\hat{a}(x)| \leq A$

$\gamma=\sqrt{\frac{b_{\max }}{b_{\min }}}$

$b_{\min } \leq b(x) \leq b_{\max }$

Nota-se que se $\hat{a}=a$ e $\hat{b}=b$ o controle se comporta como um rastreador de trajetória e o ganho $K_{c}$ apenas leva o sistema da condição inicial para a superfície. Quanto maiores são os erros entre os parâmetros estimados, maior deve ser o ganho $K_{c}$ para compensar os desvios e levar o sistema para a referência.

Como foi mencionado, a lei de controle por modos deslizantes permite fazer com que o sistema atinja a superfície de escorregamento em tempo finito. Dessa forma, outro importante parâmetro de projeto é o tempo de alcance na superfície de escorregamento, o qual é definido conforme a equação (3.26) (Slotine,1991). 


$$
t_{r} \leq \frac{S(t=0)}{\eta}
$$

\subsubsection{CAMADA LIMITE}

Segundo (Slotine, 1991), devido às imperfeições do controle (chaveamento não instantâneo e valor de $S$ não conhecido com precisão infinita), ocorre o fenômeno denominado chattering, o qual trata-se de oscilações em torno da superfície $S=0$. A figura 3.4 ilustra este fenômeno para um sistema de segunda ordem.

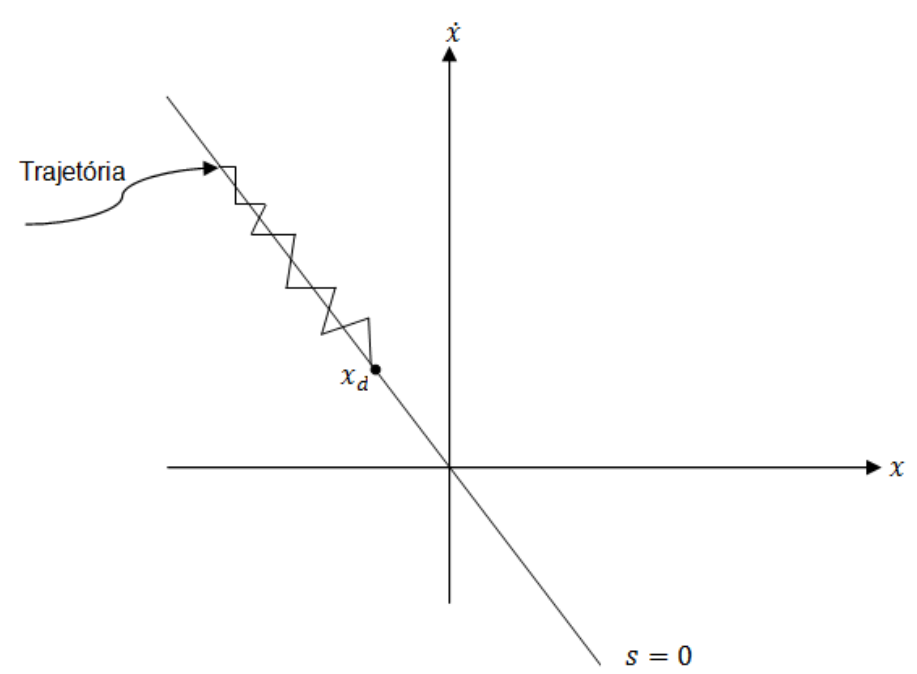

Figura 3.4 Chattering para um sistema de segunda ordem.

Para suavizar o efeito do chaveamento do sinal de controle devido à função sign() , (Slotine, 1991) sugere o uso da função saturação no lugar da função sign(), dessa forma, o sinal de controle deve ser reescrito segundo a equação (3.27).

$$
u=\frac{\left(\hat{u}-K_{c} \cdot \operatorname{sat}\left(\frac{S}{\phi}\right)\right)}{\hat{b}(x)}
$$

onde:

$\phi$ : camada limite 
$\operatorname{sat}\left(\frac{S}{\phi}\right)= \begin{cases}\frac{S}{\phi} & \text { se }|S| \leq \phi \\ \operatorname{sign}(S) & \text { se }|S|>\phi\end{cases}$

Esta técnica permite eliminar o efeito do chattering, mas introduz um erro de acompanhamento que é definido através de (3.28).

$$
|\tilde{y}| \leq \frac{\phi}{\lambda^{n-1}}
$$

\subsubsection{CONTROLE INTEGRAL}

Para corrigir os erros em regime estacionário, Slotine (1991) sugere adicionar uma ação integrativa no controlador, substituindo $\tilde{y}$ por $\int \tilde{y} d r$, dessa forma a ordem do sistema passa a ser $n+1$. Assim, basta redefinir a superfície de escorregamento, $S$, e $\hat{u}$, conforme as equações (3.29) e (3.30), respectivamente.

$$
\begin{gathered}
S=\dot{y}+2 \lambda \tilde{y}+\lambda^{2} \int \tilde{y} d r \\
\hat{u}=-\hat{a}(x)+\dddot{y}_{d}-2 \cdot \lambda \cdot \dot{\tilde{y}}-\lambda^{2} \cdot \tilde{y}
\end{gathered}
$$

Nota-se que a funções $a(x)$ e $b(x)$ são as mesmas da abordagem anterior, já que o sistema é o mesmo, apenas há uma mudança na variável controlada, que passa a ser $\int \tilde{y} d r$, ou seja, a integral do erro.

\subsubsection{CONTROLE POR MODELO INTERNO (IMC)}

O controle por modelo interno ou IMC (Internal Model Control) é uma técnica de controle na qual é incorporado o modelo do processo para controlar o sistema. Caso o modelo do sistema seja exato, ou seja, o modelo represente exatamente o 
processo industrial, é possível projetar o controlador para que a saída seja idêntica à referência, que no caso seria o controlador ideal.

A figura 3.5 apresenta o diagrama de blocos do controlador IMC, considerando que todos os sinais são incrementais.

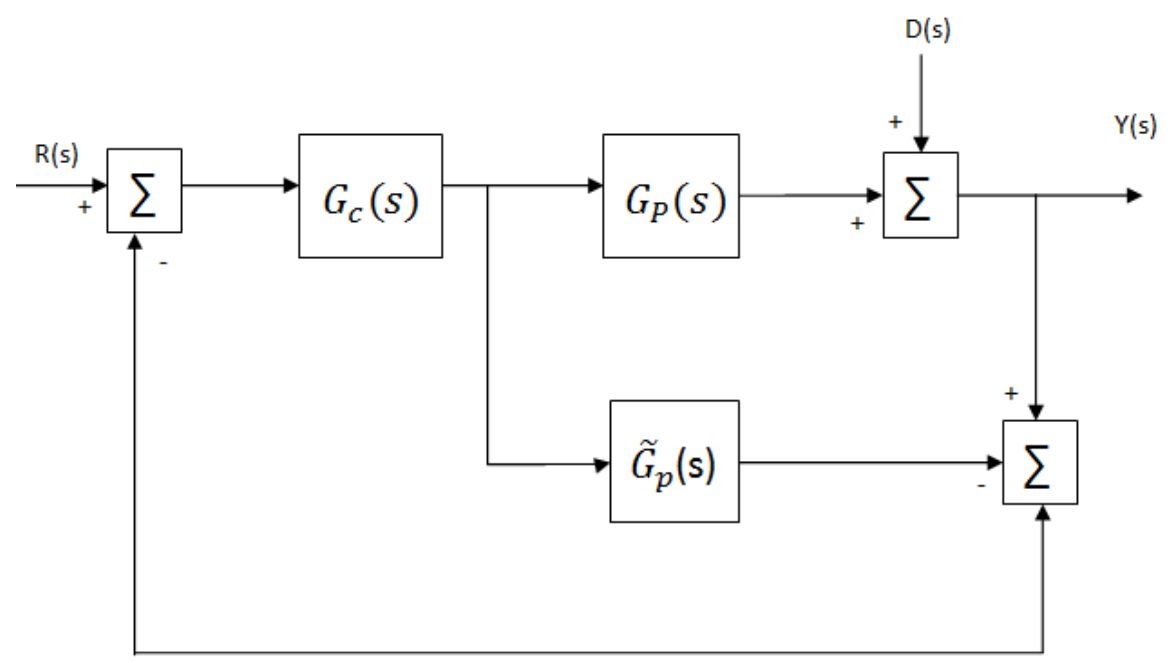

Figura 3.5 Diagrama de blocos do controlador IMC.

onde:

$G_{C}(s):$ Controlador

$G_{p}(s)$ : Processo real

$\widetilde{G_{P}}(s)$ : Modelo do processo

$R(s)$ : Sinal de referência

$D(s)$ : Perturbação

Considerando um modelo linear para o processo, de acordo com o diagrama de blocos da figura 3.5, a saída do sistema é dada por:

$$
Y(s)=\frac{G_{C}(s) \cdot G_{P}(s) \cdot R(s)+\left[1-G_{C}(s) \cdot \widetilde{G_{P}}(s)\right] \cdot D(s)}{1+\left[G_{P}(s)-\widetilde{G_{P}}(s)\right] \cdot G_{C}(s)}
$$

Se $G_{C}(s)=\widetilde{G_{P}}(s)^{-1}$ e $\widetilde{G}_{P}(s)=G_{P}(s)$, então:

$$
Y(s)=R(s)
$$


Dessa forma, a saída y é exatamente a referência desejada, o que constitui a situação ideal de um sistema de controle.

Ao projetar $G_{C}(s)=\widetilde{G_{P}}(s)^{-1}$, a função de transferência $G_{C}(s)$ pode tornar-se não própria, dessa forma, o sinal de controle será derivativo, o qual na presença de ruído acaba amplificando este efeito indesejado, fazendo com que o sistema não acompanhe a referência desejada. Para melhorar o projeto do controlador IMC, é recomendável adicionar um filtro passa-baixa ao controlador, dessa forma, o sinal de controle pode ser escrito conforme a equação (3.32).

$$
G_{C}(s)=\widetilde{G_{P}}(s)^{-1} \cdot G_{f}(s)
$$

A ordem do filtro deve ser escolhida de forma que $\mathrm{G}_{\mathrm{C}}(\mathrm{s})$ seja próprio. $\mathrm{O}$ filtro também é conveniente para atenuar o efeito de ruídos de medição.

A figura 3.6 apresenta o diagrama de blocos geral para o controlador IMC genérico.

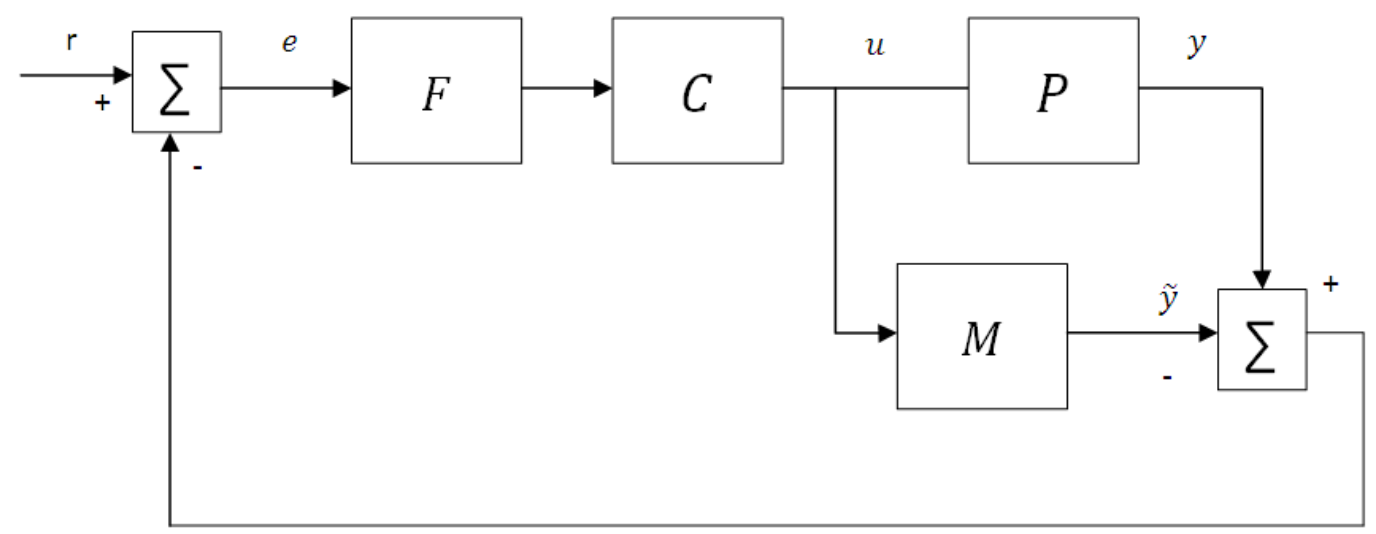

Figura 3.6 Diagrama de blocos do controlador IMC genérico.

onde:

$C$ : Controlador

$F$ : Filtro

$P$ : Processo

M: Modelo do processo 
Esta abordagem é bastante conveniente para sistemas lineares, porém quando o sistema é não linear, esta técnica torna-se complexa de ser aplicada, já que não se pode aplicar o conceito de polos e zeros para projetar os ganhos do controlador, como no caso de sistemas lineares.

Henson e Seborg em 1991 apresentaram em seu trabalho o controlador com modelo interno com uma abordagem para controle não linear. Porém, a estrutura de controle utiliza a mesma do diagrama de blocos da figura 3.6.

Seja o sistema (3.1) com campos suaves $f(x), g(x)$ e $h(x)$. O objetivo do controlador $C$ é minimizar o erro de rastreamento (Henson e Seborg,1991), conforme (3.33).

$$
\min _{C}|| r(t)-y(t)||
$$

De acordo com o diagrama de blocos da figura 3.6, o erro do sistema pode ser definido como a equação (3.34).

$$
e \triangleq r-y+\tilde{y}
$$

Assumindo $M=P$ e $F=1$ tem-se:

$$
y=P \cdot C \cdot F \cdot e=M \cdot C \cdot r
$$

Dessa forma, a equação (3.33) pode ser reescrita como:

$$
\min _{C}|| r(t)-M \cdot C \cdot r \|
$$

Assim, o problema de otimização pode ser resolvido com:

$$
\mathrm{C}=M^{-1}
$$

Nestas condições, o controlador que inverte 0 modelo que satisfaz a equação (3.37) é dado por: 


$$
u=\frac{-L_{f}^{p} h(x)}{L_{g} L_{f}^{p-1} h(x)}+\frac{v}{L_{g} L_{f}^{p-1} h(x)}=C(x)+D(x) \cdot v
$$

Para a implementação do filtro, Henson e Seborg (1991) sugerem o filtro não linear descrito pela equação (3.39). Assim como no caso dos sistemas lineares o filtro tem a função de tornar o sistema não derivativo ("próprio") e rastrear a referência.

$$
v=-\theta_{p} \cdot L_{f}^{p-1} h(x)-\theta_{p-1} \cdot L_{f}^{p-2} h(x)-\theta_{1} \cdot h(x)+\theta_{1} \cdot e=A(x)+\theta_{1} \cdot e
$$

A figura 3.7 apresenta o diagrama de blocos para o sistema com o controlador IMC não linear.

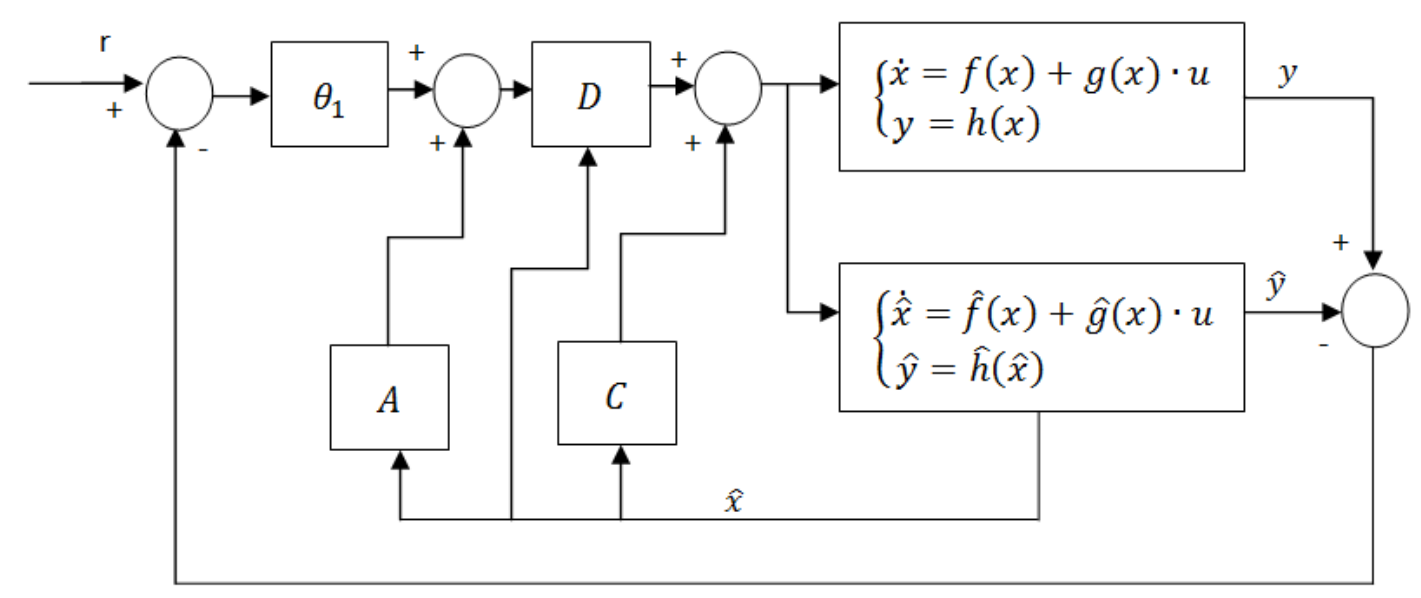

Figura 3.7 Diagrama de blocos do controlador IMC não linear.

Nota-se através das equações (3.38) e (3.39) que o controlador, assim como os anteriores, possui basicamente uma estrutura com a linearização por realimentação e um termo para rastreamento da referência. Porém, neste controlador utiliza-se o próprio modelo como observador de estados.

Para a sintonia dos parâmetros $\theta_{i}$, de acordo com (Henson e Seborg,1991), considera-se o sistema inicialmente em repouso e $y(0)=r(0)$.

Nestas condições, para se ter uma relação do tipo da equação (3.40) 


$$
\frac{Y(s)}{E(s)}=\frac{\theta_{1}}{s^{p}+\theta_{p} \cdot s^{p-1}+\cdots+\theta_{2} \cdot s+\theta_{1}}
$$

onde:

$p$ : grau relativo do sistema.

Se o modelo for igual à planta, a equação (3.40) pode ser reescrita como a equação (3.41):

$$
\frac{Y(s)}{R(s)}=\frac{\theta_{1}}{s^{p}+\theta_{p} \cdot s^{p-1}+\cdots+\theta_{2} \cdot s+\theta_{1}}
$$

\subsubsection{CONTROLADOR PI NÃO LINEAR}

O algoritmo de controle PID é o mais utilizado na indústria de processos industriais, dessa forma, é bastante interessante associar esta técnica à linearização por realimentação, para aprimorar o desempenho dos sistemas de controle. Como para a aplicação deste trabalho há presença de ruído, optou-se pelo controlador $\mathrm{PI}$, já que o termo derivativo pode agir como amplificador do ruído. Este trabalho utiliza o controlador PI conforme a equação (3.42).

$$
u=K_{p i} \cdot\left[(r-y)+\frac{1}{T_{i}} \cdot \int(r-y) \cdot d t\right]
$$

onde:

r: referência desejada

$y:$ saída do sistema

Assim, pode-se implementar o controlador PI no algoritmo de linearização por realimentação, conforme a lei de controle (3.43) (Henson e Seborg, 1997). 


$$
\begin{aligned}
u=\frac{1}{L_{g} L_{f}^{p-1} h(x)} & {\left[-L_{f}^{p} h(x)-C_{0} \cdot h(x)-C_{1} \cdot L_{f} h(x)-\cdots-C_{p-1} \cdot L_{f}^{p-1} h(x)\right.} \\
& \left.+K_{p i} \cdot\left((w-y)+\frac{1}{T_{i}} \cdot \int(w-y) \cdot d t\right)\right]
\end{aligned}
$$

onde:

w: nova referência para o sinal de controle

Como o sistema resultante é linear e a dinâmica é conhecida, pode-se projetar os ganhos $K_{p i}$ e $T_{i}$ analiticamente, para que o sistema tenha o desempenho desejado, de acordo com as técnicas de controle linear. 


\section{CAPÍTULO 4 TÉCNICAS DE CONTROLE APLICADAS A VÁLVULAS DE CONTROLE}

Este capítulo apresenta o equacionamento das leis de controle aplicadas à válvula de controle e discussões para a sintonia de cada um dos controladores.

\subsection{LEI DE CONTROLE LINEARIZANTE}

Esta seção apresenta a lei de controle sem considerar a dinâmica do atuador, para simplificar o desenvolvimento dos algoritmos, pois isto implicaria que o sistema seria de terceira ordem. Nestas condições, o sistema dinâmico da válvula de controle no espaço de estados pode ser escrito de acordo com o sistema (4.1).

$$
\left\{\begin{array}{l}
\dot{x}_{1}=x_{2} \\
\dot{x}_{2}=\frac{1}{m} \cdot\left[u \cdot K_{p} \cdot S_{a}-K \cdot x_{1}-\left(F_{C}+\left(F_{S}-F_{C}\right) \cdot e^{-\left(\frac{x_{2}}{V_{S}}\right)^{2}}\right) \cdot \tanh \left(\sigma \cdot x_{2}\right)-F_{V} \cdot x_{2}\right] \\
y=x_{1}
\end{array}\right.
$$

Nota-se que este sistema é afim e que foi adicionada a constante $K_{p}$ multiplicando o sinal de controle para modelar a interface entre o sinal de controle, normalmente elétrico, e o sinal de pressão no atuador. Os campos $f(x), g(x)$ e a função escalar $h(x)$ são:

$$
f(x)=\left(\frac{1}{m} \cdot\left[P \cdot S_{a}-K \cdot x_{1}-\left(F_{C}+\left(F_{S}-F_{C}\right) \cdot e^{-\left(\frac{x_{2}}{V_{S}}\right)^{2}}\right) \cdot \tanh \left(\sigma \cdot x_{2}\right)-F_{V} \cdot x_{2}\right]\right)
$$




$$
\begin{gathered}
g(x)=\left(\frac{K_{p}^{0} \cdot S_{a}}{m}\right) \\
h(x)=x_{1}
\end{gathered}
$$

Dessa forma, pode-se calcular o grau relativo do sistema, dado por:

$$
\begin{gathered}
L_{g} L_{f}^{0} h(x)=L_{g} h=0 \\
L_{g} L_{f}^{1} h(x)=\frac{K_{p} \cdot S_{a}}{m}
\end{gathered}
$$

Assim, o grau relativo do sistema é igual a 2. Dessa forma, o sistema pode ser linearizado por linearização exata e, consequentemente, haverá linearização entrada-saída.

A equação (4.2) apresenta a lei de controle linearizante para a válvula de controle, obtida através da lei de controle (3.2):

$$
u=\frac{K \cdot x_{1}+\left(F_{C}+\left(F_{S}-F_{C}\right) \cdot e^{-\left(\frac{x_{2}}{V_{S}}\right)^{2}}\right) \cdot \tanh \left(\sigma \cdot x_{2}\right)+F_{V} \cdot x_{2}+m \cdot v}{K_{p} \cdot S_{a}}
$$

onde:

$v$ : Nova entrada. 


\subsection{LEI DE CONTROLE LINEARIZANTE COM IMPOSIÇÃO DE POLOS}

Como o grau relativo do sistema (4.1) é igual a 2 e o sistema é completamente linearizável, o novo sistema, nas novas coordenadas, não possui dinâmica interna não observável. Portanto, pode-se impor os polos desejados para a válvula através da lei de controle. A equação (4.3) apresenta a lei de controle com a imposição de polos aplicada à válvula de controle.

$$
\begin{gathered}
u=\frac{K \cdot x_{1}+\left(F_{C}+\left(F_{S}-F_{C}\right) \cdot e^{-\left(\frac{x_{2}}{V_{S}}\right)^{2}}\right) \cdot \tanh \left(\sigma \cdot x_{2}\right)+F_{V} \cdot x_{2}}{K_{p} \cdot S_{a}}+ \\
+\frac{m \cdot\left(-C_{0} \cdot x_{1}-C_{1} \cdot x_{2}+w\right)}{K_{p} \cdot S_{a}}
\end{gathered}
$$

onde:

w: Nova entrada do sistema

Assim, basta impor os polos desejados com parte real negativa no polinômio característico para estabilizar o sistema. A função de transferência do sistema é dada por:

$$
\frac{Y(s)}{W(s)}=\frac{1}{s^{2}+C_{1} \cdot s+C_{0}}
$$

As seções 4.1 e 4.2 apresentaram as leis de controle que linearizam o sistema. As próximas seções deste capítulo apresentam os algoritmos de controle para fazer com que o sistema siga uma determinada referência desejada. Esta é, em geral, uma das funções mais importantes do sistema de controle. Neste trabalho são apresentados cinco algoritmos para o rastreamento da referência: controlador rastreador de trajetória, controle por modelos deslizantes, controle por modos deslizantes integrador, controlador por modelo interno não linear e controlador PI não linear. 


\subsection{CONTROLADOR RASTREADOR DE TRAJETÓRIA}

Conforme foi discutido na seção 4.1, o grau relativo do sistema é igual a dois e o sistema é completamente linearizável. Portanto, pode-se rastrear a saída para que esta siga uma trajetória desejada, sem que seja necessário analisar a estabilidade dos estados internos. A lei de controle (4.5) apresenta a entrada que lineariza e rastreia o sistema com a trajetória desejada $y_{d}(t)$, que deve possuir as derivadas de segunda ordem bem definidas e limitadas.

$$
\begin{gathered}
u=\frac{K \cdot x_{1}+\left(F_{C}+\left(F_{S}-F_{C}\right) \cdot e^{-\left(\frac{x_{2}}{V_{S}}\right)^{2}}\right) \cdot \tanh \left(\sigma \cdot x_{2}\right)+F_{V} \cdot x_{2}}{K_{p} \cdot S_{a}}+ \\
+\frac{m \cdot\left(y_{d}{ }^{(2)}-C_{0} \cdot\left(x_{1}-\dot{y}_{d}\right)-C_{1} \cdot\left(x_{2}-\dot{y}_{d}\right)\right)}{K_{p} \cdot S_{a}}
\end{gathered}
$$

Dessa forma, basta sintonizar os ganhos para se ter uma relação (4.6)

$$
\ddot{\tilde{y}}+C_{1} \cdot \dot{\tilde{y}}+C_{0} \cdot \tilde{y}=0
$$

onde:

$$
\tilde{y}=y-y_{d}
$$

Através da equação (4.6), pode-se projetar os ganhos $C_{1}$ e $C_{0}$ de forma que o erro convirja assintoticamente para zero.

\subsection{CONTROLADOR POR MODOS DESLIZANTES}

Para o projeto do controlador por modos deslizantes, utiliza-se a lei de controle apresentada na equação (3.27) para um sistema de segunda ordem, de forma que $S, \hat{b}$ e $\hat{u}$ sejam dados por: 


$$
\begin{gathered}
s=\dot{\tilde{y}}+\lambda \cdot \tilde{y} \\
\hat{b}=\mathrm{K}_{\mathrm{p}} \cdot \mathrm{S}_{\mathrm{a}} \\
\hat{u}=-\widehat{K} \cdot x_{1}+\left(\hat{F}_{C}+\left(\hat{F}_{S}-\hat{F}_{C}\right) \cdot e^{-\left(\frac{x_{2}}{V_{S}}\right)^{2}}\right) \cdot \tanh \left(\sigma \cdot x_{2}\right)+\hat{F}_{V} \cdot x_{2}+\ddot{y}_{d}-\lambda \cdot \dot{\tilde{y}}
\end{gathered}
$$

O ganho $K_{c}$ deve ser sintonizado de forma a compensar o erro máximo entre o modelo e o sistema real, conforme a equação (3.20). Para a sintonia da camada limite $\phi$, deve-se levar em consideração o nível do chaveamento causado pelo chaterring e o erro máximo admissível em regime estacionário, conforme a equação (3.23).

Para a sintonia do ganho $\lambda$, Slotine (1991) sugere que se deve selecionar o mínimo dos critérios definidos a seguir:

(i) $\quad \lambda$ deve ser menor do que a frequência $v_{R}$ do menor modo ressonante não modelado: $\lambda \leq \lambda_{R} \approx \frac{2 \pi}{3} v_{R}$

(ii) $\lambda$ deve ser menor do que o maior tempo morto $\left(T_{A}\right)$ não modelado:

$$
\lambda \leq \lambda_{A} \approx \frac{1}{3 T_{A}} \text {. }
$$

(iii) $\lambda$ deve ser menor do que a frequência de amostragem do sistema $v_{S}$ : $\lambda \leq \lambda_{S} \approx \frac{1}{5} v_{S}$

Dessa forma, $\lambda$ é tal que:

$$
\lambda \leq \min \left(\lambda_{S}, \lambda_{R}, \lambda_{A}\right)
$$

\subsection{CONTROLADOR POR MODOS DESLIZANTES INTEGRADOR}

No caso da abordagem com o controle integral, utiliza-se a mesma lei de controle (3.27), porém com mudanças em $\hat{u}$ e na superfície de escorregamento, conforme as equações (4.10) e (4.11): 


$$
\begin{gathered}
\hat{u}=K \cdot x_{1}+\left(F_{C}+\left(F_{S}-F_{C}\right) \cdot e^{-\left(\frac{x_{2}}{V_{S}}\right)^{2}}\right) \cdot \tanh \left(\sigma \cdot x_{2}\right)+F_{V} \cdot x_{2}+\dddot{y}_{d} \\
-2 \cdot \lambda \cdot \dot{\tilde{y}}-\lambda^{2} \cdot \tilde{y}
\end{gathered}
$$

$$
S=\dot{y}+2 \lambda \tilde{y}+\lambda^{2} \int \tilde{y} d r
$$

Para a sintonia dos parâmetros $K_{c}, \lambda$ e $\phi$, utilizam-se os mesmos critérios definidos na seção 4.4 .

\subsection{CONTROLADOR POR MODELO INTERNO NÃO LINEAR}

Conforme a subseção 3.5.3, a lei de controle (3.31) para a válvula de controle é dada por:

$$
\begin{gathered}
u=\frac{1}{K_{p} \cdot S_{a}}\left[K \cdot x_{1}+\left(F_{C}+\left(F_{S}-F_{C}\right) \cdot e^{\left.-\left(\frac{x_{2}}{V_{S}}\right)^{2}\right) \cdot \tanh \left(\sigma \cdot x_{2}\right)+F_{V} \cdot x_{2}}\right.\right. \\
\left.-\theta_{2} \cdot x_{2}-\theta_{1} \cdot x_{1}+\theta_{1} \cdot e\right]
\end{gathered}
$$

Como o grau relativo do sistema é 2 , se:

$$
y(0)=r(0)
$$

Então:

$$
\frac{Y(s)}{R(s)}=\frac{\theta_{1}}{s^{2}+\theta_{2} \cdot s+\theta_{1}}
$$


Para a sintonia, considera-se que o modelo seja perfeito, assim pode-se utilizar a relação (4.13). Desse modo, pode-se projetar os ganhos $\theta_{1}$ e $\theta_{2}$ para se obter a resposta desejada.

\subsection{CONTROLAdor PI NÃo linear}

Conforme a subseção 3.5.4, a equação (4.14) apresenta o controlador PI não linear aplicado para a válvula de controle.

$$
\begin{gathered}
u=\frac{1}{K_{p} \cdot S_{a}}\left[K \cdot x_{1}+\left(F_{C}+\left(F_{S}-F_{C}\right) \cdot e^{-\left(\frac{x_{2}}{V_{s}}\right)^{2}}\right) \cdot \tanh \left(\sigma \cdot x_{2}\right)+F_{V} \cdot x_{2}-C_{0}\right. \\
\left.\cdot x_{1}-C_{1} \cdot x_{2}+K_{p i} \cdot\left(\left(y_{d}-y\right)+\frac{1}{T_{i}} \cdot \int\left(y_{d}-y\right) \cdot d t\right)\right]
\end{gathered}
$$

Nota-se através de (4.14) que considerando que o modelo é perfeito, pode-se impor os polos desejados no sistema através de $C_{0}$ e $C_{1}$ e sintonizar os ganhos $K_{p i} \mathrm{e}$ $\mathrm{T}_{\mathrm{i}}$, de forma a rastrear a referência $\mathrm{y}_{\mathrm{d}}$ e impor a dinâmica desejada em malha fechada. 


\section{CAPÍTULO 5 RESULTADOS SIMULADOS}

Este capítulo apresenta os testes dos compensadores do capítulo 4 em ambiente simulado, sendo que o principal objetivo é a preparação do sistema de controle para o projeto em ambiente real. Adicionalmente, no final do capítulo comparam-se os resultados dos controladores não lineares com um controlador PI tradicional simulado no mesmo sistema.

As simulações são feitas através do software Matlab/Simulink da Mathworks. A figura 5.1 apresenta o diagrama de blocos do ambiente em que são feitas as simulações.

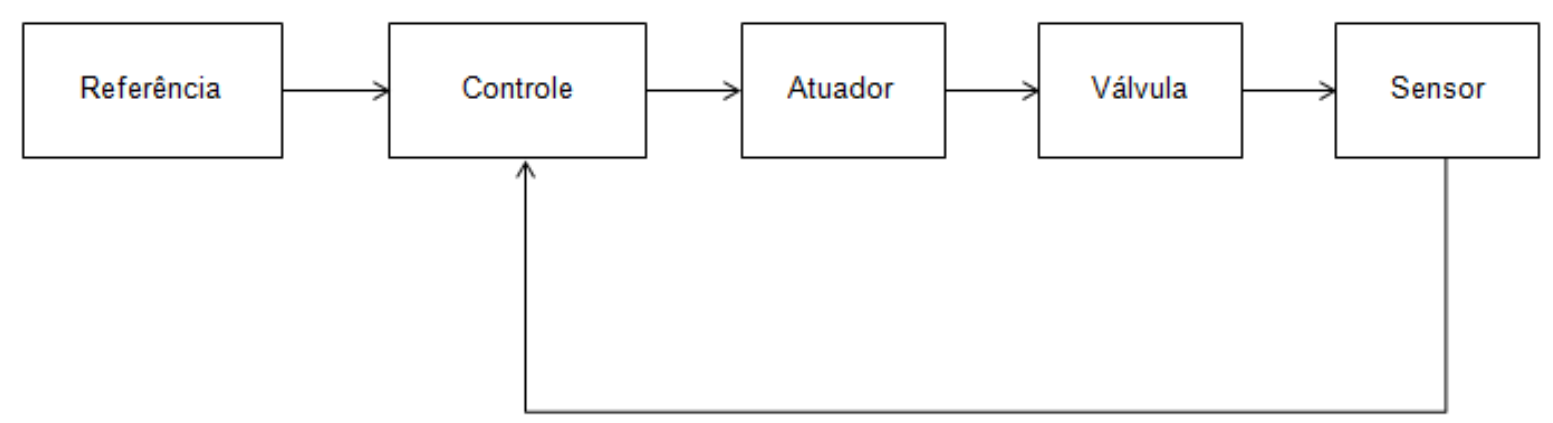

Figura 5.1 Diagrama de blocos da simulação.

No diagrama de blocos estão implementados os algoritmos de controle do capítulo 4, o modelo da válvula, atuador e o bloco sensor, cuja função é fornecer os sinais de posição e velocidade.

O bloco "Sensor" apresenta os sinais de posição e velocidade, nos quais se pode inserir ruído ou não. Em caso de sinal com ruído, há um filtro passa-baixas para filtrar o ruído de posição. A velocidade é gerada através da derivação do sinal da posição. Além disso, há um bloco adicional que impõe uma velocidade limite, cujo 
objetivo é definir que sinais de velocidade abaixo deste valor sejam considerados nulos. A razão para a existência deste bloco é que mesmo com filtro há ainda um ruído na posição da haste com ela parada, dessa forma haveria velocidade não nula mesmo quando a haste não está em movimento, o que implicaria em ação que pode provocar oscilações.

Para as simulações foi projetado um filtro Butterworth de quinta ordem com frequência de corte de $120 \mathrm{rad} / \mathrm{s}$. A equação (5.1) apresenta a função de transferência do filtro.

$$
H_{f}(s)=\frac{2,49 \cdot 10^{10}}{s^{5}+3,88 \cdot 10^{2} \cdot s^{4}+7,54 \cdot 10^{4} \cdot s^{3}+9,05 \cdot 10^{6} \cdot s^{2}+6,71 \cdot 10^{8} \cdot s+2,49 \cdot 10^{10}}
$$

O bloco "Atuador" insere ou não a dinâmica do atuador definida na função de transferência (2.6). Além disso, este bloco possui uma função saturação, para que a válvula trabalhe com sinais limitados de 0 a 20 psi.

. O bloco "Válvula" implementa o modelo dinâmico da válvula de controle. A tabela 5.1 apresenta os parâmetros da válvula, os quais foram obtidos através da estimação de uma válvula real Fisher/Emerson. O bloco "Controle" representa a implementação dos algoritmos de controle: controlador rastreador de trajetória, controle por modelos deslizantes, controle por modos deslizantes integrador, controlador por modelo interno não linear e controlador PI não linear. 


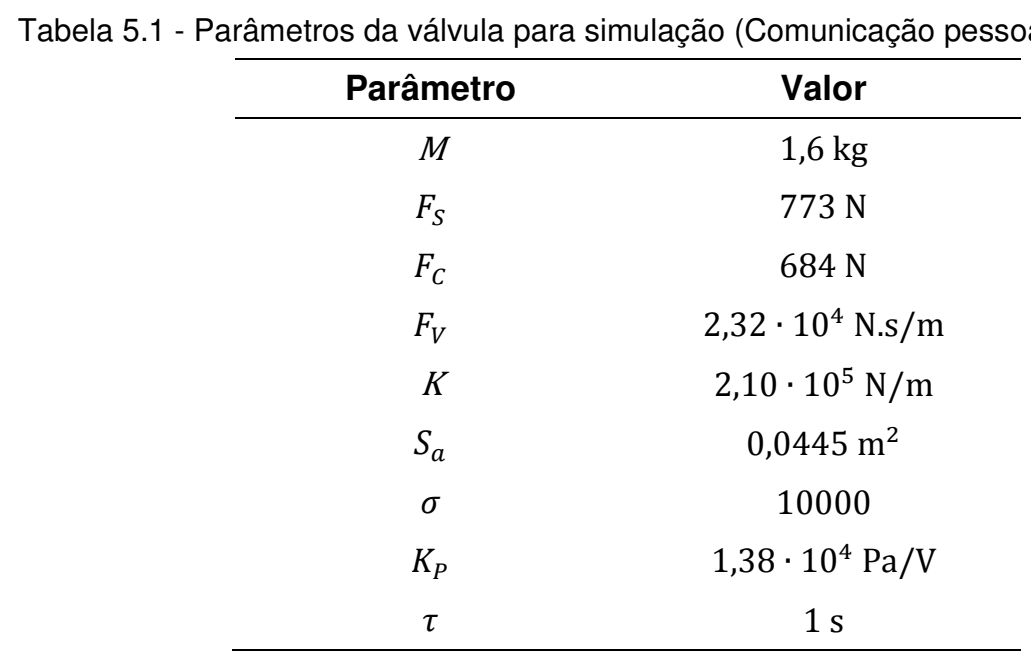

Neste trabalho, considera-se que a área de válvula $\left(S_{a}\right)$ e o ganho $K_{P}$ são conhecidos, pois são parâmetros fornecidos pelo fabricante da válvula e do conversor $\mathrm{l} / \mathrm{P}$.

A velocidade limite estimada experimentalmente nas simulações é de $2 \mathrm{~mm} / \mathrm{s}$.

\subsection{LINEARIZAÇÃO E IMPOSIÇÃO DE POLOS}

Nesta seção implementa-se a linearização por realimentação com imposição de polos conforme a seção 4.2, com o objetivo de demonstrar o funcionamento do controlador. Todo desenvolvimento é apresentado considerando a válvula de controle sem a dinâmica do atuador ou ruído.

A figura 5.2 apresenta o resultado da simulação aplicando um degrau de $50 \%$ na entrada. Os ganhos foram ajustados de forma a ter polos duplos iguais a -1 $\left(C_{0}=1\right.$ e $\left.C_{1}=2\right)$. A saída da válvula foi comparada com a de um sistema linear com a mesma dinâmica, imposta pela realimentação dada pela equação (4.3). Além disso, nesta seção considera-se que todos os parâmetros sejam conhecidos, assim não há erro de estimação de parâmetros. 


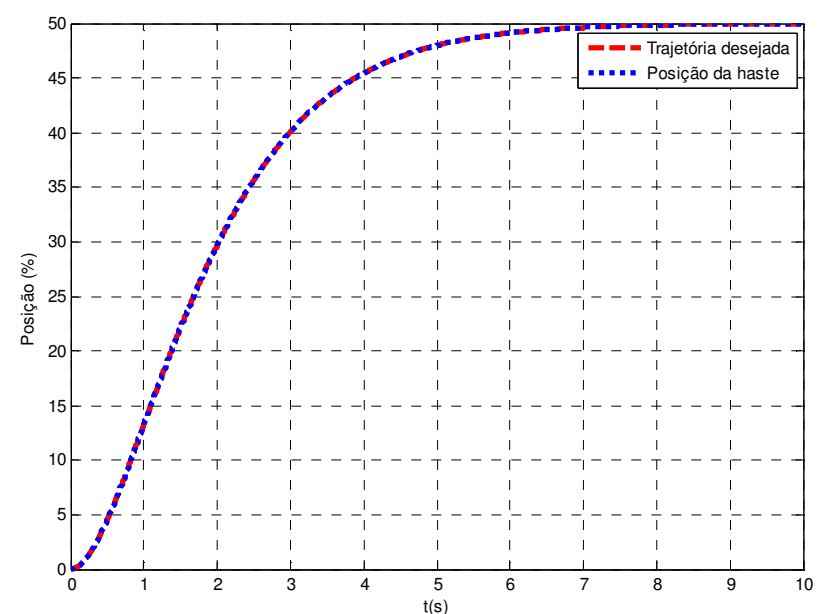

Figura 5.2 Resposta ao degrau simulada da válvula linearizada e do modelo linear desejado.

Através da figura 5.2 é possível constatar que de fato o algoritmo de linearização e imposição de polos, através da lei de controle (4.3), funcionou de forma adequada. Este é um passo importante, já que, todos os algoritmos de controle utilizam a lei de controle linearizante desta seção.

É importante notar também que não foi implementado um algoritmo de correção da posição da haste da válvula e que o modelo é perfeito. Nas próximas seções são apresentadas as simulações para os controladores considerando erros no modelo e ruído de medição.

\subsection{CONTROLADOR RASTREADOR DE TRAJETÓRIA}

Nesta seção é apresentado o resultado da simulação do controlador rastreador de trajetória, conforme a seção 4.3. A trajetória escolhida, conforme foi mencionado na subseção 3.5.1, deve ser bem definida e limitada até a derivada de ordem $p-1$. Neste caso, foi aplicado um sinal de entrada que é filtrado pela equação dinâmica (5.2) $\operatorname{com} \tau_{S}=3$.

$$
G_{S}(s)=\frac{\tau_{S}^{4}}{\left(s+\tau_{S}\right)^{4}}
$$


Para esta primeira simulação considerou-se que não há desvios nos parâmetros do sistema, o qual foi simulado sem considerar a dinâmica do atuador e ruído. No caso, os ganhos do controlador foram ajustados de forma a ter polos duplos iguais a -2 na dinâmica do erro da equação (4.6). A entrada é um degrau de $50 \%$ suavizado pela dinâmica (5.2). A tabela 5.2 apresenta os parâmetros do controlador e a figura 5.3 mostra o resultado da simulação.

Tabela 5.2 - Parâmetros de simulação do controlador rastreador de trajetória.

\begin{tabular}{cc}
\hline Parâmetro & Valor \\
\hline $\mathrm{C}_{0}$ & 4 \\
$\mathrm{C}_{1}$ & 4 \\
\hline
\end{tabular}

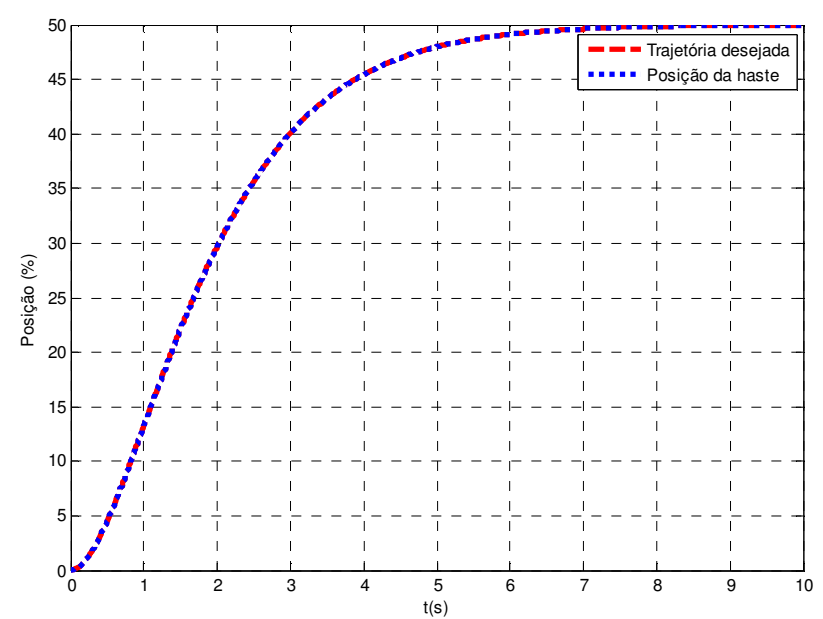

Figura 5.3 Resultado da simulação do controlador rastreador de trajetória.

Como era esperado, nas condições ideais o controlador respondeu perfeitamente e rastreou a trajetória.

A seguir foi adicionado ruído branco na medição da posição com variância de $10^{-9}$, sendo que o resultado da simulação é apresentado na figura 5.4. Este nível de ruído é o mesmo encontrado nos resultados práticos obtidos em laboratório. Além disso, considerou-se que os parâmetros do sistema utilizados no controlador são 
menores do que o real em $10 \%$ e que o sistema está em uma condição inicial desconhecida. O sinal de entrada é composto por degraus suavizados pela dinâmica (5.2). A figura 5.4 apresenta o resultado da simulação e a figura 5.5 o sinal de controle. Para alcançar resultados satisfatórios, os ganhos foram aumentados conforme os parâmetros da tabela 5.3.
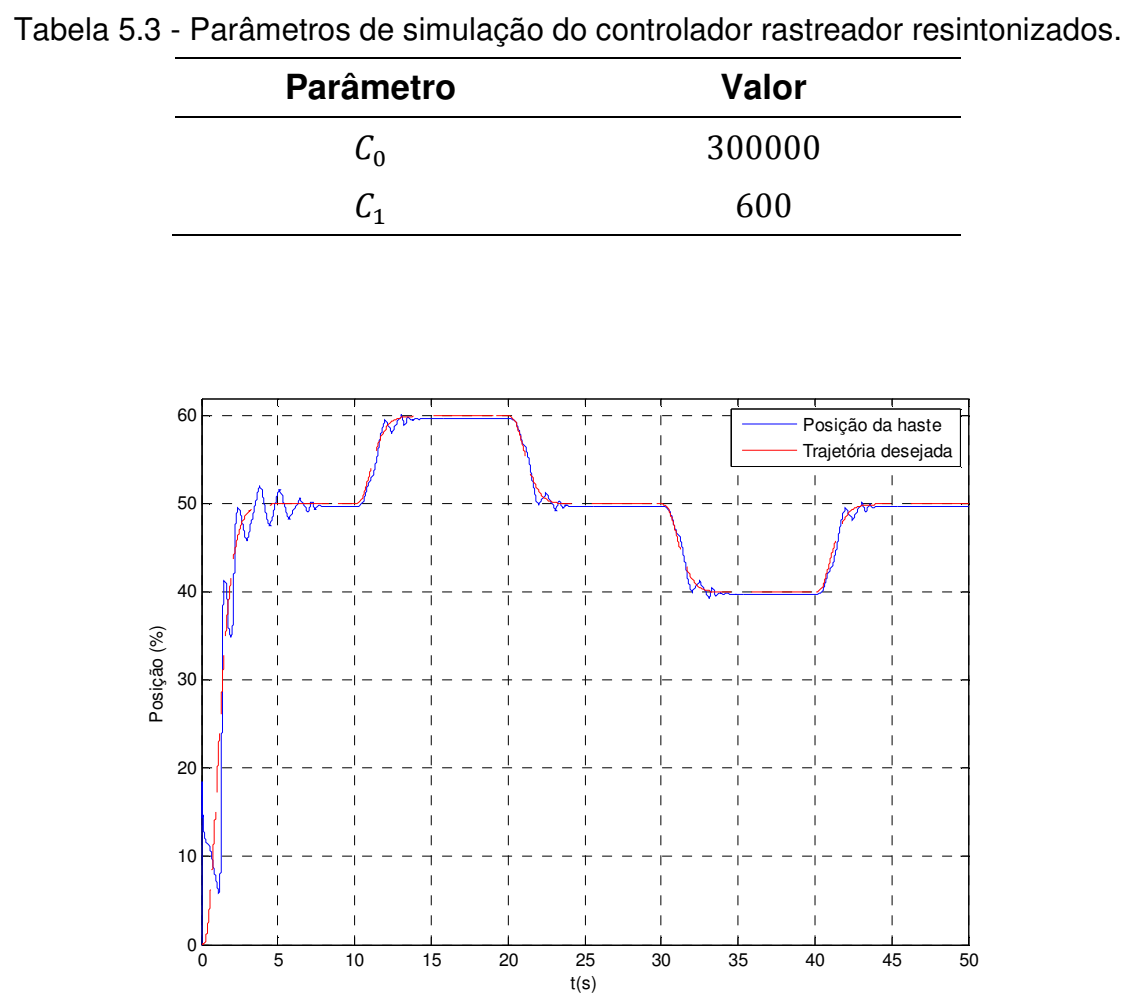

Figura 5.4 Resultado da simulação do rastreador de trajetória com ruído e parâmetros 10\% menores.

Nota-se através da figura 5.4 que o algoritmo de controle rastreou a referência, porém com pequenas oscilações transitórias. 


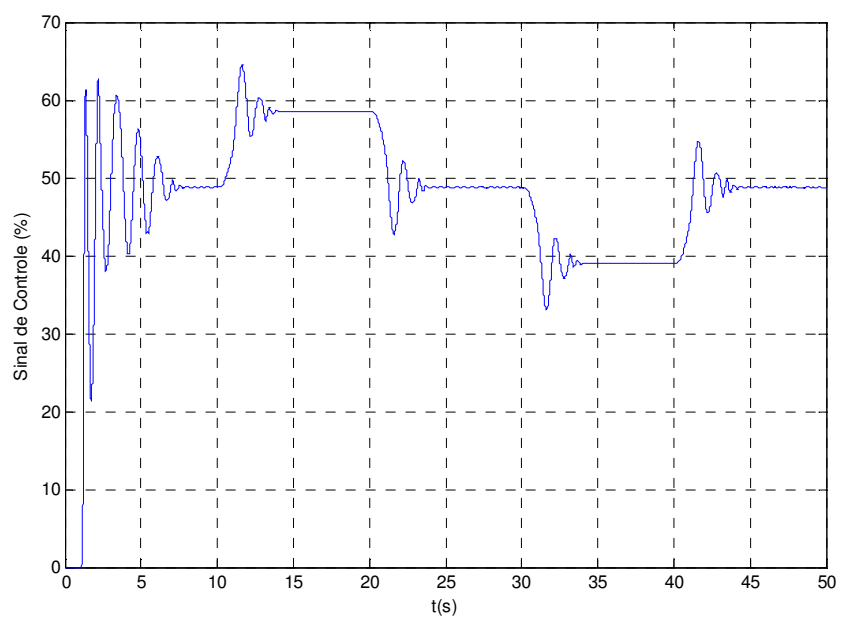

Figura 5.5 Sinal de saída do controlador rastreador de trajetória simulado com ruído e parâmetros 10\% menores.

As figuras 5.6 e 5.7 apresentam os resultados da simulação para as mesmas condições anteriores, porém com os parâmetros do controlador $10 \%$ maiores do que os reais.

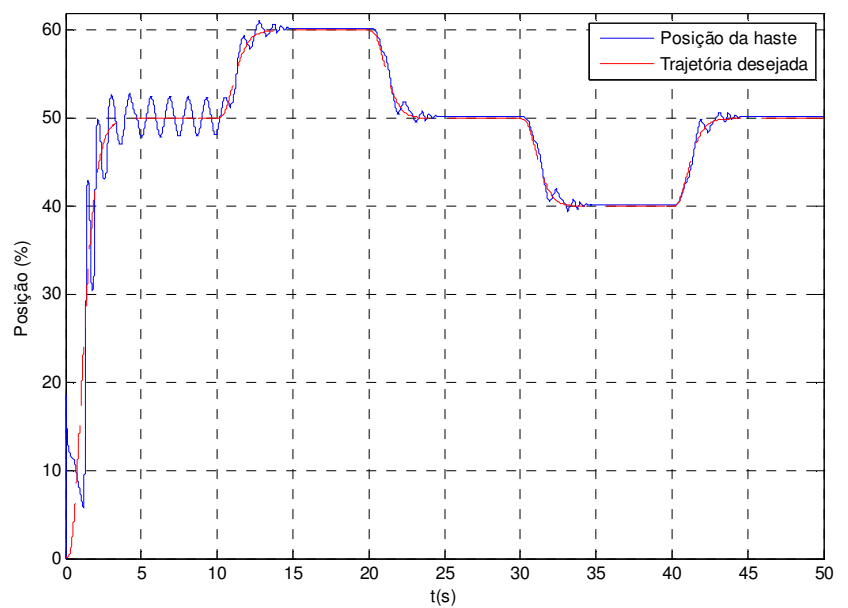

Figura 5.6 Resultado da simulação do controlador rastreador de trajetória com ruído e parâmetros $10 \%$ maiores. 


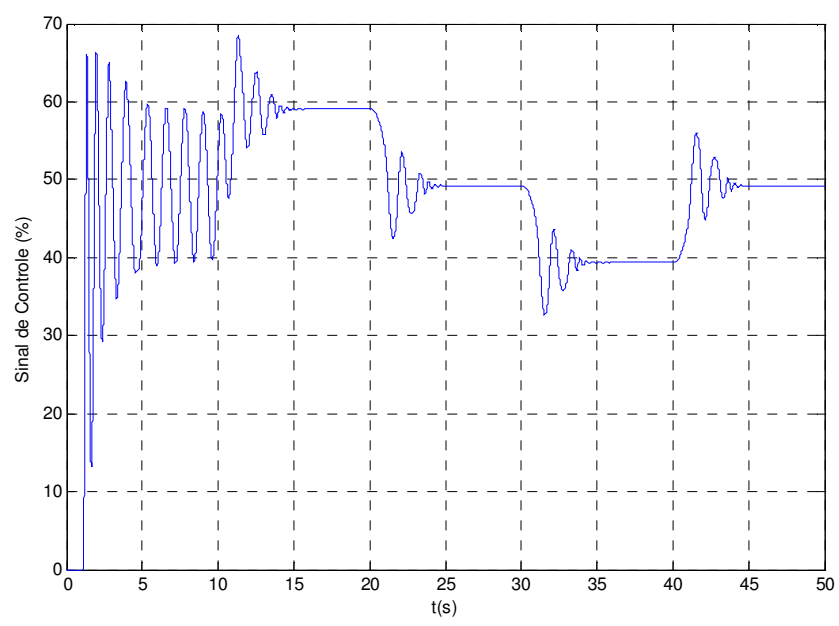

Figura 5.7 Sinal de saída do controlador de trajetória simulado com ruído e parâmetros 10\% maiores.

Através dos resultados, nota-se que com os ganhos elevados sintonizados foi possível rastrear a referência, mesmo com desvio nos parâmetros e ruído. Apesar dos ganhos serem elevados não houve saturação do sinal de controle, conforme pode ser observado nas figura 5.5 e 5.7. Porém, observa-se que em todos os casos há algumas oscilações transitórias.

\subsection{CONTROLADOR POR MODOS DESLIZANTES}

Nesta seção se apresenta o projeto do controlador por modos deslizantes em ambiente simulado conforme a seção 4.4. Na primeira simulação, o controlador foi desenvolvido sem a camada limite para ilustrar o efeito do chattering. A tabela 5.4 apresenta os parâmetros do controlador.

Como não há modos ressonantes não modelados ou tempo morto, o critério utilizado para a sintonia do parâmetro $\lambda$ é o (iii) da seção (4.4). 
Tabela 5.4 - Parâmetros de simulação do controlador por modos deslizantes.

\begin{tabular}{cc}
\hline Parâmetro & Valor \\
\hline$K_{c}$ & 3000 \\
$\lambda$ & 180 \\
\hline
\end{tabular}

A figura 5.8 apresenta o resultado da simulação, a 5.9 o sinal de controle e a 5.10 a superfície de escorregamento.

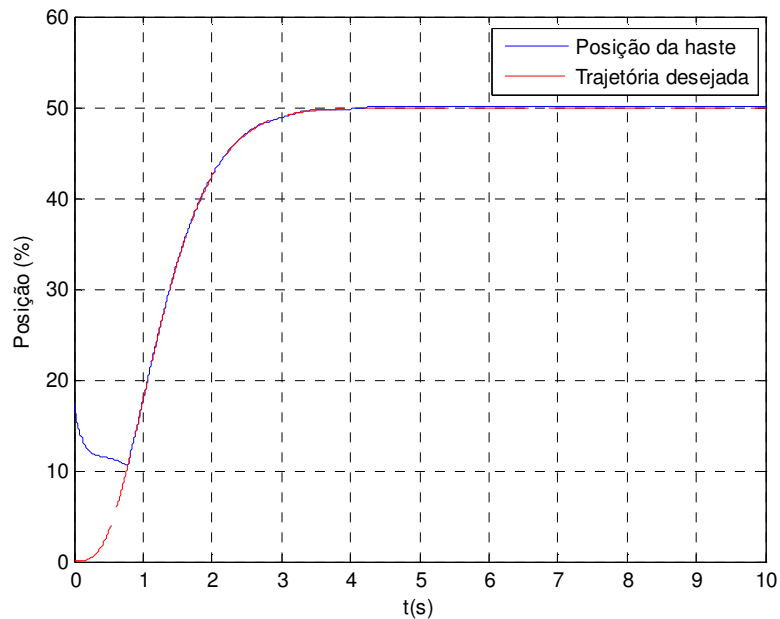

Figura 5.8 Resultado da simulação do controlador por modos deslizantes sem a camada limite.

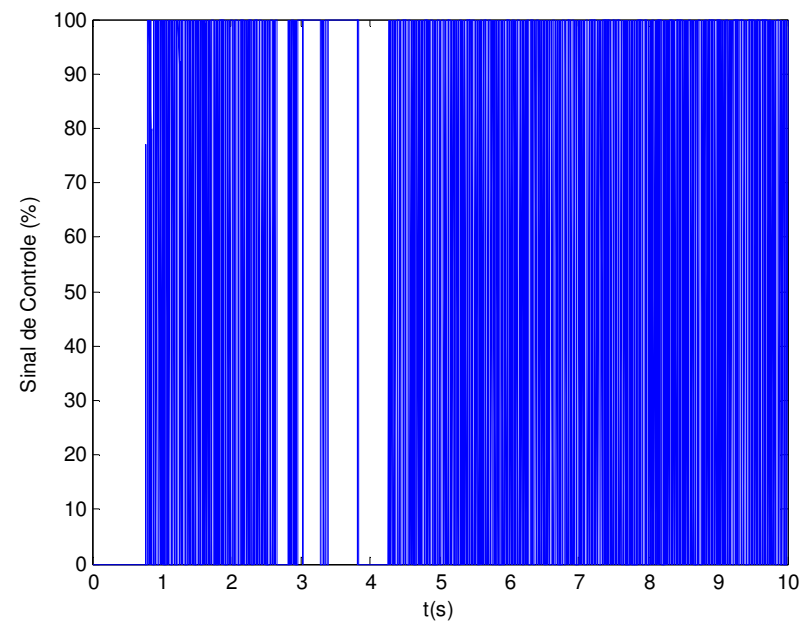

Figura 5.9 Sinal da saída do controlador por modos deslizantes sem a camada limite. 


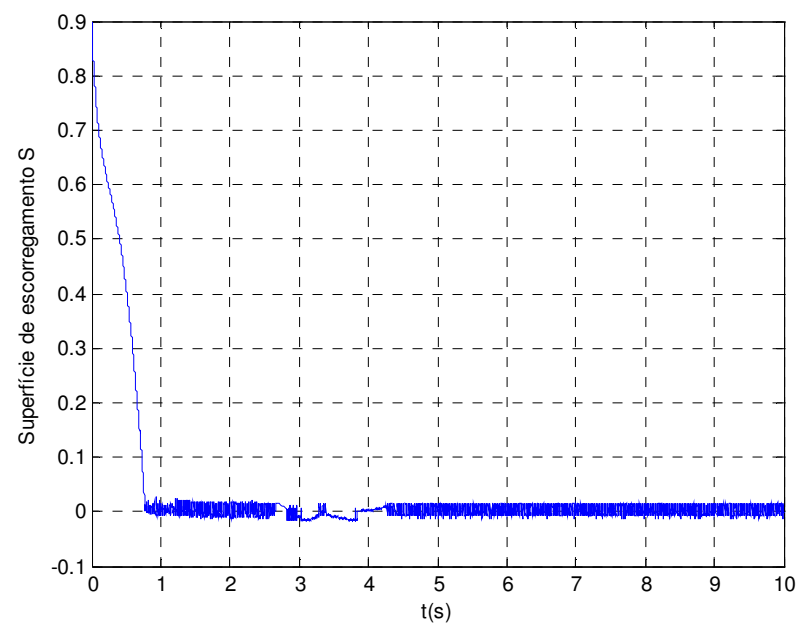

Figura 5.10 Superfície de escorregamento sem a camada limite.

Nota-se que o controlador atingiu a referência, porém com um elevado nível de oscilações em altas frequências, chattering, devido à função sign(). Também é possível verificar que a superfície de escorregamento foi atingida com sucesso.

Para a especificação da faixa limite verifica-se o nível de chattering e o erro máximo em regime estacionário. Verificou-se que $\phi=0,015$ elimina o chattering e $o$ erro em regime estacionário é menor que $1 \%$, conforme a equação (3.23).

A figura 5.11 apresenta o resultado da simulação do controlador por modos deslizantes nas mesmas condições da anterior, porém com a faixa limite projetada. A figura 5.12 o sinal de controle e a 5.13 a superfície de escorregamento. 


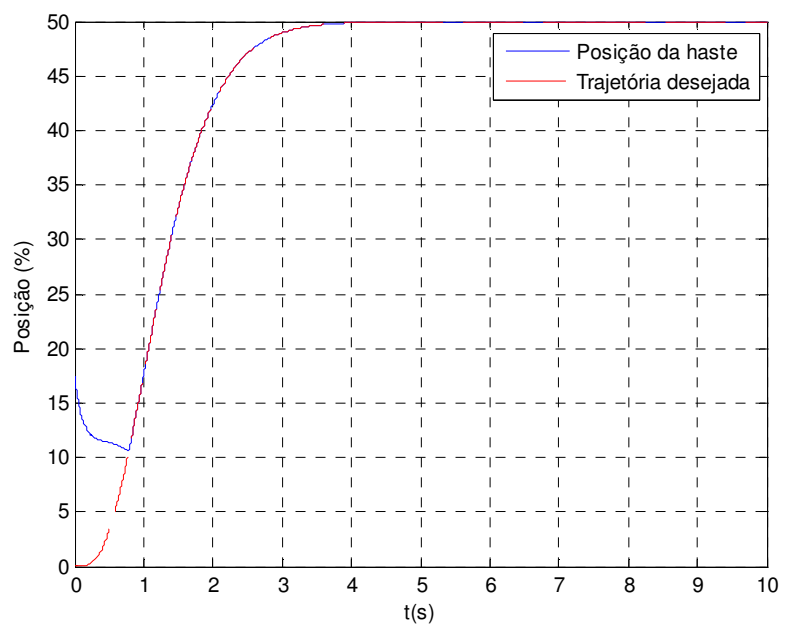

Figura 5.11 Resultado da simulação do controlador por modos deslizantes com a camada limite.

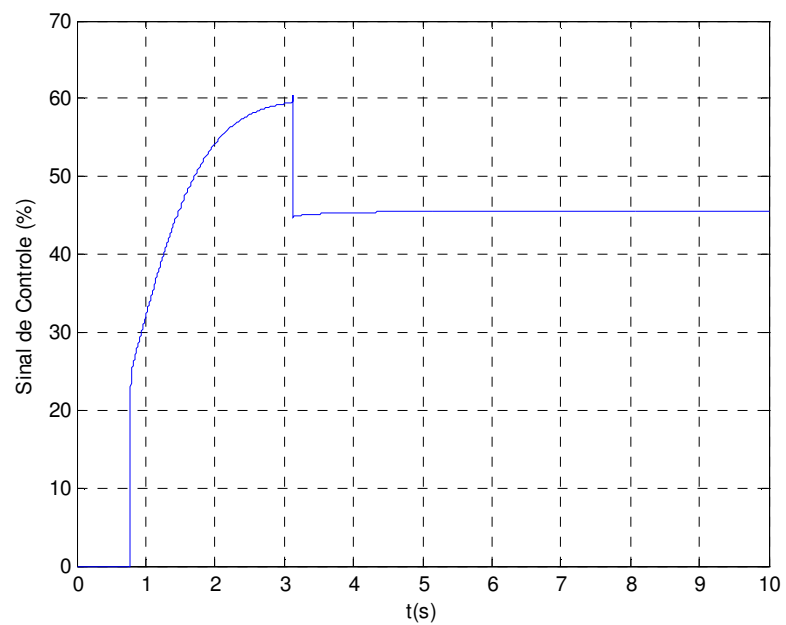

Figura 5.12 Sinal de saída do controlador por modos deslizantes simulado com a camada limite. 


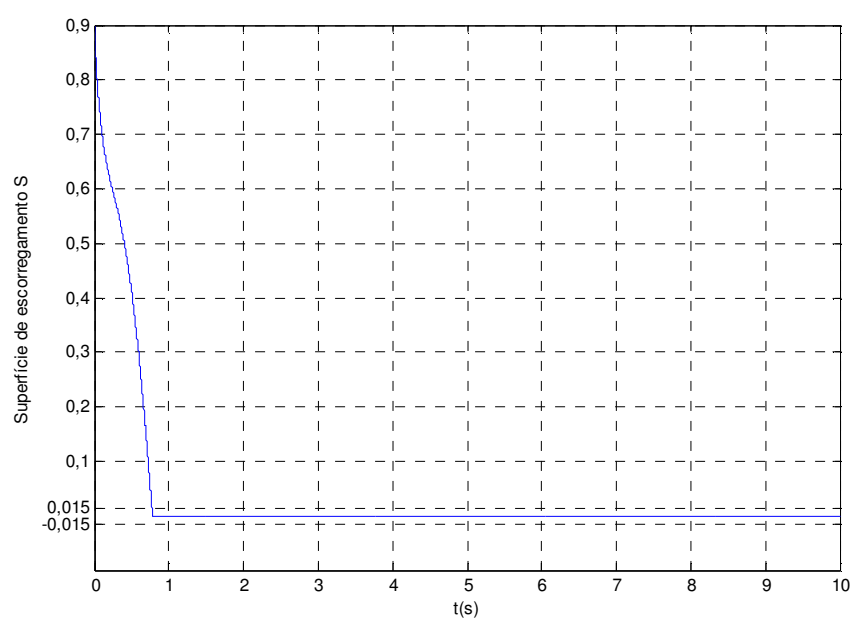

Figura 5.13 Superfície de escorregamento com a camada limite.

Os resultados da simulação mostram que o controlador atingiu a referência novamente, mas sem a presença do efeito indesejado do chattering. Além disso, a superfície de escorregamento ficou dentro da faixa limite projetada.

Nas simulações seguintes, o compensador com a faixa limite foi testado com erro nos parâmetros de $10 \%$, presença do atuador, ruído e filtro. O sinal de entrada corresponde aos mesmos degraus suavizados da seção anterior. Inicialmente apresenta-se o resultado da simulação com os parâmetros da válvula $10 \%$ menores do que os reais do sistema. Para o projeto o ganho $K_{c}$ deve ser suficiente para compensar os desvios de $10 \%$ nos parâmetros e proporcionar um tempo de alcance menor que $1 \mathrm{~s}$, conforme a equação (3.21). A sintonia do controlador é a mesma, porém foi projetada uma faixa limite maior $(\phi=0,3)$ para eliminar as oscilações. Com esta faixa limite e $\lambda=180$, o erro em regime estacionário é menor que $6 \%$, conforme a equação (3.23).

A figura 5.14 apresenta o resultado da simulação, a 5.15 o sinal de controle e 5.16 a superfície de escorregamento. 


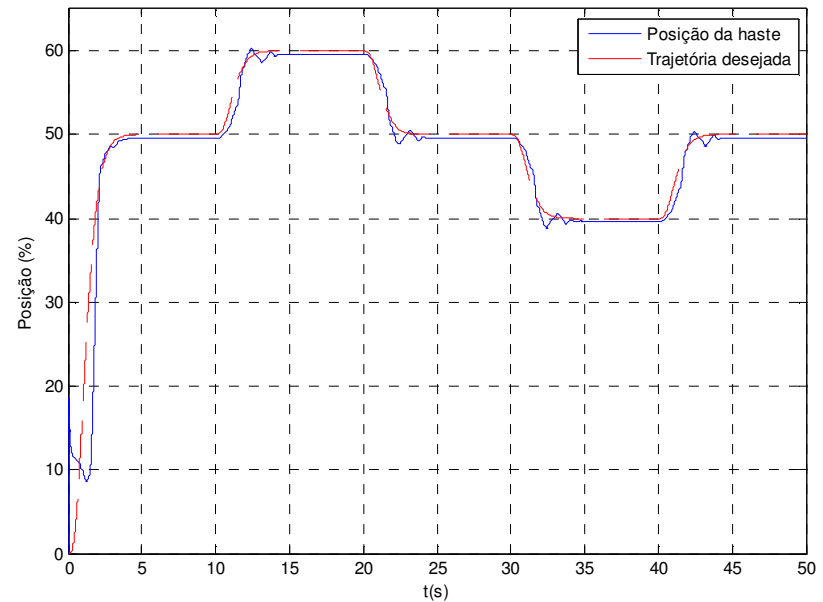

Figura 5.14 Resultado da simulação do controlador por modos deslizantes com os parâmetros 10\% menores.

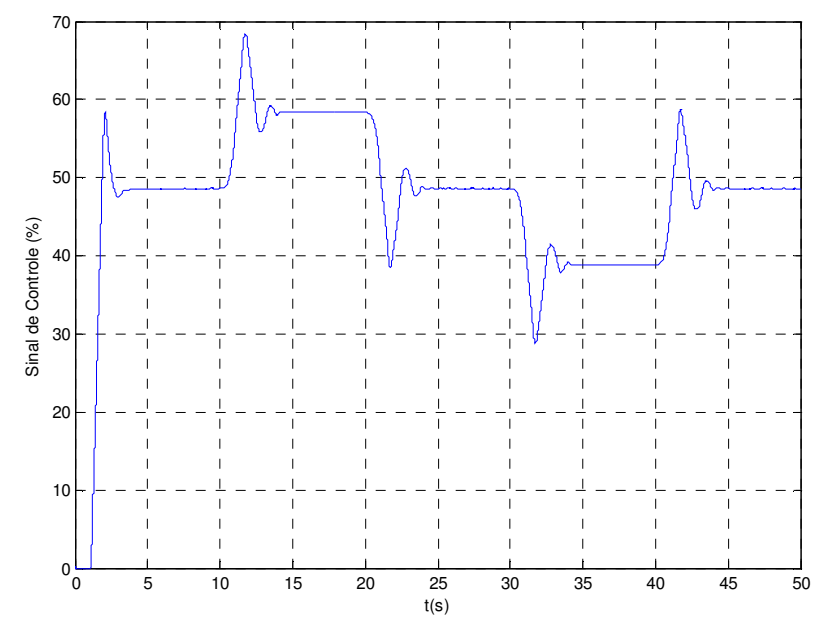

Figura 5.15 Sinal de saída do controlador por modos deslizantes simulado com os parâmetros 10\% menores. 


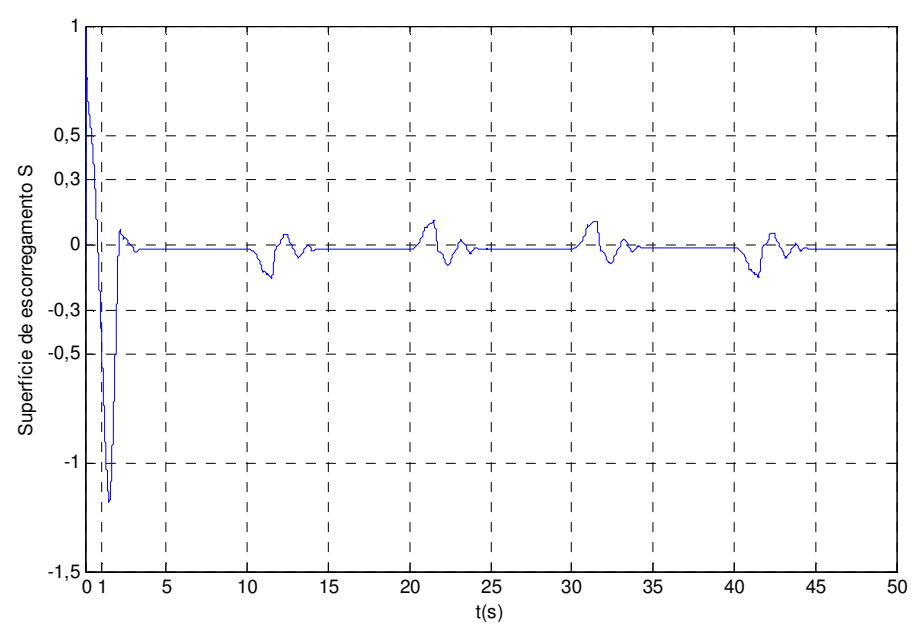

Figura 5.16 Superfície de escorregamento do controlador por modos deslizantes simulado com os parâmetros $10 \%$ menores.

Nota-se que o sistema atingiu a referência com um pequeno erro em regime estacionário. Observa-se também que o sistema atingiu a superfície de escorregamento e não há chattering. $\mathrm{O}$ erro em regime estacionário pode ser justificado pela ausência de ação integradora do controlador para corrigir o erro.

O próximo passo é repetir o ensaio anterior, mas com os parâmetros do controlador $10 \%$ maiores do que o real. Nestas condições, a figura 5.17 apresenta a resposta da posição da haste, enquanto as figuras 5.18 e 5.19 apresentam o sinal de controle e a superfície de escorregamento, respectivamente.

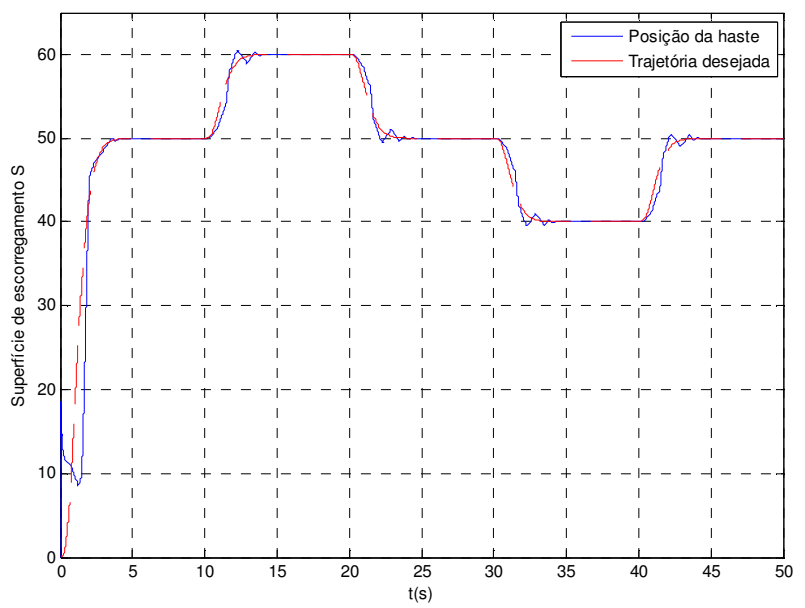

Figura 5.17 Resultado da simulação do controlador por modos deslizantes com os parâmetros 10\% maiores. 


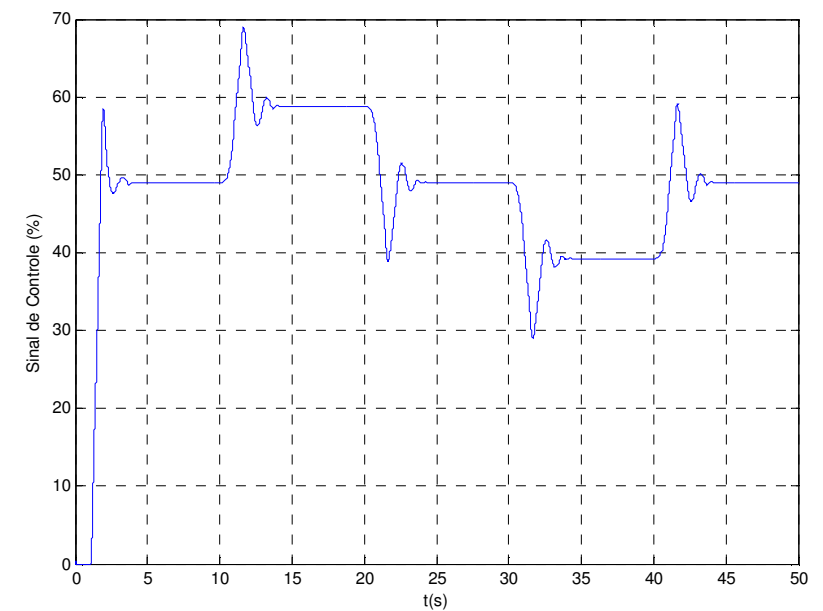

Figura 5.18 Sinal de saída do controlador por modos deslizantes simulado com os parâmetros 10\% maiores.

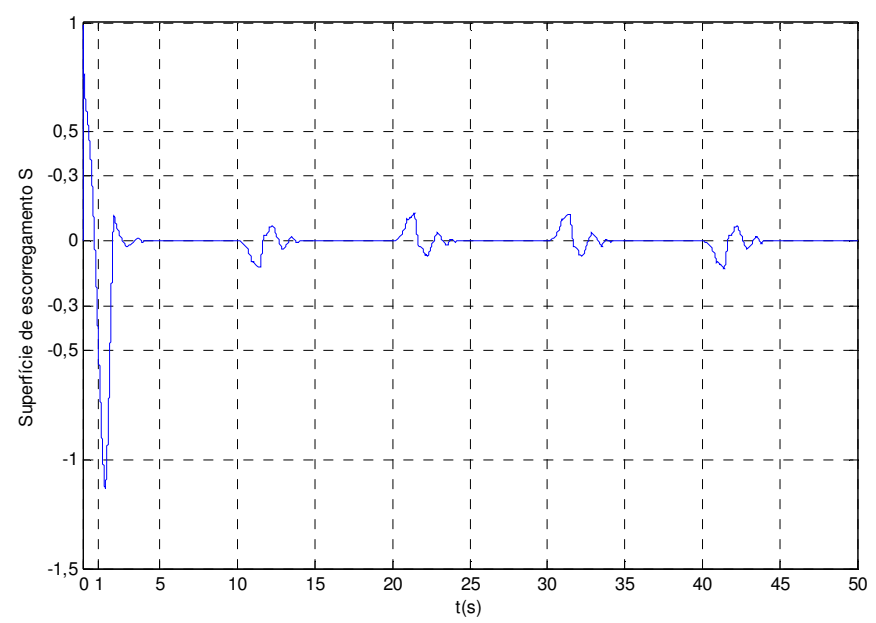

Figura 5.19 Superfície de escorregamento do controlador por modos deslizantes simulado com os parâmetros $10 \%$ maiores.

O resultado obtido foi bastante similar ao anterior, novamente o sistema atingiu a referência e a superfície de escorregamento dentro da faixa limite, mas sem erros aparentes em regime estacionário. 


\subsection{CONTROLADOR POR MODOS DESLIZANTES INTEGRADOR}

Esta seção apresenta 0 projeto do mesmo controlador por modos deslizantes, porém com uma ação integradora conforme a seção 4.5, com o objetivo de eliminar o erro em regime estacionário observado na seção anterior, mas, como na seção anterior, com um tempo de alcance de até $1 \mathrm{~s}$. Na primeira simulação considerou-se o sistema com ruído, presença da dinâmica do atuador da válvula e parâmetros do controlador $10 \%$ menores. A tabela 5.5 apresenta os parâmetros do controlador.

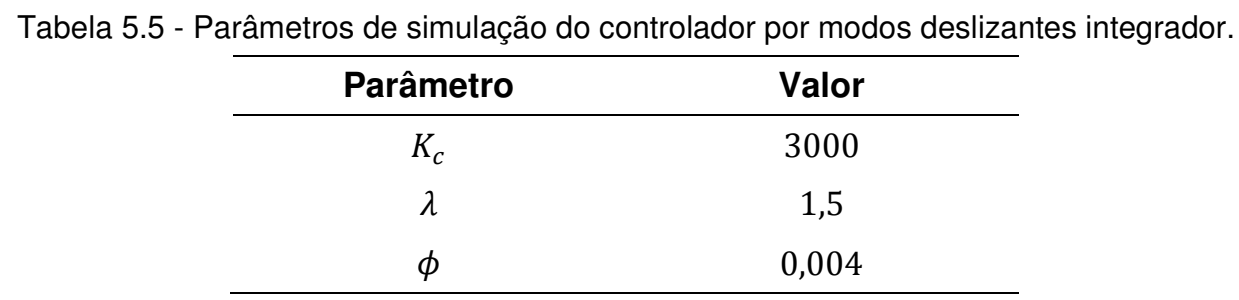

Nota-se que devido à ação integrativa adicionada no controlador, os valores sintonizados dos parâmetros $\lambda$ e $\phi$ são menores do controlador por modos deslizantes da seção anterior. Ao se utilizar valores próximos do controlador por modos deslizantes convencional, o sistema teve uma resposta oscilatória.

A figura 5.20 apresenta o resultado da simulação com parâmetros $10 \%$ menores, as figuras 5.21 e 5.22 apresentam o sinal de controle e a superfície de escorregamento, respectivamente. 


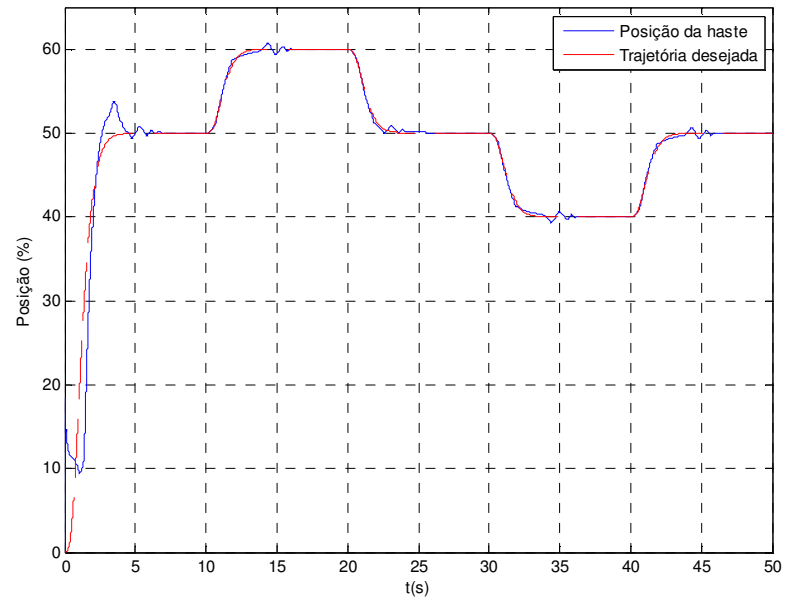

Figura 5.20 Resultado da simulação do controlador por modos deslizantes integrador com os parâmetros $10 \%$ menores.

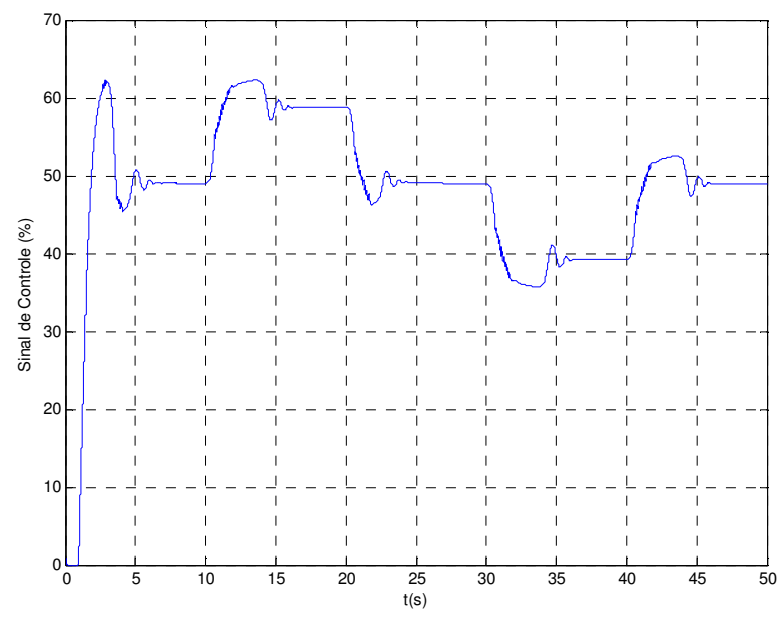

Figura 5.21 Sinal de saída do controlador por modos deslizantes integrador simulado com os parâmetros $10 \%$ menores. 


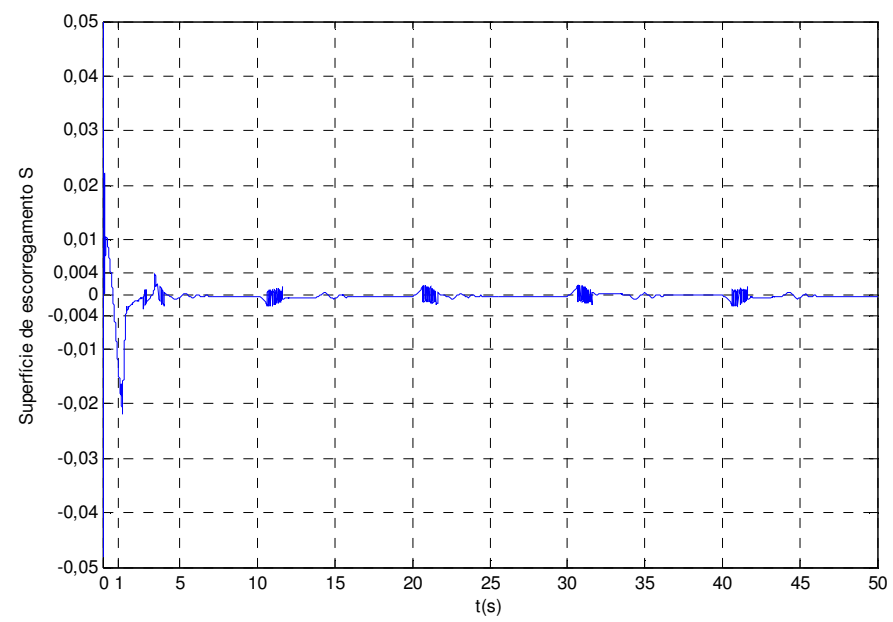

Figura 5.22 Superfície de escorregamento do controlador por modos deslizantes integrador simulado com os parâmetros $10 \%$ menores.

A figura 5.20 mostra que a válvula de controle rastreou a referência com poucas oscilações. Além disso, o sinal de controle (figura 5.21) manteve-se limitado e sem variações em alta frequência. A superfície de escorregamento (figura 5.22) foi atingida e o sistema manteve-se dentro da faixa limite projetada.

A seguir, a figura 5.23 apresenta o resultado da simulação para as mesmas condições da simulação anterior, porém com os parâmetros $10 \%$ maiores. Adicionalmente, as figuras 5.24 e 5.25 apresentam o sinal de controle e superfície de escorregamento. 


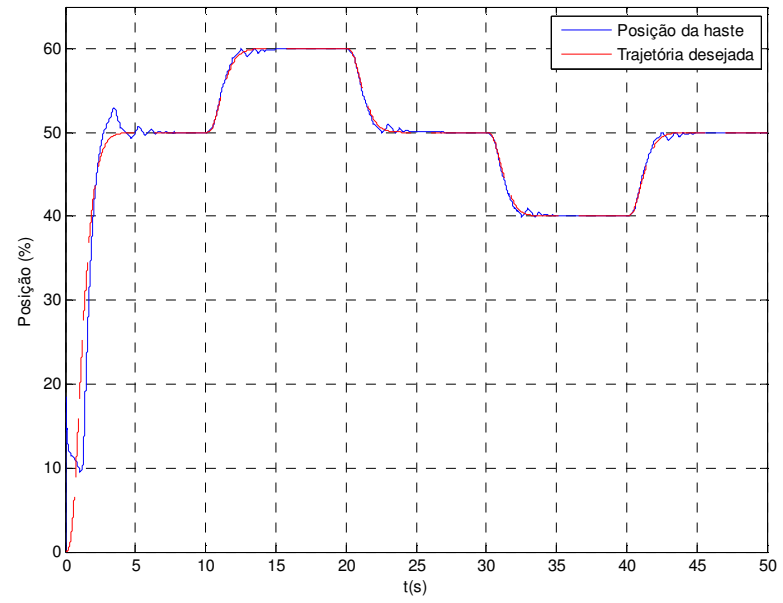

Figura 5.23 Resultado da simulação do controlador por modos deslizantes integrador com os 10\% maiores.

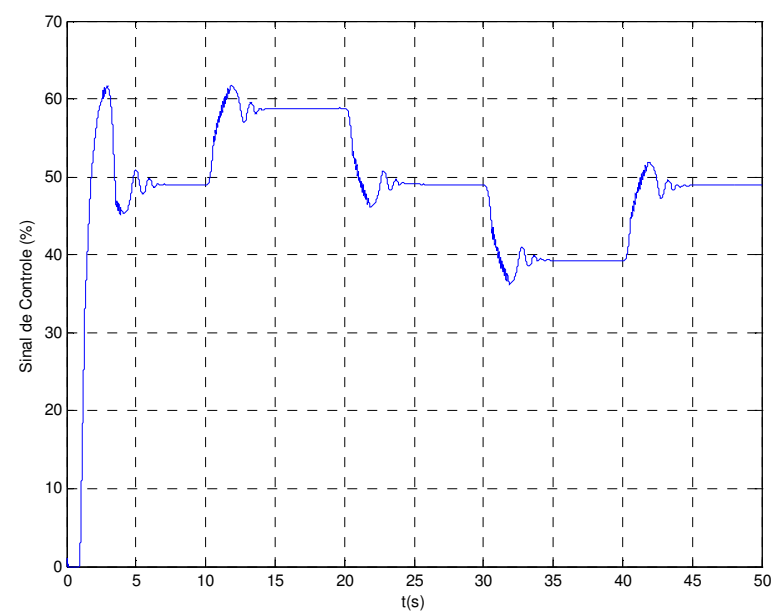

Figura 5.24 Sinal de saída do controlador por modos deslizantes integrador com os parâmetros $10 \%$ menores. 


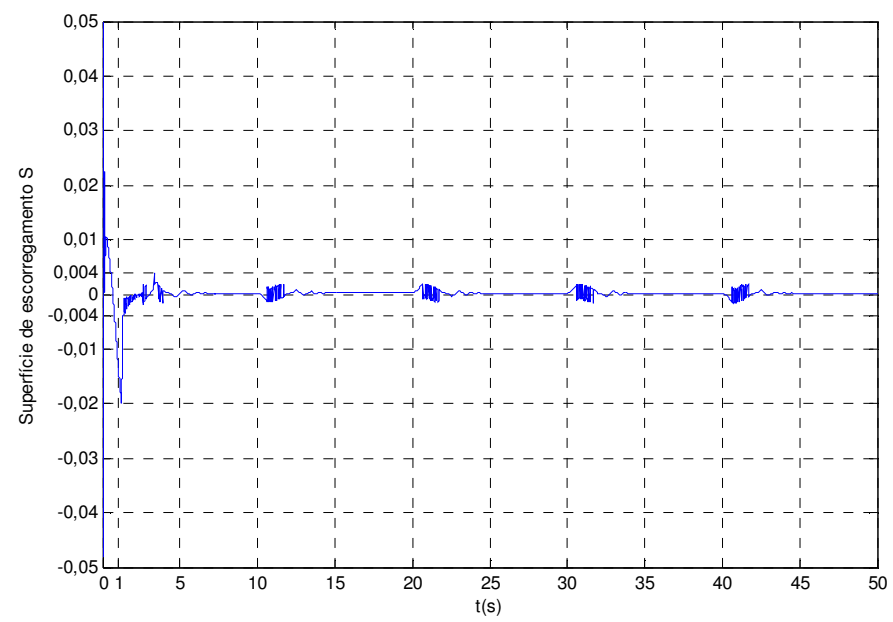

Figura 5.25 Superfície de escorregamento do controlador por modos deslizantes integrador com os parâmetros $10 \%$ maiores.

O resultado obtido através da simulação na figura 5.23 é bastante similar aos da 5.20. Novamente, o sistema rastreou a trajetória e a superfície de escorregamento foi atingida. Os resultados mostram que o controlador teve um comportamento robusto aos erros no modelo e ao ruído. Além disso, o sistema conseguiu rastrear a referência de forma bastante satisfatória, sem erros aparentes em regime estacionário.

\subsection{CONTROLADOR POR MODELO INTERNO NÃO LINEAR}

Esta seção apresenta o projeto do controlador por modelo interno não linear conforme a seção 4.6. Como nas seções anteriores será serão feitas simulações considerando um desvio de $10 \%$ nos parâmetros, ruído e a presença da dinâmica do atuador, a qual não é modelada no projeto do controlador. A tabela 5.6 apresenta os parâmetros do controlador. 
Tabela 5.6 - Parâmetros de simulação do controlador por modelo interno não linear.

\begin{tabular}{cc}
\hline Parâmetro & Valor \\
\hline$\theta_{1}$ & 4 \\
$\theta_{2}$ & 4 \\
\hline
\end{tabular}

A figura 5.26 apresenta o resultado da simulação com parâmetros $10 \%$ menores e a 5.27 o sinal de controle.

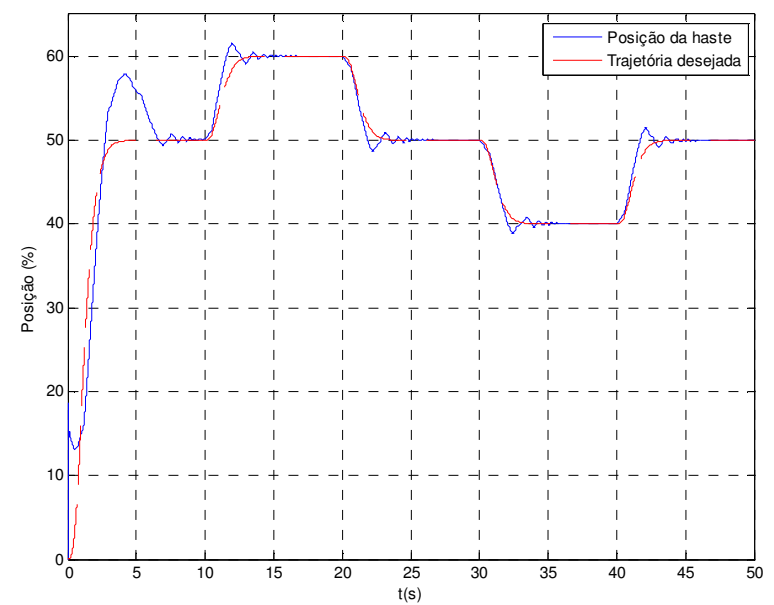

Figura 5.26 Resultado da simulação do controlador por modelo interno não linear com os parâmetros 10\% menores.

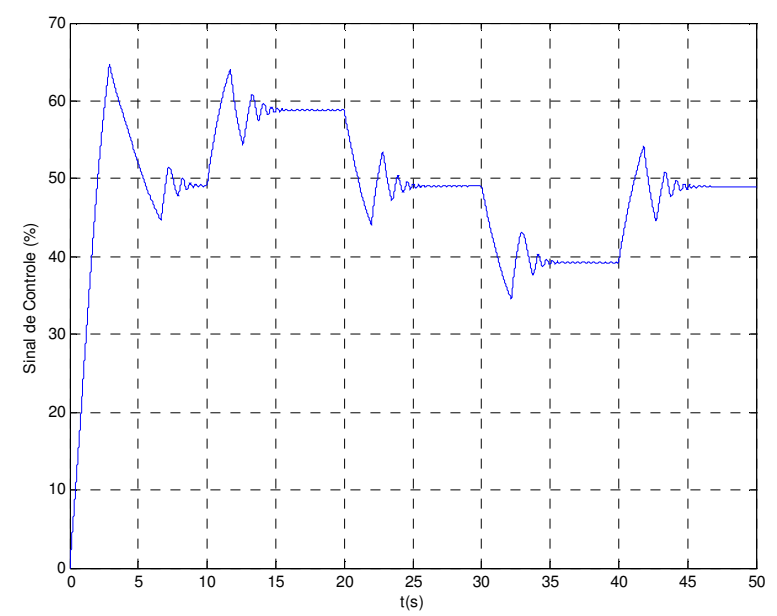

Figura 5.27 Sinal de saída do controlador por modelo interno não linear com os parâmetros 10\% menores. 
Através da figura 5.26 é possível constatar que apesar do sobressinal, presente em cada mudança de set-point, o sistema rastreou a referência mesmo com os desvios no modelo. Observa-se também que o sinal de controle não apresentou variações em alta frequência ou saturações.

A seguir, realizou-se a mesma simulação, mas com os parâmetros $10 \%$ maiores. A figura 5.28 apresenta a posição da haste e a figura 5.29 o sinal de controle.

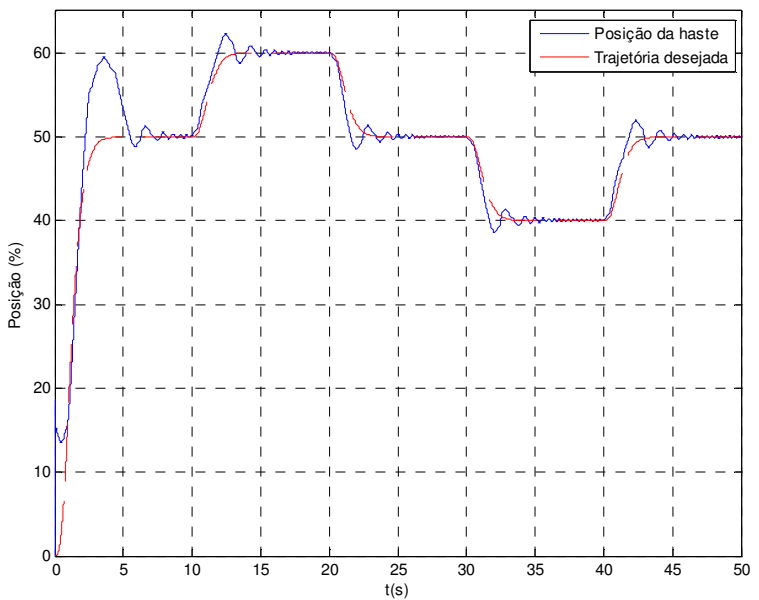

Figura 5.28 Resultado da simulação do controlador por modelo interno não linear com os parâmetros 10\% maiores.

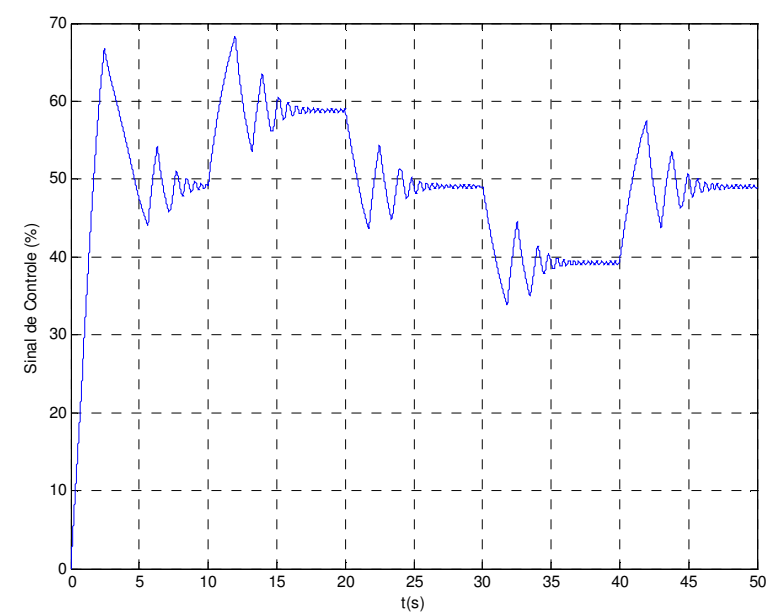

Figura 5.29 Sinal de saída do controlador por modelo interno simulado não linear com os parâmetros $10 \%$ maiores. 
Assim como na primeira simulação o sistema atingiu a referência com sobressinal e sem erro em regime estacionário. Dessa forma, pode-se concluir que o controlador comportou-se de forma robusta em relação aos erros de modelagem e ruído. Além disso, o controlador rastreou a referência de forma bastante satisfatória.

\subsection{CONTROLAdOR PI NÃo LINEAR}

Esta seção apresenta no projeto do controlador PI não linear apresentado na seção 4.7. O controlador é testado de forma similar à realizada na seção anterior. $\mathrm{Na}$ primeira simulação o modelo realimentado no controlador possui os parâmetros $10 \%$ menores que os reais e na segunda $10 \%$ maiores. Os parâmetros do controlador foram sintonizados por tentativa e erro. A tabela 5.7 apresenta os parâmetros do controlador.

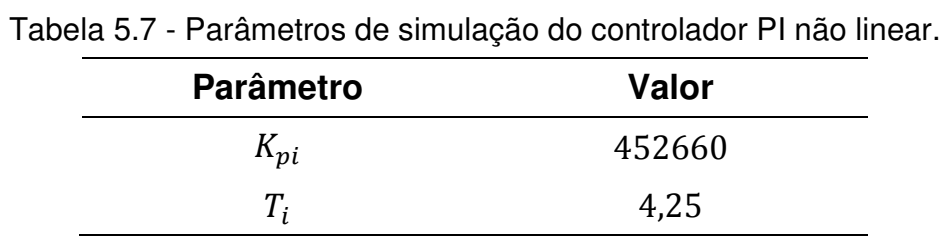

A figura 5.30 apresenta a resposta do sistema com os parâmetros $10 \%$ menores e a figura 5.31 o sinal de controle. 


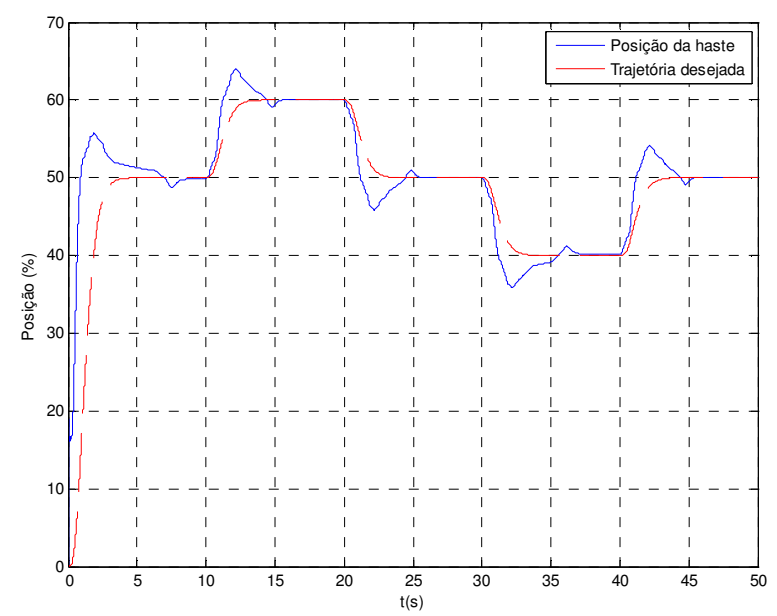

Figura 5.30 Resultado da simulação do controlador PI não linear com os parâmetros 10\% menores.

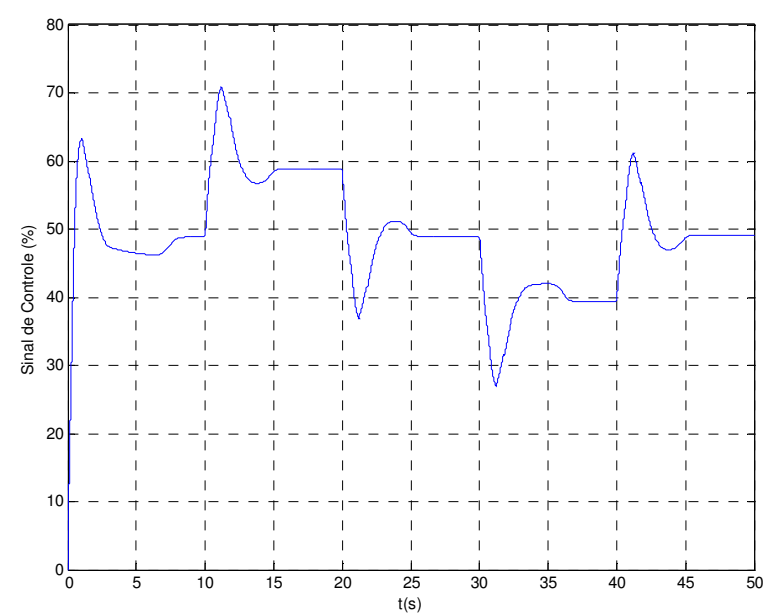

Figura 5.31 Sinal de saída do controlador PI não linear simulado com os parâmetros 10\% menores.

Através dos resultados, nota-se que apesar do sobressinal o sistema rastreou a referência. $O$ sinal de controle manteve-se limitado e sem variações em alta frequência.

A figura 5.32 apresenta o resultado da simulação com os parâmetros do sistema realimentados $10 \%$ maiores do que os reais e a figura 5.33 o sinal de controle. 


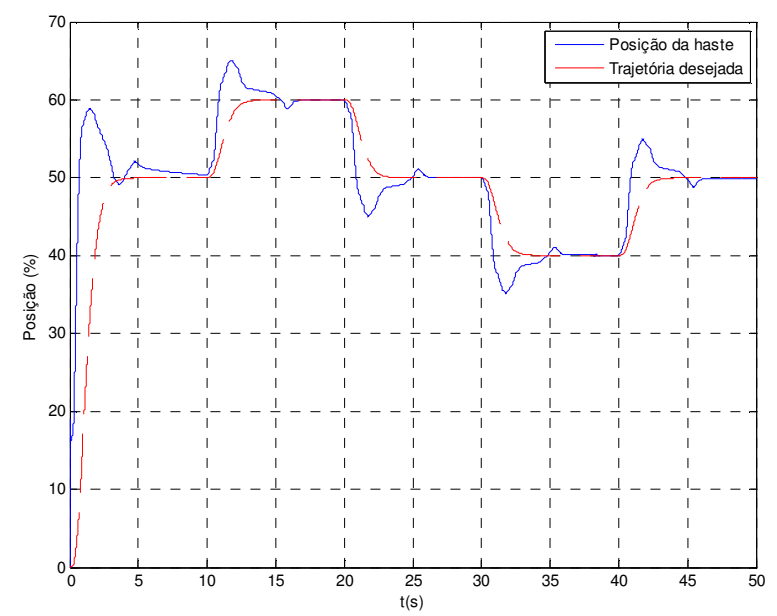

Figura 5.32 Resultado da simulação do controlador PI não linear com os parâmetros 10\% maiores.

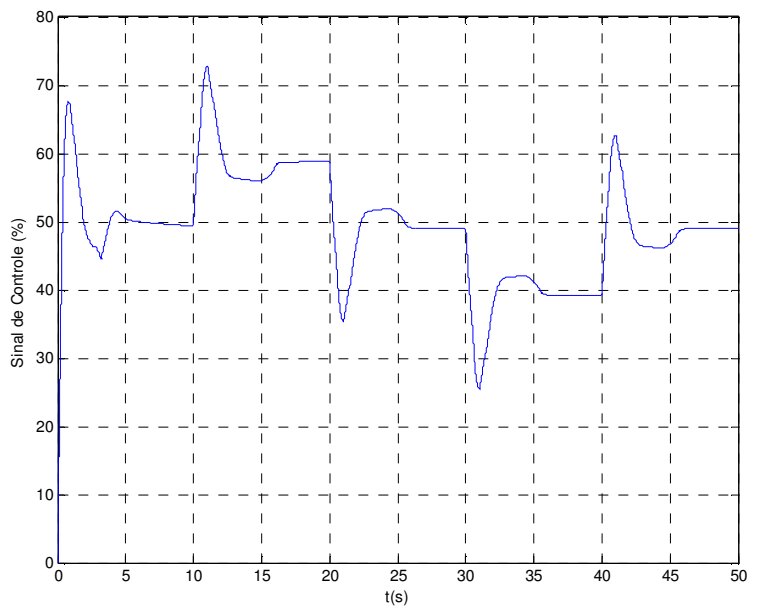

Figura 5.33 Sinal de saída do controlador PI não linear com os parâmetros 10\% maiores.

A figura 5.32 mostra que assim como na simulação anterior o controlador rastreou a. O comportamento do sinal de controle foi similar ao da figura 5.31.

Os resultados, do ponto de vista qualitativo, de todos os controladores foram bastante satisfatórios. Todos os compensadores foram sintonizados e conseguiram rastrear a referência sem saturar o sinal de controle. 


\subsection{CONTROLADOR PI TRADICIONAL}

Esta seção mostra a simulação do controlador $\mathrm{PI}$ tradicional, o qual foi projetado conforme a equação (3.42). O principal objetivo é comparar com os controladores não lineares das seções anteriores. A tabela 5.8 apresenta os parâmetros sintonizados do controlador PI tradicional através do método da síntese direta.

Tabela 5.8 - Parâmetros de simulação do controlador PI tradicional.

\begin{tabular}{cc}
\hline Parâmetro & Valor \\
\hline$K_{p i}$ & 209190 \\
$T_{i}$ & 1,8 \\
\hline
\end{tabular}

A figura 5.34 apresenta a resposta do controlador e a figura 5.35 o sinal de controle.

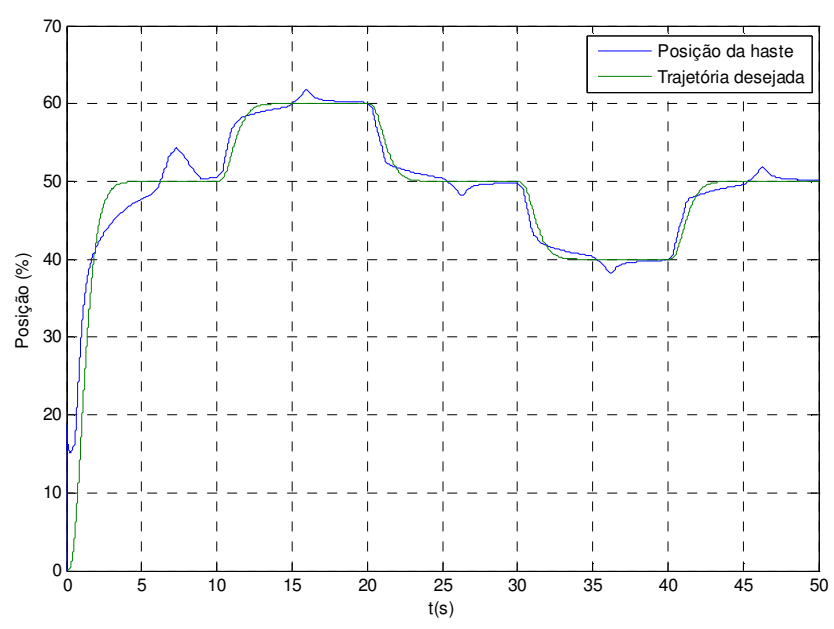

Figura 5.34 Resultado da simulação do controlador PI tradicional. 


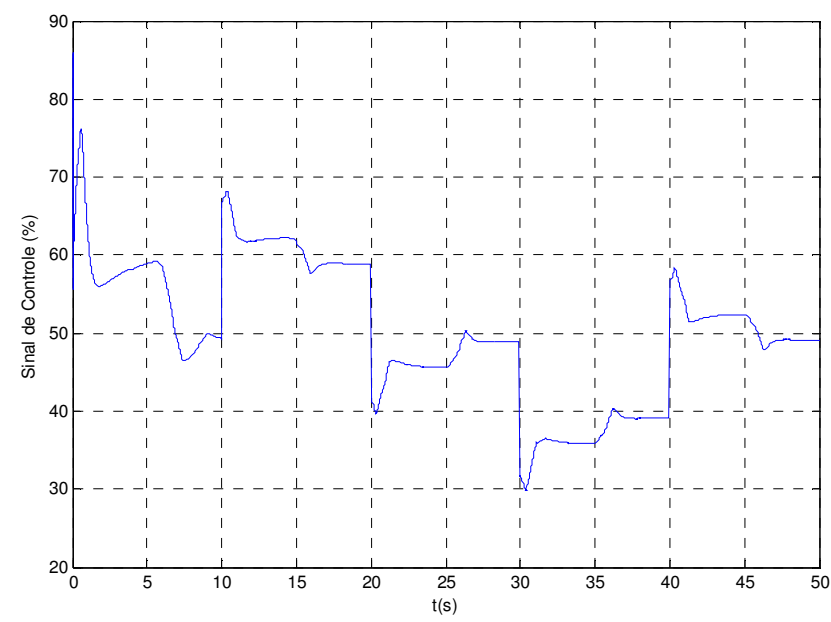

Figura 5.35 Sinal de saída do controlador PI tradicional simulado.

Através da figura 5.34, observa-se que o sistema apresentou sobressinal e o rastreamento não foi perfeito em regime estacionário.

\subsection{COMPARAÇÃO DOS RESULTADOS}

Nesta seção é feita a comparação dos controladores apresentados nas seções anteriores. Para cada controlador foi calculada integral do erro quadrático (ISE) para a situação com parâmetros 10\% maiores e 10\% menores com a presença do atuador e ruído de medição, conforme a equação (5.3).

$$
I S E=\int(r(t)-y(t))^{2} \cdot d t
$$


Tabela 5.9 - ISE dos controladores.

\begin{tabular}{ccc}
\hline Controlador & ISE (10\% menores) & ISE (10\% maiores) \\
\hline Rastreador de & 19,59 & 21,92 \\
trajetória & 39,19 & 30,26 \\
Modos Deslizantes & 24,71 & 19,38 \\
$\begin{array}{c}\text { Modos Deslizantes } \\
\text { Integrador } \\
\text { Modelo interno não }\end{array}$ & 32,47 & 33,42 \\
$\quad$ linear & 152,71 & 225,28 \\
PI não linear & 25,45 & 34,09 \\
\hline
\end{tabular}

De acordo com a tabela a 5.9, o controlador que apresentou o melhor desempenho foi rastreador de trajetória, pois apresentou o menor ISE. O pior desempenho ficou com o PI não linear, o qual a apresentou os mais elevados índices ISE. Adicionalmente, pode-se apontar que o controlador por modos deslizantes integrador apresentou um desempenho bastante positivo, sendo o controlador com segundo melhor desempenho nas sintonias apresentadas. 


\section{CAPÍTULO 6 RESULTADOS PRÁTICOS}

Este capítulo apresenta os resultados práticos obtidos no Laboratório de Controle de Processos Industriais. Os algoritmos de controle estudados e analisados foram implementados para controlar uma válvula de controle real Fisher/Emerson com gaxetas de grafite. Além disso, são discutidos o procedimento experimental e o desempenho de cada um dos controladores.

\subsection{Procedimento experimental}

Os experimentos foram realizados através de uma placa de aquisição de dados National 6229, a qual permite fazer a leitura e escrita de sinais analógicos. Os algoritmos de controle foram desenvolvidos em ambiente Matlab/Simulink, o qual também realiza a interface com a placa de aquisição de dados.

A válvula de controle possui um sensor de posição do tipo LVDT (Linear Variable Diferential Transformer), o qual permite medir a posição da haste (0 a $100 \%$ ) através do sinal analógico transmitido de 0 a 10V.

Para enviar o sinal de controle, a placa de aquisição de dados envia um sinal analógico de 0 a $10 \mathrm{~V}$ para um conversor de 0 a $10 \mathrm{~V}$ para 4 a $20 \mathrm{~mA}$ (conversor $\mathrm{V} / \mathrm{I}$ ), o qual transmite o sinal para o conversor de corrente para pressão (conversor I/P). Este conversor envia o sinal de pressão para o atuador da válvula.

O diagrama de blocos da figura 6.1 apresenta a estrutura do ambiente experimental. 


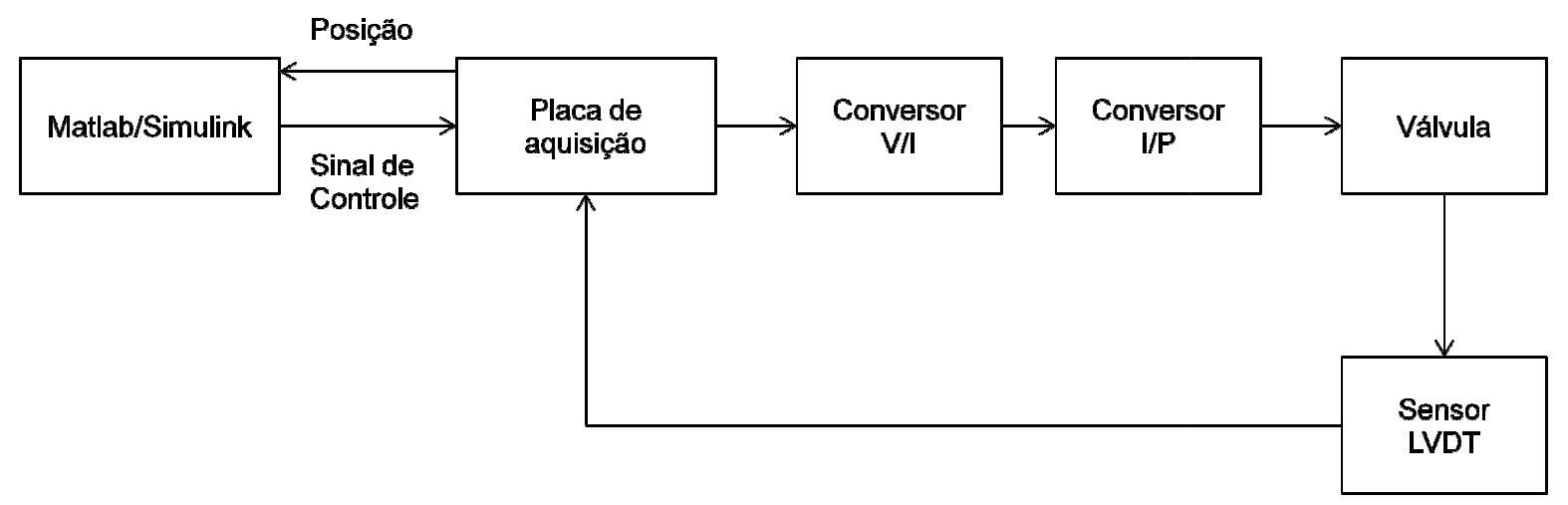

Figura 6.1 Diagrama de blocos do procedimento experimental.

A estratégia de projeto dos controladores é a mesma do projeto simulado no capítulo 5, ou seja, utiliza-se a mesma estrutura de controle do diagrama 5.1, porém os blocos "Atuador" e "Válvula" agora são reais.

A tabela 6.1 apresenta os parâmetros da válvula, os quais são utilizados por todos os controladores para a linearização.

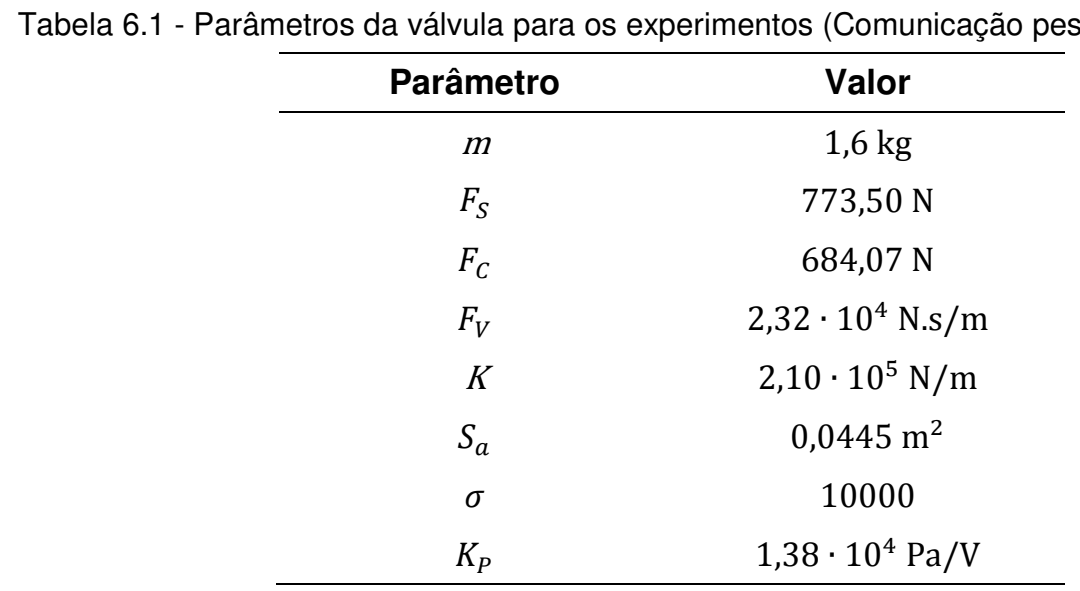

Para avaliar os controladores serão analisados a integral do erro quadrático (ISE equação 5.3), o índice de variabilidade (IV) e a distância percorrida pela haste (D). 


$$
I V=\frac{2 \cdot \operatorname{std}(y) \cdot 100}{\bar{y}}
$$

onde:

$\operatorname{std}(y)$ : Desvio padrão de $y$

$\bar{y}$ : Valor médio de $y$

A distância $(D)$ percorrida pela haste quantifica o quanto a válvula se movimentou para cada sinal de controle. Como o sinal referência é o mesmo para todos os controladores, quanto menor a distância percorrida menor é o desgaste da válvula gerado pelo controlador.

$$
D=\sum_{i=1}^{N}|y(i)-y(i-1)|
$$

onde:

$y$ : Posição da haste

$N$ : Número de amostras

Os ensaios foram realizados a uma taxa de amostragem de $1 \mathrm{kHz}$. Para a sintonia dos controladores utilizou-se como ponto de partida os valores obtidos no capítulo 5.

\subsection{CONTROLADOR RASTREADOR DE TRAJETÓRIA}

O controlador rastreador de trajetória foi projetado conforme a seção 4.3. A tabela 6.2 apresenta os parâmetros sintonizados do controlador. 
Tabela 6.2 - Parâmetros do controlador rastreador de trajetória.

\begin{tabular}{cc}
\hline Parâmetro & Valor \\
\hline$C_{0}$ & 1000000 \\
$C_{1}$ & 2000 \\
\hline
\end{tabular}

A figura 6.2 apresenta a resposta e a figura 6.3 o sinal de controle do controlador rastreador de trajetória na válvula de controle real.

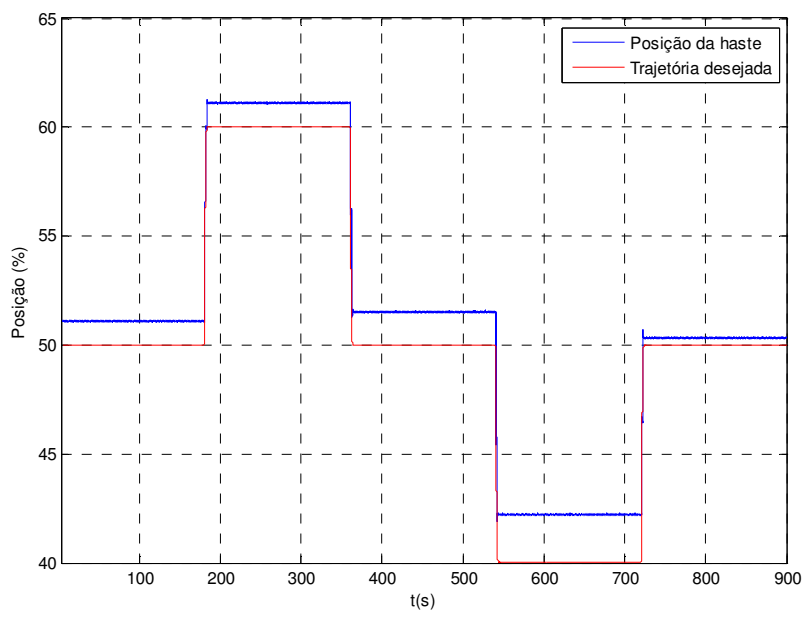

Figura 6.2 Resposta do controlador rastreador de trajetória na válvula de controle real.

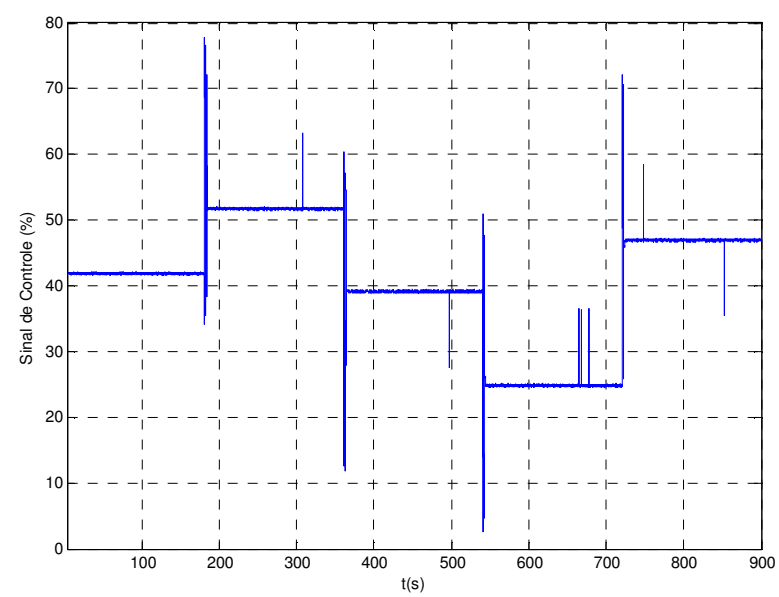

Figura 6.3 Sinal de saída do controlador rastreador de trajetória na válvula de controle real. 
A tabela 6.3 apresenta os resultados dos índices de desempenho do controlador.

Tabela 6.3 - Análise do controlador rastreador de trajetória.

\begin{tabular}{cc}
\hline Parâmetro & Valor \\
\hline ISE & 178,03 \\
Distância percorrida & 887 \\
Variabilidade & 23,41 \\
\hline
\end{tabular}

Observa-se que a válvula rastreou a referência e que não houve saturação do sinal de controle, porém, assim como nas simulações do capítulo 5, houve um erro em regime estacionário. Isto ocorre porque o controlador não possui ação integradora para corrigir o erro em regime estacionário.

Durante os testes, verificou-se que ganhos maiores diminuem o erro em regime estacionário, porém o sistema torna-se oscilatório.

\subsection{CONTROLADOR POR MODOS DESLIZANTES}

O controlador por modos deslizantes foi implementado conforme a seção 4.4. A tabela 6.4 apresenta os parâmetros sintonizados do controlador.

\begin{tabular}{cc}
\hline Tabela 6.4 - Parâmetros do controlador por modos deslizantes \\
\hline Parâmetro & Valor \\
\hline$K_{c}$ & 1200 \\
$\lambda$ & 200 \\
$\phi$ & 0,15 \\
\hline
\end{tabular}


A figura 6.4 apresenta a resposta do controlador por modos deslizantes, a figura 6.5 o sinal de controle na válvula de controle real, a figura 6.6 a superfície de escorregamento e a figura 6.7 mostra o detalhe do tempo de alcance na superfície.

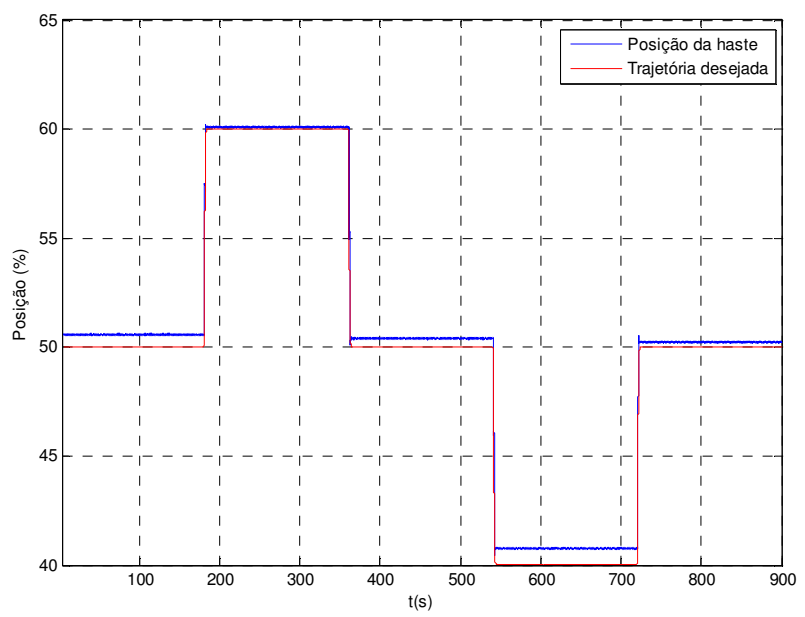

Figura 6.4 Resposta do controlador por modos deslizantes na válvula de controle real.

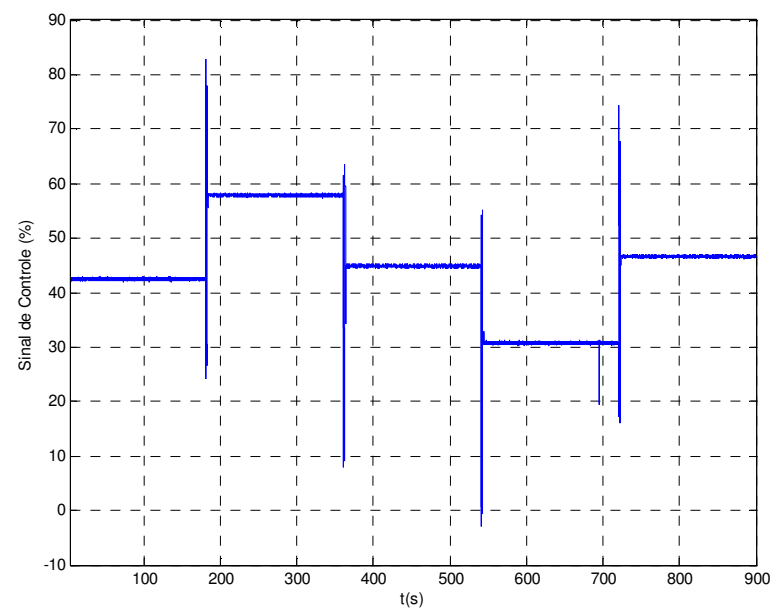

Figura 6.5 Sinal de saída do controlador por modos deslizantes na válvula de controle real. 


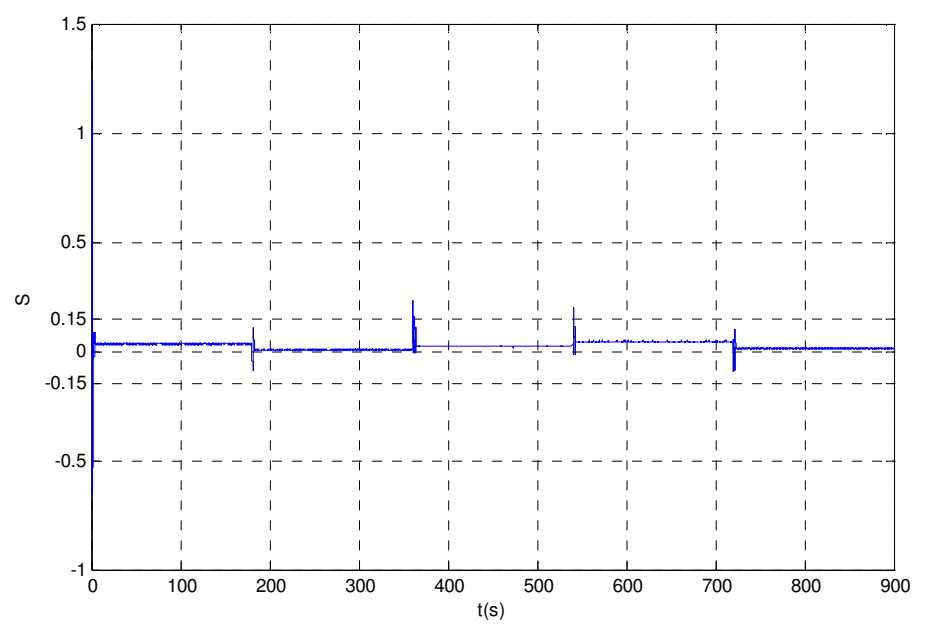

Figura 6.6 Superfície de escorregamento do controlador por modos deslizantes na válvula de controle real.

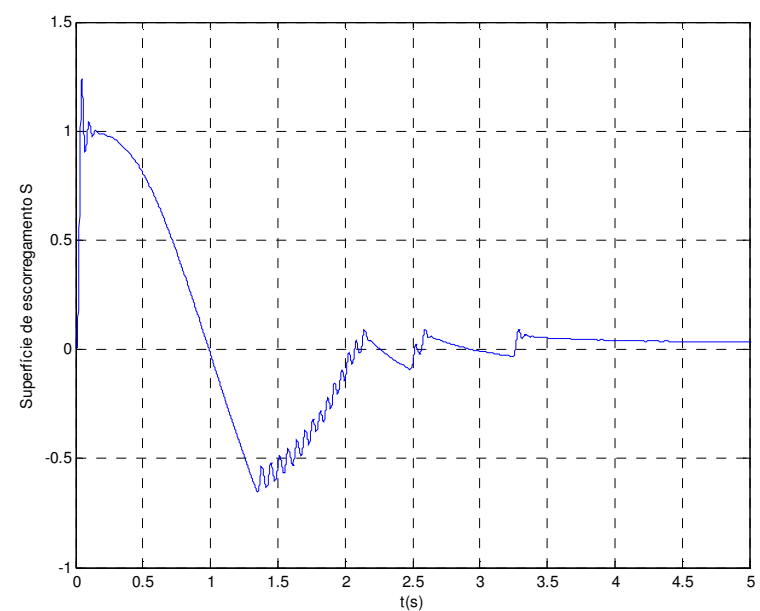

Figura 6.7 Tempo de alcance na superfície de escorregamento do controlador por modos deslizantes na válvula real.

A tabela 6.5 apresenta os resultados dos índices de desempenho do controlador por modos deslizantes. 
Tabela 6.5 - Análise do controlador por modos deslizantes.

\begin{tabular}{cc}
\hline Parâmetro & Valor \\
\hline ISE & 22,31 \\
Distância percorrida & 850 \\
Variabilidade & 24,28 \\
\hline
\end{tabular}

Os resultados mostram que o controlador rastreou a referência e a superfície de escorregamento foi atingida sem chattering com tempo de alcance menor do que $1 \mathrm{~s}$. Nota-se também, que a superfície ficou dentro da faixa limite projetada. Porém, assim como no capítulo 5 , há erros em regime estacionário.

Nota-se também que a ISE foi significativamente menor do que a do controlador rastreador de trajetória, assim como a distância percorrida pela haste e a variabilidade.

\subsection{CONTROLADOR POR MODOS DESLIZANTES INTEGRADOR}

O controlador por modos deslizantes integrador foi implementado conforme a seção 4.5. A tabela 6.6 apresenta os parâmetros do controlador.

\begin{tabular}{cc} 
Tabela 6.6 - Parâmetros do controlador por modos deslizantes integrador. \\
\cline { 2 - 2 } Parâmetro & Valor \\
\hline$K_{c}$ & 1000 \\
$\lambda$ & 1,33 \\
$\phi$ & 0,005 \\
\hline
\end{tabular}

A figura 6.8 apresenta a resposta do controlador por modos deslizantes integrador na válvula de controle real, a figura 6.9 o sinal de controle, a figura $6.10 \mathrm{a}$ superfície de escorregamento e a figura 6.11 mostra o detalhe do tempo de alcance na superfície. 


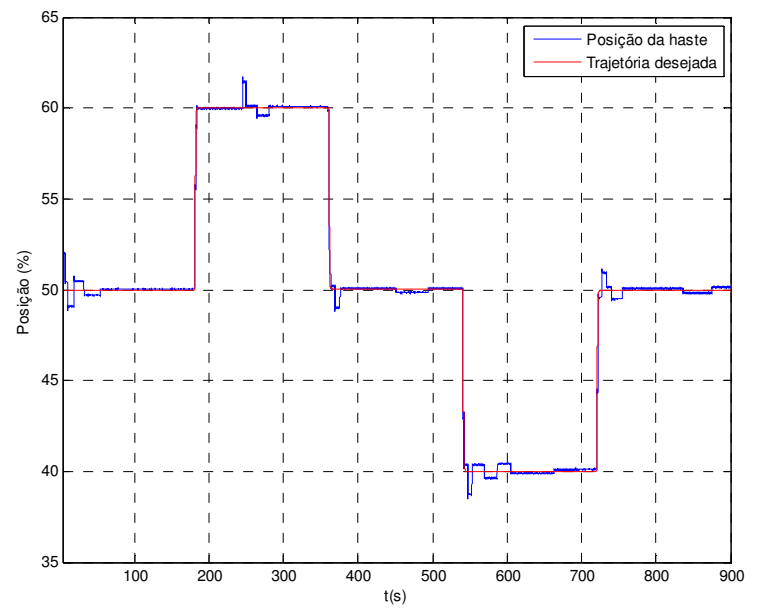

Figura 6.8 Resposta do controlador por modos deslizantes integrador na válvula de controle real.

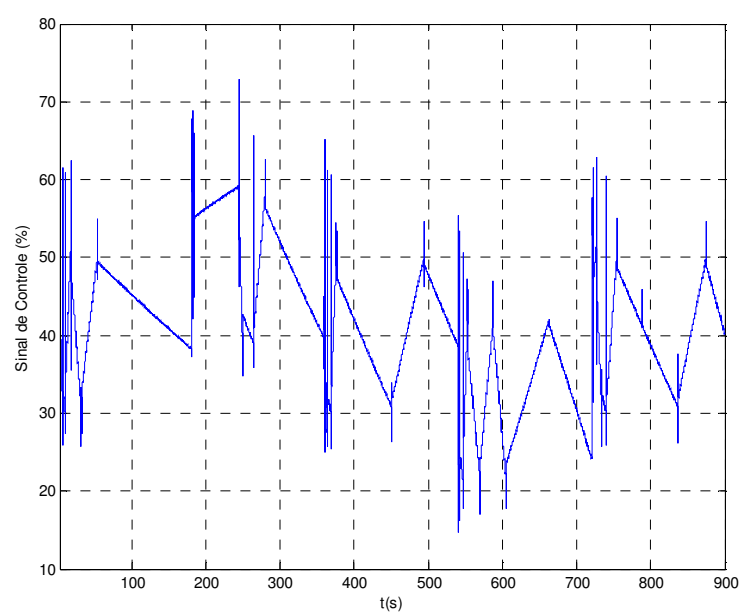

Figura 6.9 Sinal de saída do controlador por modos deslizantes integrador na válvula de controle real. 


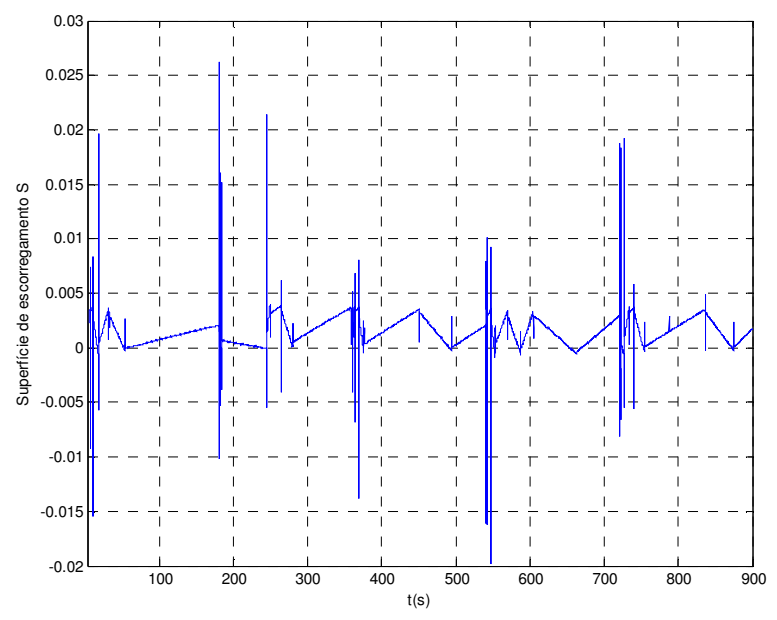

Figura 6.10 Superfície de escorregamento do controlador por modos deslizantes integrador na válvula de controle real.

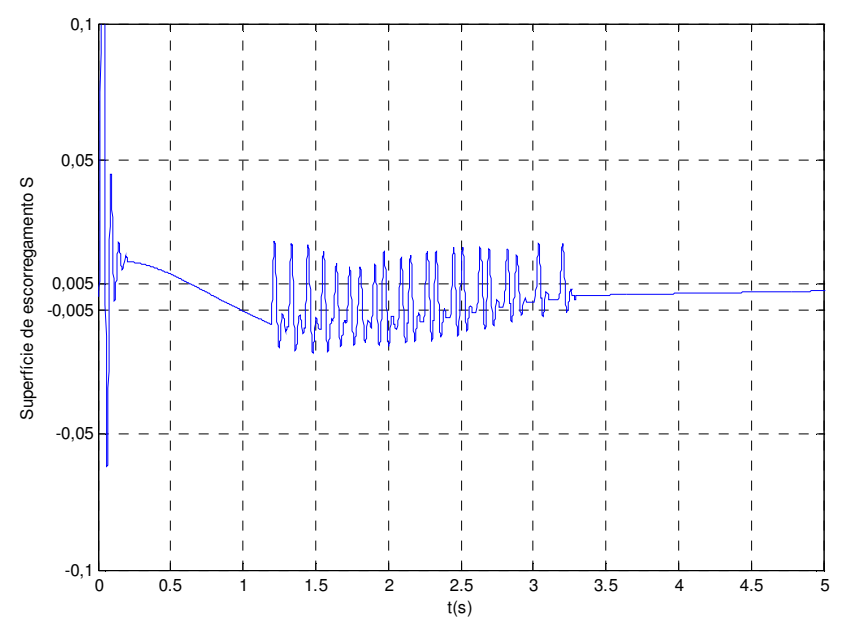

Figura 6.11 Tempo de alcance na superfície de escorregamento do controlador por modos deslizantes integrador na válvula de controle real.

A tabela 6.7 apresenta os resultados dos índices de desempenho do controlador por modos deslizantes integrador. 
Tabela 6.7 - Análise do controlador por modos deslizantes integrador.

\begin{tabular}{cc}
\hline Parâmetro & Valor \\
\hline ISE & 8,83 \\
Distância percorrida & 830 \\
Variabilidade & 25,38 \\
\hline
\end{tabular}

Assim como na seção 6.3, os resultados mostram que o controlador rastreou a referência e a superfície de escorregamento foi atingida sem chattering com tempo de alcance menor do que $1 \mathrm{~s}$. Nota-se também, que a superfície de escorregamento ficou dentro da faixa limite projetada e que não houve erros em regime estacionário, devido à ação integrativa do controlador.

Observa-se através da tabela 6.7 que o ISE, foi significativamente menor do que o controlador por modos deslizantes. Houve redução também na distância percorrida pela haste, mas um pequeno aumento na variabilidade.

\subsection{CONTROLADOR POR MODELO INTERNO NÃO LINEAR}

O controlador por modelo interno não linear foi implementado conforme a seção 4.6. A tabela 6.8 apresenta os parâmetros do controlador.

Tabela 6.8 - Parâmetros do controlador por modelo interno não linear.

\begin{tabular}{cc}
\hline Parâmetro & Valor \\
\hline$\theta_{1}$ & 1 \\
$\theta_{2}$ & 2 \\
\hline
\end{tabular}

A figura 6.12 apresenta a resposta do controlador por modelo interno não linear na válvula de controle real e a figura 6.13 o sinal de controle. 


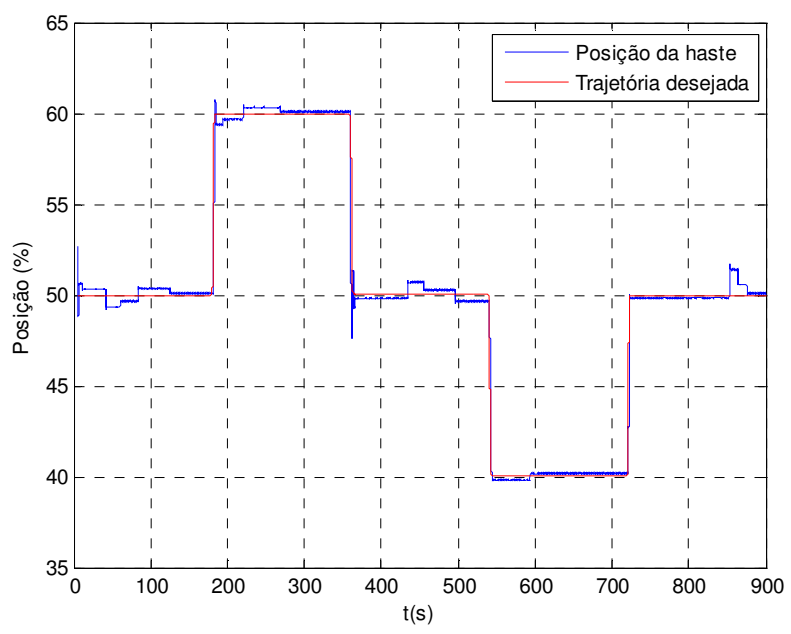

Figura 6.12 Resposta do controlador por modelo interno não linear na válvula de controle real.

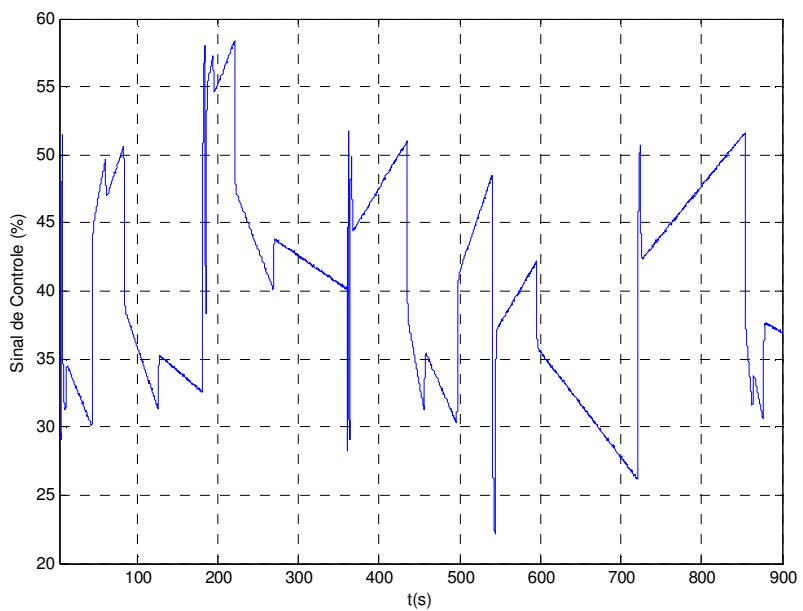

Figura 6.13 Sinal de saída do controlador por modelo interno não linear na válvula de controle real.

A tabela 6.9 apresenta os resultados dos índices de desempenho do controlador por modelo interno não linear. 
Tabela 6.9 - Análise do controlador por modelo interno não linear.

\begin{tabular}{cc}
\hline Parâmetro & Valor \\
\hline ISE & 24,89 \\
Distância percorrida & 882 \\
Variabilidade & 25,30 \\
\hline
\end{tabular}

Através da figura 6.12 observa-se que o controlador seguiu a referência se forma bastante satisfatória, os resultados foram similares aos do controlador por modos deslizantes integrador, porém a ISE e a distância percorrida pela haste foram maiores.

\subsection{CONTROLADOR PI NÃO LINEAR}

O controlador PI não linear foi implementado conforme a seção 4.7. A tabela 6.10 apresenta os parâmetros do controlador.

Tabela 6.10 - Parâmetros do controlador PI não linear.

\begin{tabular}{cc}
\hline Parâmetro & Valor \\
\hline$K_{p i}$ & 532536 \\
$T_{i}$ & 5 \\
\hline
\end{tabular}

A figura 6.14 apresenta a resposta do controlador na válvula de controle real e a figura 6.15 o sinal de controle. 


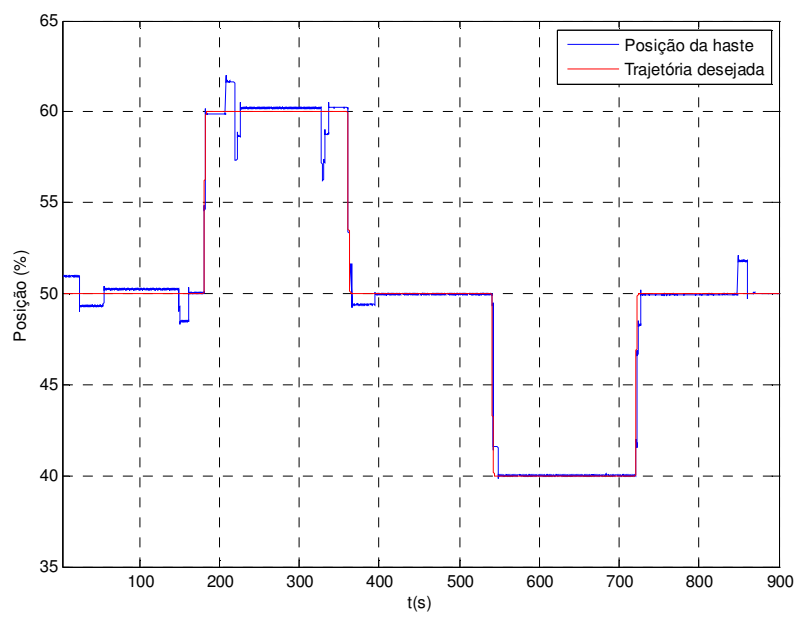

Figura 6.14 Resposta do controlador PI não linear na válvula de controle real.

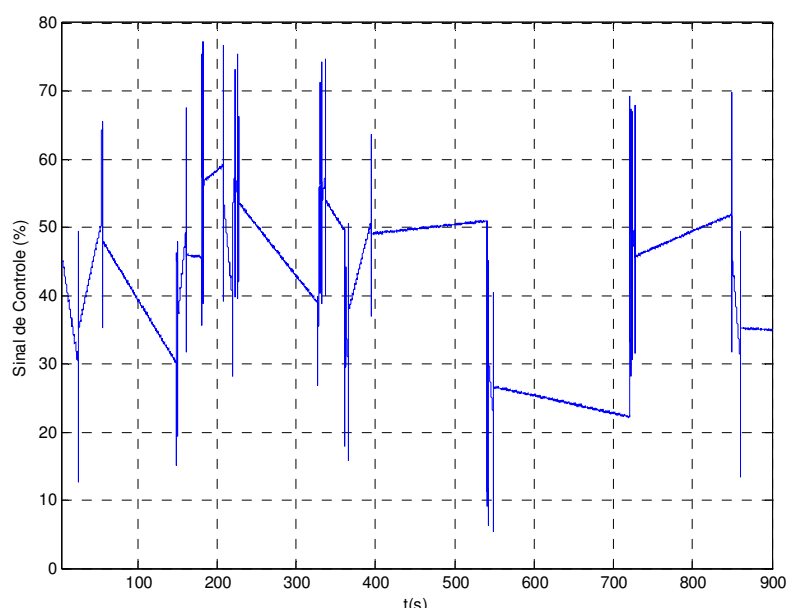

Figura 6.15 Sinal de saída do controlador PI não linear na válvula de controle real.

A tabela 6.11 apresenta os resultados dos índices de desempenho do controlador PI não linear. 
Tabela 6.11 - Análise do controlador PI não linear.

\begin{tabular}{cc}
\hline Parâmetro & Valor \\
\hline ISE & 33,94 \\
Distância percorrida & 742 \\
Variabilidade & 25,32 \\
\hline
\end{tabular}

Os resultados mostram que o controlador rastreou a referência de forma trajetória de forma satisfatória, porém nota-se que a ISE foi maior do que nos controladores por modos deslizantes, porém a distância percorrida foi menor que os demais controladores.

\subsection{CONTROLAdOR PI tRadicional}

Esta seção apresenta o resultado do controlador PI tradicional na válvula de controle. O objetivo principal é comparar o desempenho com os demais controladores não lineares projetados.

O controlador PI foi implementado conforme a equação (3.35), a sintonia foi feita através do método da síntese direta. A tabela 6.12 apresenta os parâmetros do controlador.

Tabela 6.12 - Parâmetros do controlador PI tradicional.

\begin{tabular}{cc}
\hline Parâmetro & Valor \\
\hline$K_{p i}$ & 221540 \\
$T_{i}$ & 0,635 \\
\hline
\end{tabular}

A figura 6.16 apresenta a resposta do controlador na válvula de controle real e a figura 6.17 o sinal de controle. 


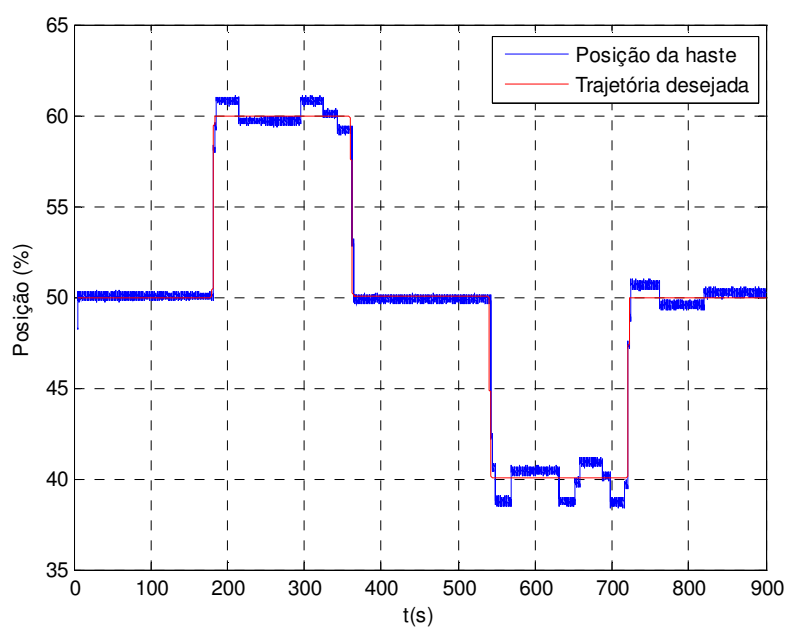

Figura 6.16 Resposta do controlador PI tradicional na válvula de controle real.

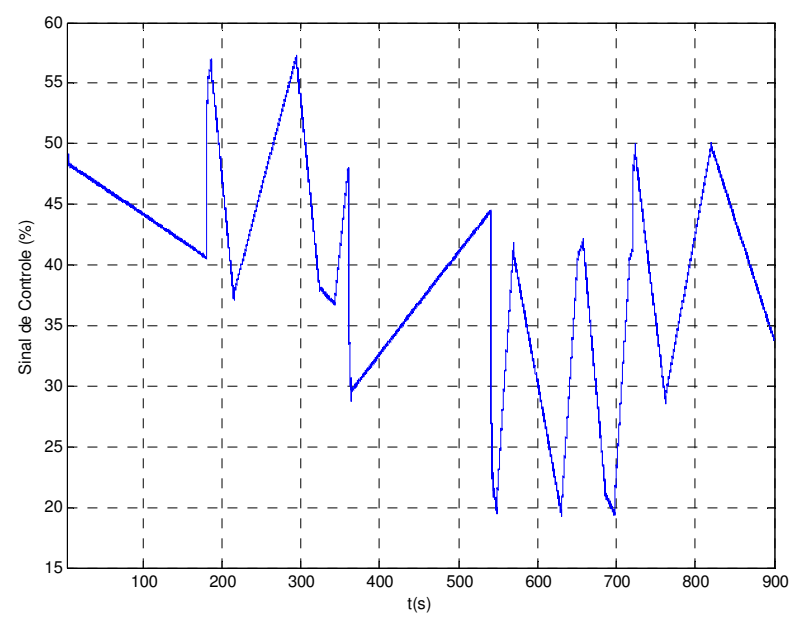

Figura 6.17 Sinal de saída do controlador PI tradicional na válvula de controle real.

Conforme pode ser obervado na figura 6.16, o ruído é mais elevado do que os controladores anteriores. Este fato pode ser justificado pela ausência de um filtro passa-baixas no sensor de posição. Dessa forma, para comparar com os controladores anteriores, a resposta da válvula foi filtrada pelo mesmo filtro (5.1) usado nos compensadores não lineares.

A figura 6.18 mostra a resposta da válvula filtrada pelo filtro (5.1). 


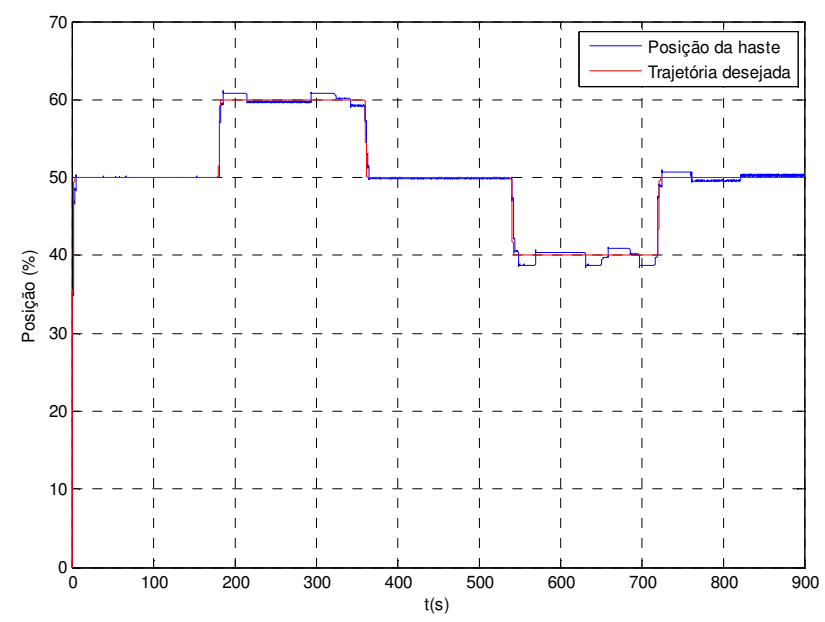

Figura 6.18 Resposta do controlador PI tradicional filtrado na válvula de controle real.

A tabela 6.13 apresenta os resultados dos índices de desempenho do controlador PI tradicional com os sinais filtrados.

\begin{tabular}{cc} 
Tabela 6.13 - Análise do controlador PI tradicional. \\
\hline Parâmetro & Valor \\
\hline ISE & 33,77 \\
Esforço de controle & 920 \\
Variabilidade & 25,54
\end{tabular}

Através da figura 6.18 nota-se que o controlador rastreou a trajetória, mas em alguns momentos oscilou em torno da referência. 


\section{CAPÍTULO 7 CONCLUSÃO}

Este capítulo apresenta as conclusões de todos os resultados apresentados durante o trabalho. Além disso, no final do capítulo, são apresentadas algumas sugestões para trabalhos futuros.

\subsection{Resultados}

O trabalho apresentou cinco controladores não lineares: Controlador Rastreador de Trajetória, Controlador por Modos Deslizantes, Controlador por Modos Deslizantes Integrador, Controlador por Modelo Interno não linear e o Controlador PI não linear. Para cada controlador, foram discutidas a teoria e a metodologia de projeto, com o objetivo de implementar em uma válvula de controle real e discutir o seu desempenho.

Para isso, inicialmente, foram desenvolvidos o modelo teórico da válvula de controle e a teoria necessária para o entendimento e desenvolvimento dos controladores. Logo após, com as leis de controle desenvolvidas, foram feitas simulações para verificar o desempenho e sintonia dos controladores.

Nas simulações, os resultados mostraram que o controlador rastreador de trajetória apresentou o melhor resultado, seguido pelo controlador por modos deslizantes integrador.

Porém, a principal função das simulações foi verificar a coerência e o desempenho dos controladores para aplicação prática. Além disso, foi a base para a sintonia e o projeto na válvula real.

Como todos os controladores responderam de forma satisfatória nas simulações, foi possível concluir que o direcionamento estava correto para o projeto prático. 
O capítulo 6 mostrou que todos os controladores responderam de forma bastante aceitável também na válvula de controle real. Não foram observadas oscilações, saturação do sinal de controle ou instabilidade. Adicionalmente, em todos os casos o controlador agiu para rastrear a trajetória.

Além dos controladores não lineares, o capítulo 6 apresentou o resultado da aplicação de um controlador PI tradicional na válvula de controle, com o objetivo de comparar com os compensadores não lineares.

A tabela 7.1 integra os resultados obtidos no capítulo 6 , na implementação prática com a válvula de controle real.

Tabela 7.1 - Resultados dos controladores.

\begin{tabular}{cccc}
\hline Controlador & ISE & D & IV \\
\hline Rastreador de & 178,03 & 887 & 23,41 \\
trajetória & 22,31 & 850 & 24,28 \\
Modos Deslizantes & 8,83 & 830 & 25,38 \\
$\begin{array}{c}\text { Modos Deslizantes } \\
\text { Integrador }\end{array}$ & 24,89 & 882 & 25,30 \\
$\begin{array}{c}\text { Modelo interno não } \\
\text { linear }\end{array}$ & 33,94 & 742 & 25,32 \\
PI não linear & 33,77 & 920 & 25,54 \\
PI tradicional & & &
\end{tabular}

onde:

ISE: Integral do erro quadrático

D : Distância percorrida pela haste

IV: Índice de variabilidade

Através da tabela 7.1, observa-se que o índice de variabilidade nos controladores apresentou uma variação muito pequena nos diferentes controladores. Apenas pode-se notar que os controladores sem ação integradora apresentaram os menores valores. 
Observa-se que o controlador rastreador de trajetória apresentou o maior ISE, a segunda maior distância percorrida, mas o menor índice de variabilidade. Apesar disso, pode-se concluir que este controlador apresentou o pior desempenho devido ao alto erro em regime estacionário.

O controlador por modos deslizantes apresentou o segundo menor ISE e a terceira menor distância percorrida.

Nota-se que controlador por modos deslizantes integrador apresentou um ISE muito menor do que os demais controladores, portanto foi o que melhor rastreou a referência. Além disso, apresentou a segunda menor distância percorrida pela haste. Dessa forma, pode-se concluir que este controlador foi o que apresentou 0 melhor desempenho.

O controlador por modelo interno não linear apresentou um desempenho inferior aos controladores por modos deslizantes, mas apresentou um ISE menor que o controlador PI não linear e o PI tradicional.

O controlador PI não linear apresentou um ISE maior do que o PI tradicional, mas a distância percorrida pela haste foi significativamente menor.

Através dos resultados obtidos, pode-se concluir que o trabalho mostrou que apesar da maior complexidade, os controladores não lineares propostos possuem um bom potencial para serem desenvolvidos na prática.

Além disso, diante dos avanços da eletrônica embarcada, observa-se que os algoritmos de controle propostos podem ser desenvolvidos em microcontroladores, com o objetivo de atuar como posicionador para válvulas de controle.

\subsection{SUGESTÃo PARA TRABALHOS FUtUROS}

Diante da complexidade do tema deste trabalho, há várias possibilidades de trabalhos futuros. A seguir, são apresentadas algumas sugestões: 
- Implementar os controladores propostos em uma válvula de controle operando em um processo industrial real.

- Estudo de técnicas de controle adaptativo para compensação de atrito.

- Implementar os algoritmos em um microcontrolador em um hardware que atue como um posicionador de válvulas de controle.

- Estudo de outras possibilidades de projeto com o controlador por modos deslizantes, como o uso de modos deslizantes de ordem superior.

- Estudo de observadores e derivadores para a obtenção da velocidade da haste. 


\section{REFERÊNCIAS BIBLIOGRÁFICAS}

Bialkowski, W. L. Mill audits can cut costs by reducing control Loop variability. Pulp \& Paper Magazine, v. 72, n. 12, p. 79-84, 1998.

Edwards C.; Spurgeon S. K. Sliding mode control: Theory and applications. 1 ed. Taylor \& Francis, 1998.

Emerson. Control valves handbook. 4 ed., Fisher Controls International, 2005.

Garcia, C. Modelagem de atrito em válvulas de controle. Salvador: XVI Congresso Brasileiro de Automática, 2006.

Garcia, C. Parameter estimation of friction model for control valves. Preprints of the 8th International IFAC Symposium on Dynamics and Control of Process Systems, v.2, p. 273-278, 2007.

Garcia, C. Comparison of friction models applied to a control valve. Control Engineering Practice, v. 16, n. 10, p. 1231 - 1243, 2008.

Hägglund, T. A friction compensator for pneumatic control valves. Journal of Process Control, v.. 12, n. 8, p. $897-904,2002$.

Hägglund, T. Automatic on-line estimation of backlash in control loops. Journal of Process Control, v. 17, n. 6, p. 489 - 499, 2007.

Henson M. A.; Seborg D. E. An Internal Model Control Strategy for Nonlinear Systems. American Institute of Chemicals Engineers Journal, v. 37, n. 7, p. 1065 1081, 1991. 
Henson M. A.; Seborg D. E. Nonlinear Process Control 1 ed. Prentice Hall, 1997.

Isidori, A. Nonlinear control systems An Introduction. 2 ed., New York: Springer, 1989.

Karnopp, D. Computer simulation of stick-slip friction in mechanical dynamic systems. Journal of Dynamic Systems, Measurement and Control, v. 107, n. 1, p. $100-103,1985$.

Kayihan, A.; Doyle III, F. J. Friction compensation for a process control valve. Control Engineering Practice, n. 8, 799-812, 2000.

Kano, K.; Maruta H., Kugemoto, Shimizu K. Pratical model and detectation algorithm for valve stiction. Proceedings of the $7^{\text {th }}$ IFAC DYCOPS, Boston, 2004.

Kravaris, C.; Chung, C. B. Nonlinear state feedback synthesis by global input/output linearization. A.I.Ch.E Journal v. 33, n. 4, p. 592-603, 1987.

Kravaris, C.; Kantor, J. C. Geometric methods for nonlinear process control. 1. Background 2. Controller synthesis. Industrial and Engineering Chemistry Research,v. 29, n. 12, p. $2295-2323,1990$.

Ravambo, S., L.; A. Besançon V. Friction identification using the Karnopp model, applied to an electropneumatic actuator. Proc. Inst. Mech. Engrs., Part I: Journal of Systems and Control Engineering, v. 217, n. 2, p. 123-138, 2003.

Romano, R. A.; Garcia, C. Karnopp friction model identification for a real control valve. Proceedings of the 17th World Congress the International Federation of Automatic Control, p. 14906 - 14911, 2008. 
Romano, R. A. Identificação de processos não lineares e quantificação de atrito em válvulas de controle. Tese (Doutorado) - Escola Politécnica da Universidade de São Paulo. Departamento de Engenharia de Telecomunicações e Controle, 2009.

Sastry, S. Nonlinear Systems Analysis, Stability and Control. New York. Spinger, 1999.

Slotine, J. J. E.; Li, W. Applied nonlinear control, Prentice Hall, New Jersey, 1991.

Srinivasan R.; Rengaswamy, R. Stiction compensation in process control loops:A framework for integrating stiction measure and compensation. Industrial \& Engineering Chemistry Research, n. 44, p. 9164 - 9174, 2005.

Sirinivasan, R.; Rengaswamy, R. Approaches for efficient stiction compensation in process control valves. Computers and Chemical Engineering, v. 32, p. 218229, 2007.

Uehara, D. Detecção e quantificação de atrito em válvulas de controle. Dissertação (Mestrado) - Escola Politécnica da Universidade de São Paulo. Departamento de Engenharia de Telecomunicações e Controle, 2009.

Utikin, V. I. Sliding Mode Control Design Principles and Applications to Electric Drives, IEEE Transactions On Industrial Electronics, v. 40, p. 23-36, 1993. 